University of Northern Colorado Scholarship \& Creative Works @ Digital UNC

$8-2013$

\title{
Interrelationships among attachment style, personality traits, interpersonal competency, and Facebook use
}

Michael A. Jenkins-Guarnieri

Follow this and additional works at: http://digscholarship.unco.edu/dissertations

\section{Recommended Citation}

Jenkins-Guarnieri, Michael A., "Interrelationships among attachment style, personality traits, interpersonal competency, and Facebook use" (2013). Dissertations. Paper 342. 
(C) 2013

Michael A. Jenkins-Guarnieri

ALL RIGHTS RESERVED 


\title{
UNIVERSITY OF NORTHERN COLORADO
}

\author{
Greeley, Colorado
}

The Graduate School

\section{THE INTERRELATIONSHIPS AMONG ATTACHMENT STYLE, PERSONALITY TRAITS, INTERPERSONAL COMPETENCY, AND FACEBOOK USE}

\author{
A Dissertation Submitted in Partial Fulfillment \\ of the Requirements for the Degree of \\ Doctor of Philosophy
}

\author{
Michael A. Jenkins-Guarnieri
}

College of Education and Behavioral Sciences Department of Counseling Psychology

August 2013 
This Dissertation by: Michael A. Jenkins-Guarnieri

Entitled: The Interrelationships Among Attachment Style, Personality Traits, Interpersonal Competency, and Facebook Use

has been approved as meeting the requirement for the Degree of Doctor of Philosophy in the College of Education and Behavioral Sciences in the Department of Counseling Psychology

Accepted by the Doctoral Committee

Brian Johnson, PhD, Co-Chair

Stephen Wright, $\mathrm{PhD}$, Co-Chair

Jennifer Murdock, PhD, Committee Member

Thomas Dunn, PhD, Faculty Representative

Date of Dissertation Defense

Accepted by the Graduate School

Linda L. Black, Ed.D., LPC

Acting Dean of the Graduate School and International Admissions 


\begin{abstract}
Jenkins-Guarnieri, Michael A. The Interrelationships Among Attachment Style, Personality Traits, Interpersonal Competency, and Facebook Use. Published Doctor of Philosophy dissertation, University of Northern Colorado, 2012.
\end{abstract}

Online social media has become a popular way to communicate and develop interpersonal relationships. Facebook use in particular has become an important topic for researchers and clinicians, as young adults are increasingly integrating this use into their daily lives and social behavior. As empirical work on the personality traits and interpersonal competency associated with use and the potential consequences of use on social behavior is still emerging, the present study sought to investigate the interrelationships among constructs relevant to the developmental tasks associated with emerging adulthood, including adult attachment style, Five Factor Model personality traits, interpersonal competency, and Facebook use. Using data collected from 617 emerging adults in college, we utilized structural equation modeling to develop a model explaining the interrelationships among the constructs under study in order to further the research in this area. Results yielded a well-fitting model that explained the interrelationships among these latent constructs in the data, which suggested that insecure attachment had direct and positive effects on neuroticism, direct and negative effects on extraversion, direct and negative effects on interpersonal competency, and indirect effects on Facebook use. In addition, only extraversion and not neuroticism was related to interpersonal competency and Facebook use, when first accounting for attachment style. Interestingly, interpersonal competency did not seem to play a prominent mediating role between these personality traits and Facebook use. These results highlight the role of attachment style, and its importance in both developing personality traits, interpersonal 
skills, and online social behavior, which aligns well with the attachment theory

framework. Lastly, we discussed future directions for research, as well as theoretical and practice implications for psychologists. 


\section{TABLE OF CONTENTS}

\section{CHAPTER}

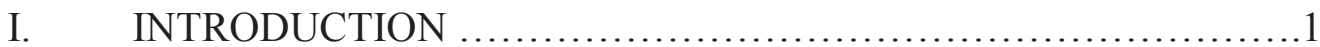

Emerging Adulthood Theoretical Framework

Attachment Theoretical Framework

Attachment and FFM Traits

Personality Traits and Interpersonal Competency

Personality Traits and Facebook Use

FFM Personality Traits and Online Social Behavior

Interpersonal Competency and Online Social Behavior

Study Rationale and Purpose

Limitations

Definition of Terms

Summary

II. REVIEW OF LITERATURE .....................................25

Theoretical Frameworks

Facebook and Social Behavior of Emerging Adults

Five Factor Model and Social Behavior

Attachment and FFM Traits

Personality Traits and Interpersonal Competence

FFM Personality Traits and Facebook Use

Attachment Style and Interpersonal Competence

Interpersonal Communication Competence 
Interpersonal Communication Competence and Online Social Behavior Social Self-Efficacy

Summary of Conclusions and Support for Research

Limitations of Literature Review

Implications and Future Directions

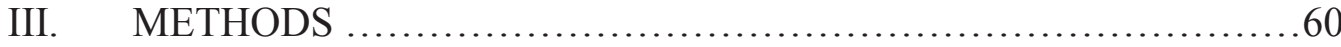

Participants

Instrumentation

Procedures

Data Analysis

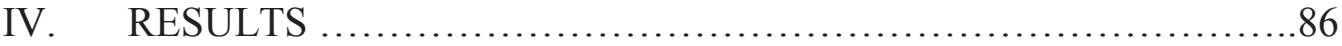

Selection of Indicators Using Exploratory Factor Analysis

Measurement Model Confirmatory Factor Analysis Results

Structural Equation Model Results

Model Interpretation

V. DISCUSSSION AND CONCLUSIONS

Study Rationale and Purpose

Attachment Style

Five Factor Model Personality Traits

Interpersonal Competency

Overall Model Interpretation

Research Implications 
Theoretical Implications

Practice Implications

Limitations

Conclusions

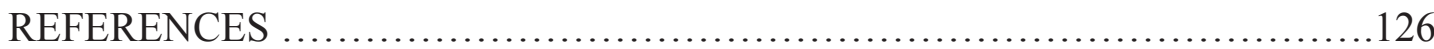

APPENDIX A - Criteria for Inclusion of Research........................... 160

APPENDIX B - Literature Search Strategy Documentation........................ 162

APPENDIX C - Participant Invitation Email................................ 164

APPENDIX D - IRB-Approved Informed Consent Letter....................... 166

APPENDIX E - Participant Debriefing Paragraph............................ 169

APPENDIX F - Institutional Review Board (IRB) Approval Letter.................171 


\section{CHAPTER I}

\section{INTRODUCTION}

Since its inception in the 1960 s and popularization in the 1990s, the internet and its most used feature, the World Wide Web, has been an increasingly pervasive presence in the lives of North Americans. Its seminal idea was, in essence, communication as government scientists sought to invent a new medium through which to share ideas and information. This same basic purpose persisted throughout its evolution, as everyday users communicated through email, online chatting, and web pages. Internet use has consistently increased over the past decade, with $79 \%$ of all adults reporting online activity this year with $95 \%$ of adults ages 18-33 (Zickuhr, 2010). These statistics and recent research suggest that young adults are increasingly incorporating the internet into their daily lives, especially as a means of communication (Correa, Hinsley, \& de Zúñiga, 2010; Ellison, Steinfeld, \& Lampe, 2007; Ross et al., 2009).

Although only rising to prominence in the past 8 years, social media and social networking sites (SNSs) have became a wildly popular (Pempek, Yermolayeva, \& Calvert, 2009) online medium through which to communicate and share information (Ross et al., 2009) (for a history and comprehensive definition of SNSs, see Boyd \& Ellison, 2007). Originally created for young adults in college, Facebook (http://www.facebook.com) has become the most used SNS for this population (Cheung, Chiu, \& Lee, 2011; Ross et al., 2009). Founded fairly recently in 2006 for public use, 
Facebook has become "nearly universal" on North American college campuses (Pempek et al., 2009, p. 228). Investigations into typical use patterns in this population show frequent and consistent use ranging from 10-30 minutes daily (Ellison et al., 2007; Ross et al., 2009) to hours each day (Raacke \& Bonds-Raacke, 2008). Pempek et al. (2009) found that Facebook users communicated most often with "friends seen regularly" (48\% of users) and less often with "hometown friends not seen regularly (35\%) and "college friends not seen regularly" (19\%). As young adults increasingly integrate Facebook into their daily social routines (Correa et al., 2010; Steinfield, Ellison \& Lampe, 2008) new research must seek to understand the characteristics of these social media users and the potential impact of this use on their development, especially in the social domain (Brown, 2006).

\section{Emerging Adulthood Theoretical Framework}

Although many developmental theories postulate that true change begins to slow after reaching 18 years of age, new research suggests that young adults continue to show prominent developmental changes into their mid 20s (Arnett, 2000). Arnett's 'emerging adulthood' developmental theory grew out of three well-known theories of development: Erikson's (1968), Levinson's (1978), and Keniston's (1971) theories, all of which extend past adolescence in some way to explain the development of young adults. However, Arnett argues that these theories fail to comprehensively and accurately capture the development of young adults, especially those in the present era. Indeed, Erikson's theory becomes less concrete and detailed after his adolescence stage, focusing on occupational identity and generativity for young adults. Arnett notes that the experience of young adults after high school is quite different in the $21^{\text {st }}$ century, as many are not content to 
simply decide upon a trade or career and in fact continue their search for a stable sense of self and place in the world. In fact, Arnett's theory stresses the continued and intensive identity exploration that occurs after adolescence when previous theorists suggest that it slows significantly. Similarly, Levinson lumps together adults from ages 17 to mid 30 s into the same category and describes their primary developmental tasks as building an established life and finding a place in the world. Lastly, Arnett argues that Keniston's theory was encapsulated in his era of youth movements and politics, with an overemphasis on the struggle between a young adult and her society.

Arnett's (2000) theory suggests that young adults from approximately 18 to 25 years of age develop through an intense period of change as they work to form a stable sense of identity and explore meaningful relationships. He highlights the observed instability of this age group as evidence of this intense change, as they exhibit pronounced diversity in living arrangements, primary life tasks (e.g., work, college attendance), and relationship status. He argues that this stage is unique from adolescence, in that these adults face a drastically different set of responsibilities, developmental tasks, and possibilities to explore. Through this theory's lens, emerging adults discover and begin to solidify their sense of self based on their own budding values, personality characteristics, and interests. In addition, they experiment with platonic and romantic relationships, seeking companionship with others that compliment their own emerging identities. Thus, this period is characterized by continued personal growth and development, resulting in "more enduring choices in love, work, and worldviews" (Arnett, 2000, p. 479). Other researchers support this conceptualization of young adults, suggesting that intrapersonal and interpersonal developmental activities continue past 
traditional adolescence into young adulthood (Montgomery, 2005). Arnett's theory forms the developmental theoretical framework for the present study, and will be one of the theories used as a lens through which to examine the associations between emerging adults' personality characteristics, interpersonal competency, and Facebook use.

For emerging adults in today's technology-saturated society, many of their developmental tasks are being carried out online (Brown, 2006), especially through SNS like Facebook. A recent study highlighted how a process commonly associated with identity development was reflected on participants' Facebook pages: users expressed "salient and highly elaborated" ethnic identities through their Facebook pages just as they would in the real world (Grasmuck, Martin \& Zhao, 2009, p. 179). Constructing an online profile page can be seen as a purposeful act, one that reflects a user's identity and self in a social environment (Manago, Graham, Greenfield, \& Salimkhan, 2008). In this way, emerging adults express themselves, representing aspects of their personality via this online medium with distinctly social motivations. Thus, developmental processes associated with emerging adulthood such as identity formation (Peluchette \& Karl, 2010) and social behavior (Gordon, Juang \& Syed, 2007) often manifest online through SNS such as Facebook.

Emerging adults also develop relationships through Facebook, maintain established relationships, and use this medium for interpersonal communication (Ellison et al., 2007). Platonic and romantic relationships are of great concern throughout emerging adulthood, and sites like Facebook are increasingly used to maintain these types of connections (Reich, 2010), maintenance which requires interpersonal communications skills and competence. Subrahmanyam, Reich, Waechter and Espinoza 
(2008) found that the internet was important in the participants' lives and that one of their most frequent activities online was using social networking sites (SNS) to maintain social connections. In addition, Reich (2010) concluded that these sites more often foster "networked individualism" than a "sense of community" (p. 703). This supports the idea that individuals use these sites as an extension of the self, an online manifestation of their personality and a tool for interpersonal relationships. In this way, SNS profiles can represent a user's overall personality, as these pages embody and demonstrate to a viewer specific personality traits, values, beliefs, and interpersonal relationships. In this way, SNS such as Facebook play a prominent role in the developmental domains of emerging adulthood, and researchers must seek to understand the potential ramifications of its use for individual identity and personality development, social behavior, and interpersonal communication with this population of users (Thayer \& Ray, 2006).

\section{Attachment Theoretical Framework}

John Bowlby developed his theory of attachment in the 1940s and 1950s. This theoretical framework emphasizes the importance of early relationships and nature of the connection between child and caretaker, which is most often the parent-child bond (Bowlby, 1969). Bowlby theorized that these early relationships help to form a child's style of attachment, which can impact relationships and personality characteristics throughout later development and the life span. He focuses on the quality of this initial child-caretaker bond, and emphasizes the level of security that the child feels in the world and in exploration thereof (Bowlby, 1969). Informed by these early attachment relationships, the child builds an internal model for his or herself in relationships with others that persist through adolescence and adulthood (Bowlby, 1969; Zimmerman, 
2004). Thus, although initially used to describe early relationships, attachment theory states that attachment style continues to dictate the formation and maintenance of adult relationships as well (Bowlby, 1980; Hazan \& Shaver, 1987; Fraley \& Shaver, 2000).

Kenny and Rice (1995) reviewed relevant research in applying attachment theory to the developmental challenges of what Arnett (2000) later conceptualized as the emerging adulthood stage. Essentially, they theorized that parental attachment plays an important role in the developmental processes of late adolescents in college, especially in their identity development, social behavior, and interpersonal relationships. Wei, Russel, and Zakalik (2005) state that research supports the link between attachment and social competency as well as social self-efficacy, finding in their study that high attachment avoidance and anxiety were associated with lower levels of social self-efficacy. Healthier adult attachment has also been associated with better college adjustment (Lapsley \& Edgerton, 2002; Mattanah, Hancock \& Brand, 2004), psychosocial adjustment (DiTommaso, Brannen-McNulty, Ross \& Burgess, 2003; Engels, Finkenauer, Meeus \& Deković, 2001; Hiester, Nordstrom \& Swenson, 2009), greater self-esteem (Kenny \& Sirin, 2006), and increased interpersonal competence (DiTommaso et al., 2003; Engels et al., 2001; Ross \& Fuertes, 2010).

The most current way of conceptualizing adult attachment style (Mikulincer \& Shaver, 2007; Rholes, Peatzold \& Friedman, 2008) was proposed by Brennan, Clark and Shaver (1998) as a two-component, dimensional model of attachment (see Figure 1). Their model defined two orthogonal dimensions, called 'anxiety' and 'avoidance,' on which an individual can vary from 'low' to 'high' on these two continuums. Brennan et al. (1998) provided a more refined way of conceptualizing the previous four-category 
(Bartholomew \& Horowitz, 1991) model of attachment (see Figure 2) and this

dimensional model was used to conceptualize adult attachment style in the present study; individuals scoring lower on attachment anxiety and avoidance were considered more securely attached and those scoring higher as more insecurely attached. A growing body of research supports the central role of attachment style in major developmental processes of emerging adults, so attachment theory will be used as an additional theoretical lens through which to view this investigation into the relationships between personality characteristics, interpersonal competency, and online social behavior.

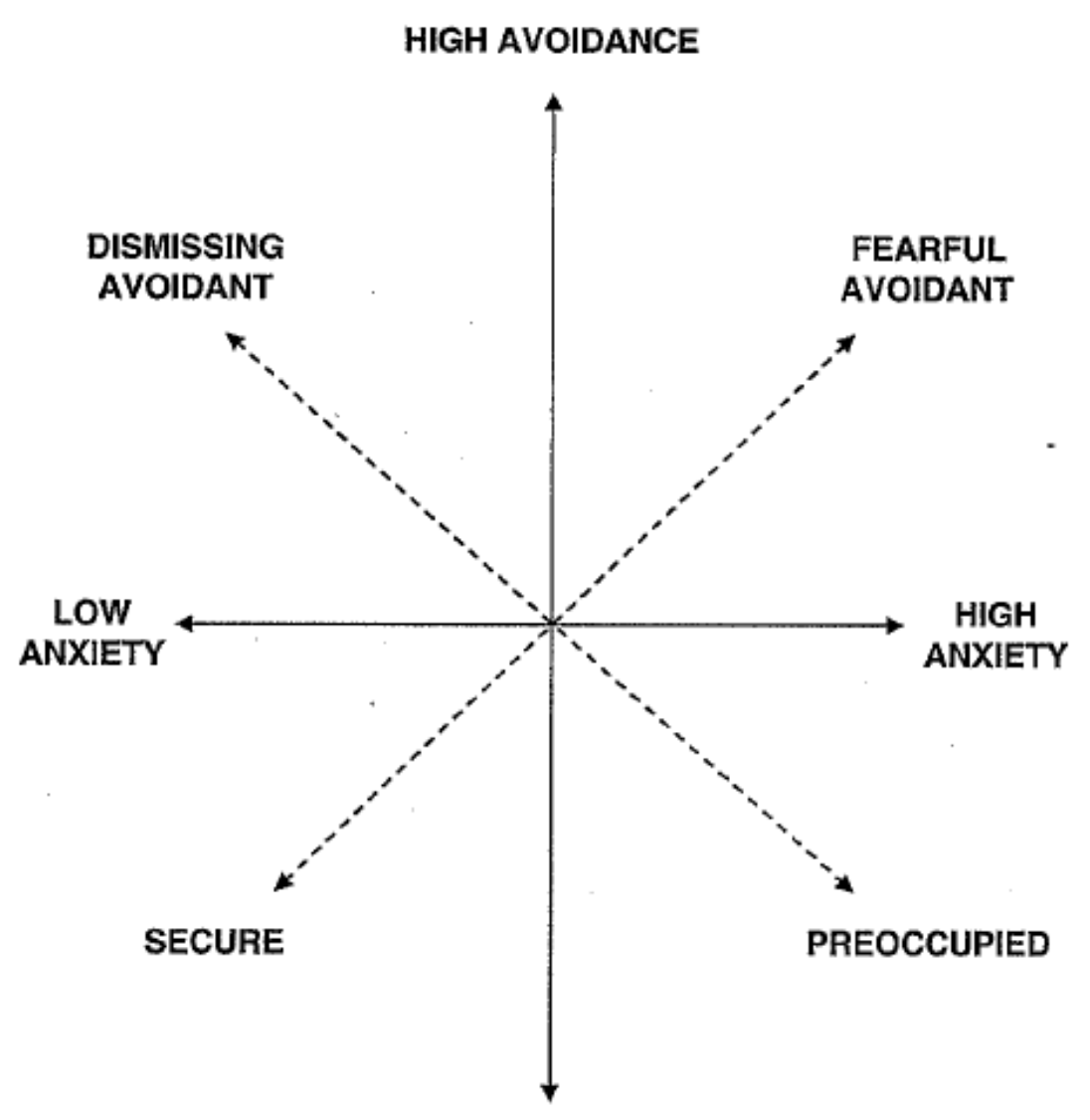

LOW AVOIDANCE

Figure 1. Dimensional model of adult attachment, reproduced from Mikulincer and Shaver, 2007, p. 89, based on Brennan, Clark and Shaver's (1998) model. 
Model of Self

(Dependence)

\begin{tabular}{c|c|c|}
\multicolumn{1}{c}{} & $\begin{array}{c}\text { Positive } \\
\text { (High) }\end{array}$ & $\begin{array}{c}\text { Negative } \\
\text { (Low) }\end{array}$ \\
\cline { 2 - 3 } Positive & Secure & Preoccupied \\
Comfortable with & Preoccupied with \\
Model of Other & intimacy and autonomy & relationships \\
(Avoidance) & Dismissing & Fearful \\
\cline { 2 - 3 } Negative & Dismissing of intimacy, \\
counter-dependent & Fearful of intimacy, socially \\
& & avoidant \\
\end{tabular}

Figure 2. Model of adult attachment recreated from Bartholomew \& Horowitz, 1992, p. 227.

\section{Attachment and FFM Traits}

Since early work investigating the relationship between adult attachment style and FFM personality traits by Shaver and Brennan (1992) and Carver (1997), research methodology and measurement techniques have developed significantly. These early studies have been backed by later work that supports the positive correlation between secure attachment styles and extraversion and agreeableness, and negatively associated with neuroticism, while anxious and avoidant attachment styles were positively correlated with neuroticism and negatively correlated with extraversion and agreeableness (Backstrom \& Holmes, 2001; Picardi, Caroppo, Toni, Bitetti \& Di Maria, 2005; Shaver \& Brennan, 1992). However, more recent work has concluded that the attachment-FFM relationships are fairly consistent but weak and should be expected 
given the nature of these constructs (Picardi et al., 2005). As research on attachment and FFM personality traits in childhood suggests that attachment is an important predictor of these traits, especially extraversion, openness, and neuroticism (Hagekull \& Bohlin, 2003), I will incorporate the developmental nature of this relationship throughout the present study.

\section{Personality Traits and Interpersonal Competency}

Although Ozer and Benet-Martínez (2006) recently lamented the dearth of research investigating interrelationships among FFM traits and social competence, they also provided support in their review for the significant relationship between personality traits and social skills, which in turn affect relationship quality. They also noted that the body of literature in this area provides support for the FFM traits Extraversion and Neuroticism as the most important predictors of social relationship outcomes (e.g., Barrett \& Pietromonaco, 1997; Berry \& Hansen, 1996; White, Hendrick \& Hendrick, 2004). Actually, FFM traits have been associated with many aspects of interpersonal communication competency and a wide variety of relationship outcomes, such as relationship satisfaction (Goodboy \& Booth-Butterfield, 2009; Ozer \& Benet-Martínez, 2006; Watson, Hubbard \& Wiese, 2000), satisfaction with sex (Fisher \& McNulty, 2008), conflict resolution (Wood \& Bell, 2008), and marital satisfaction (Donnellan, Larsen-Rife \& Conger, 2005; Karney \& Bradbury, 1995). Although other authors have found that Extraversion and Agreeableness have the strongest association with social skills (Cuperman \& Ickes, 2009), there appears to be ample and comprehensive support for the significant impact of FFM traits on social interactions (Ansell \& Pincus, 2004; Back, Schmuckle \& Egloff, 2009; Berry \& Hansen, 2000; McCrae, 1996). 
Similarly, attachment style has been repeatedly shown to significantly impact one's interpersonal communication competency and experience in close relationships (Hazan \& Shaver, 1987; Fraley \& Shaver, 2000). More secure attachment styles have been associated with greater interpersonal competence (DiTommaso et al., 2003; Engels et al., 2001; Ross \& Fuertes, 2010), and appears to guide relationships throughout the lifespan (Berlin, Cassidy \& Appleyard, 2008; Hazan \& Shaver, 1987; Mikulincer \& Shaver, 2007; Zimmerman, 2004). Also, the link between attachment and relationship satisfaction has clear support in the literature (Fraley \& Shaver, 2000; Hazan \& Shaver, 1987; Tucker, \& Anders, 1999) and may be mediated by variables such as communication style (Guerrero, Farinelli, \& McEwan, 2009), with a recent study suggesting that attachment style was related to communication style and effectiveness (Jang, Smith \& Levine, 2002). Thus, there is clear support for the theoretical link between attachment style and interpersonal communication competency.

\section{Personality Traits and Facebook Use}

Although the research is still emerging in this area, an individual's Facebook presence seems to parallel that person's offline personality as well (e.g., Weisbuch, Ivcevic, \& Ambady, 2009). Recent work by Vazire and Gosling (2004) found that subjects can form clear, comprehensive impressions about the personality of a personal web page's author, impressions which tend to correspond accurately to actual in-person ratings of the same person's personality. This may be explained by what Funder and Colvin's (1991) results imply as consistency in "underlying psychological dispositions that can be expressed behaviorally" (p. 777). This idea that viewers can rate a person's personality factors by judging that person's social networking profile with consistency 
and relative accuracy has been demonstrated in other areas as well (c.f., Kluemper \& Rosen, 2009). Related findings have been demonstrated for the trait of interpersonal shyness, as Orr et al., (2009) suggested that greater shyness was associated with fewer friends for Facebook users as well as real world relationships. Thus, many are calling for more research investigating the personality characteristics associated with Facebook use, especially as they relate to the potential impact of social media use on the social behavior of emerging adults (Brown, 2006; Steinfield et al., 2008).

\section{Five Factor Model Personality Traits and Online Social Behavior}

More stable personality characteristics, such as Bowlby's (1969) attachment style, the Five Factor Model personality traits (FFM; Digman, 1990; McCrae \& John, 1992), and self-esteem, have been shown to affect social behavior and relationships. Research supports the significant association of relationship quality with attachment style (Brennan \& Shaver, 1993; Saferstein, Neimeyer, \& Hagans, 2005; Schmitt et al., 2009; Shaver \& Brennan, 1992; Zimmerman, 2004), Five Factor model traits (Barelds, 2005; White et al., 2004; Wu, Foo, \& Turban, 2008), and self-esteem (Barelds, 2005; Hendrick, Hendrick, \& Adler, 1988; Luteijn, 1994). For online relationships, recent research supports the idea that FFM personality traits such as extraversion explain the nature and extent of a user's social behavior on the internet (Tosun \& Lajunen, 2010). In a more comprehensive investigation, Ross et al. (2009) found that extraversion, openness and neuroticism explained a user's social behavior on Facebook specifically, results which were supported by subsequent work as well (Correa et al., 2010). A recent follow-up study to Ross et al. (2009) offered further support to these results, while claiming a more rigorous methodology, suggesting that higher extroversion was associated with increased social 
behavior on Facebook, higher neuroticism was associated with less self-disclosure, and that openness was associated with more expressive Facebook communication (AmichaiHamburger \& Vinitzky, 2010).

However, the research on FFM traits and SNS use is still emerging (Zywica \& Danowski, 2008), sporadic at best, and many studies do suffer from a lack of methodological rigor. For example, although Correa et al. (2010) used a large national sample, they utilized an abbreviated and psychometrically weaker 10-item scale by Gosling, Rentfrow and Swann (2003) to measure FFM traits derived from the standard 44-item Big Five Index (BFI; John, Naumann, \& Soto, 2008). Thus far, recent work suggests that personality characteristics play a role in forming and maintaining relationships both in the real world and online. Thus, FFM personality traits may play an important role in social behavior via Facebook, and it is likely that other personality traits such as self-esteem and attachment style are also influential and must be included when investigating social behavior online.

\section{Interpersonal Competency and Online Social Behavior}

In developing their interpersonal competency questionnaire, Buhrmester, Furman, Wittenberg and Reis (1988) found a significant relationship between interpersonal competency and various relational and adjustment outcomes. Interpersonal competence has been shown to be positively associated with psychological well-being (Baumeister, Campbell, Krueger \& Vohs, 2003; Ryff \& Singer, 2000; Segrin, 2000) and recent work suggests that this strong link between social skills and well-being is heavily mediated by social relationships (Segrin \& Taylor, 2007). These associations seem to apply to online relationships as well, as Valkenburg and Peter's (2008) work suggested that online 
communication was positively associated with building social competence in the real world. Ellison et al. (2007) provided support for the link between Facebook and interpersonal competency, as increased Facebook use intensity was associated with greater social capital, an aspect of which is social competence. Mazer, Murphy and Simonds (2008) found a significant link between a specific social skill, self-disclosure, and Facebook use, suggesting that self-disclosure on Facebook was associated with positive relational outcomes. This may be explained by the SNS utility in fostering selfdisclosure, as users may be more effective in relating aspects of themselves in this context (McKenna, Green \& Gleason, 2002). Thus, although research has yet to investigate the link between interpersonal competency and Facebook use intensity specifically, there is ample support that this connection is plausible.

Another closely related construct, social self-efficacy, presents another way to understand interpersonal competence, in this case as perceived confidence in interpersonal competence (Smith \& Betz, 2000). Social self-efficacy may be related to attachment (Wright \& Perrone, 2010) and theoretically related to practical social skills although supporting research is still forthcoming (Smith \& Betz, 2000). These various findings converge to suggest that interpersonal competency and social self-efficacy are relevant and important constructs when investigating the personality variables of attachment, FFM traits and their relationship to online social behavior.

\section{Study Rationale and Purpose}

Thayer and Ray (2006) call for more research on how increased internet use may impact the relationships and communication skills of users. As SNSs have become one of the most common manifestations of social behavior and communication online, 
researchers are beginning to investigate their role in the social lives of everyday users (e.g. Steinfield et al., 2008). Others encourage further research on SNSs with the emerging adult population that uses them most, as this medium is fairly new and as yet has not been studied in depth (Ross et al., 2009), especially in relation to social behavior (Raacke \& Bonds-Raacke, 2008). Thus, the present study focuses on the college-aged population through the developmental lens of Arnett's (2000) emerging adulthood theory. This population uses Facebook more than any other age group (Zickurh, 2010), and is increasingly incorporating its use into their social lives and daily routines (Brown, 2006; Ellison et al., 2007).

The goal of the present research is to develop a model that explores the interrelationships among personality characteristics, interpersonal competence, and Facebook use. This study will investigate how the more stable personality traits commonly associated with relationship quality, relationship satisfaction, and interpersonal communication are associated with perceived interpersonal competence, and the intensity of Facebook use. Building on previous work (e.g., Jenkins-Guarnieri, Wright, \& Hudiburgh, 2011; Ross et al., 2009), this investigation will include adult attachment and the FFM personality traits Extraversion and Neuroticism. In conducting a thorough literature review, no research has been conducted with the emerging adult population on the interrelationships among personality traits, interpersonal competency, and intensity of online social behavior manifested through Facebook.

Based on the comprehensive literature review conducted in Chapter II, there was clear theoretical support for attachment directly and positively impacting interpersonal competence (e.g., more securely attached adults, or those scoring lower on the anxiety 
and avoidance continuums of attachment style, also displayed increased interpersonal competence) (Anders \& Tucker, 2000; Bippus \& Rollin, 2003; Cooley, 2005; Mallinckrodt, 2000) and extraversion (Backstrom \& Holmes, 2001; Carver, 1997), directly and negatively affecting neuroticism (Hagekull \& Bohlin, 2003) as well as indirectly impacting interpersonal competence (Guerrero, Farinelli \& McEwan, 2009; Johnson, 2003; Mikulincer \& Shaver, 2007; Rholes, Paetzold \& Friendman, 2008) and interpersonal factors related to Facebook use (Bradford, Feeney \& Campbell, 2002; Schulman, Elicker \& Srouf, 1994) through these two FFM traits (Hagekull \& Bohlin, 2003; Picardi et al., 2005). In addition, I found ample research support for the direct impact of neuroticism negatively and extraversion positively affecting interpersonal competency (Berry \& Hansen, 1996; Cuperman \& Ickes, 2009; Ozer \& Benet-Martinez, 2006) and Facebook use intensity (Amiel \& Sargent, 2004; Back et al., 2010; Correa et al., 2010), as well as indirectly affecting Facebook use intensity through the mediating variable of interpersonal competence (Caplan, 2005; Engelberg \& Sjoberg, 2004; Harman, Hansen, Cochran \& Lindsey, 2005; Ledbetter, 2010). The alternate model posits equally plausible relationships given the available research on these constructs, with the direct effects between Extraversion and Neuroticism and Facebook use removed to make interpersonal competency a full mediator between personality traits and Facebook use. Therefore, the following research questions were created to evaluate a proposed theoretical model that explains the interrelationships among attachment, extraversion and neuroticism, interpersonal competency, and Facebook use intensity: 
Q1 Does a primary theoretical explanatory model (see Figure 3) adequately fit the observed relationships in the data, conceptualized with attachment directly and positively affecting extraversion and interpersonal competency, directly and negatively impacting neuroticism while indirectly affecting Facebook use intensity through these mediating variables, with extraversion positively and neuroticism negatively and directly impacting interpersonal competency and Facebook use intensity while indirectly affecting Facebook use intensity through interpersonal competency, and with interpersonal competency directly and positively affecting Facebook use intensity?

Q2 Does the primary theoretical model demonstrate statistically better fit to the observed interrelationships between these constructs in the data than the alternate model (see Figure 4) which removes the direct effects of Extraversion and Neuroticism on Facebook use, making interpersonal communication competency a full mediator between personality traits and Facebook use intensity? 


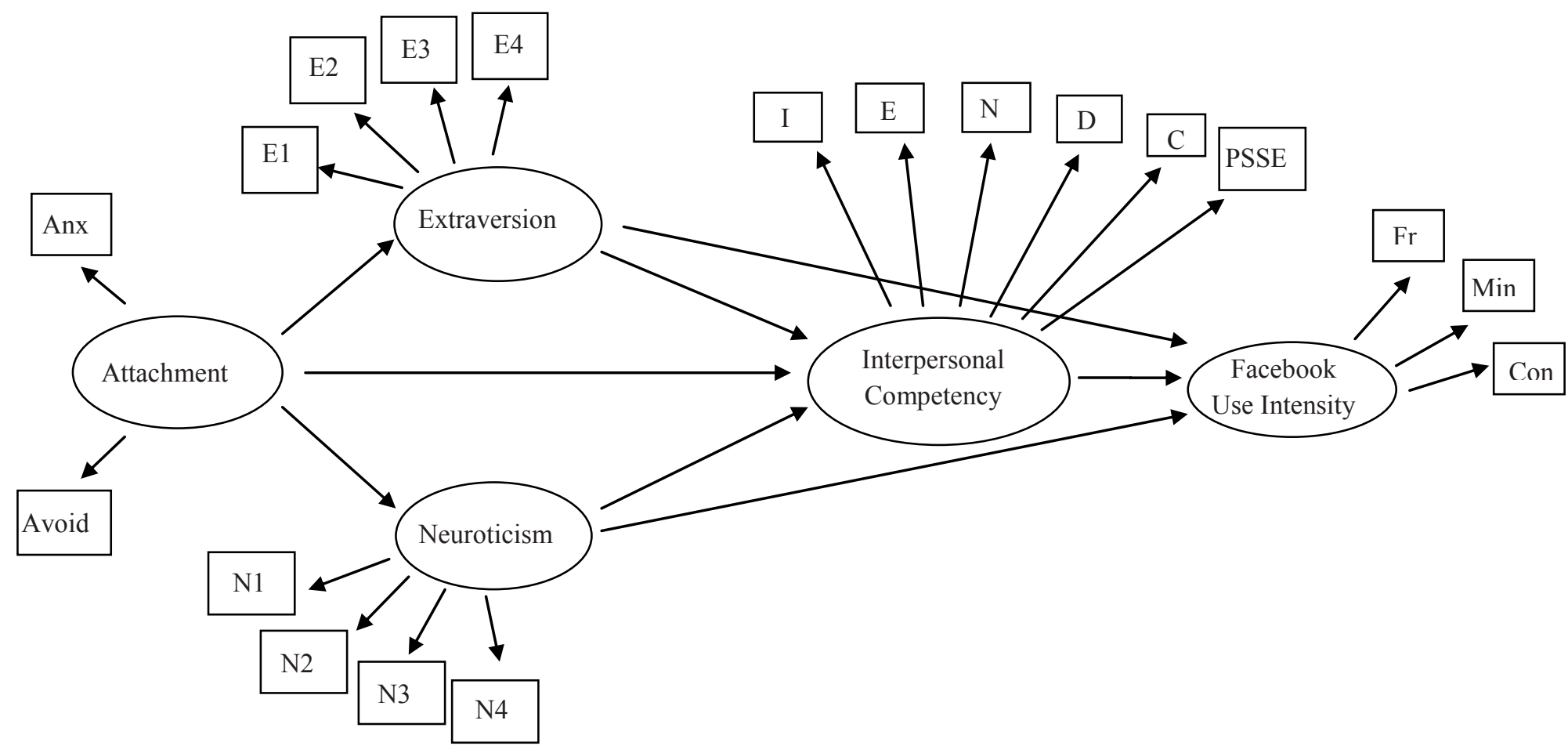

Figure 3. Primary model specifying the interrelationships among study constructs.

Note. Anx = Attachment Anxiety subscale; Avoid = Attachment Avoidance subscale; E1-E4 = BFI Extraversion subscale items; N1N4= BFI Neuroticism items; $\mathrm{Fr}=$ Standardized item capturing number of Facebook friends; Min = Standardized item capturing minutes spent weekly on Facebook; Conn = Mean of six standardized items capturing a user's attachment to Facebook; I = ICS Initiation subscale; $\mathrm{E}=$ ICS Emotional Support subscale; $\mathrm{N}=$ ICS Negative Assertion subscale; $\mathrm{D}=$ ICS Disclosure subscale; $\mathrm{C}=\mathrm{ICS}$ Conflict Management subscale; PSSE = Perceived Social Self-Efficacy scale. $\$ 


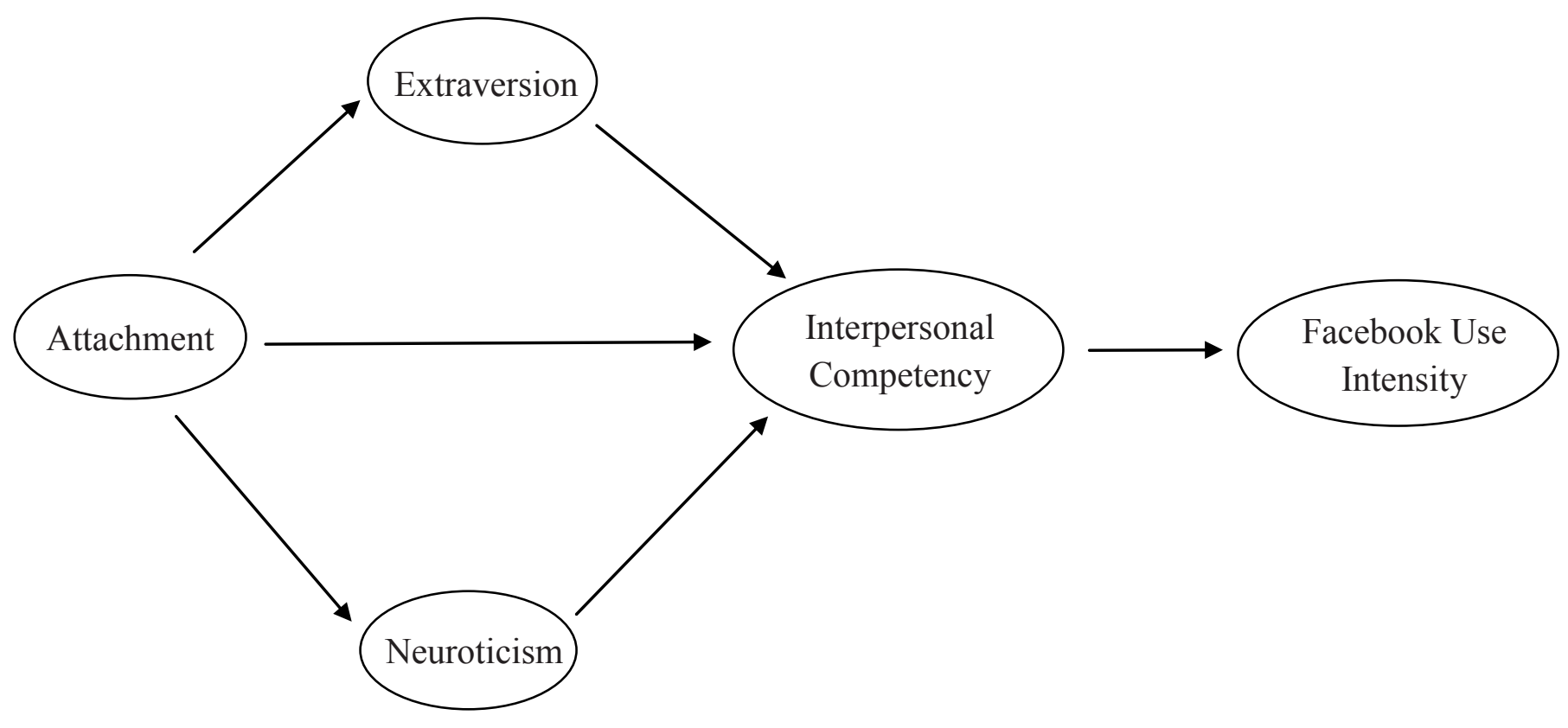

Figure 4. Primary alternate model specifying the interrelationships among study constructs. 


\section{Limitations}

As can be expected given the fairly recent popularity of SNS and Facebook specifically, the communication and psychology literatures display a dearth of research on the personality characteristics related to Facebook use or its potential effects on interpersonal relationships and communication competency. In addition, my extensive literature review found that most work in this area can be found in the communications literature, in journals such as Cyberpsychology \& Behavior, Computers in Human Behavior, and the Journal of Computer-Mediated Communication. Although some studies focusing on these issues are being published in psychology journals, further research from the perspective of the psychological sciences are needed to better understand the psychological variables associated with the nature and extent of Facebook use, as well as its potential impact on psychosocial functioning. Therefore, the present study may suffer from a sparse research base and underdeveloped theoretical foundation from which to launch a carefully constructed investigation and thereby contribute meaningfully to research in this area.

The generalizations of study findings are limited to the unique demographic characteristics of the sample used, and applying the results to populations characterized by different demographics should be done with caution. The study sample consists primarily of first year, first time undergraduate college students from a medium $(\mathrm{N}=$ 13,000), Rocky Mountain region university. In addition, the sample is expected to include few individuals identifying as ethnic/racial minorities. In previous work on the same topic, substantially more females answered the online survey than males (e.g. Jenkins- 
Guarnieri et al., 2012; Ross et al., 2009). These factors further complicate generalizations made from this study's findings.

Kraut et al. (2002) identified control variables known to influence internet use, and by inference online social behavior (age, gender, race, income, education, and the size of one's place of upbringing; urban or rural). However, to the best of my knowledge no research has sought to identify variables known to influence Facebook use specifically. The present study attempted to incorporate background and contextual variables shown to influence internet use and social behavior, however, its current design may fail to account for demographic variables that research has yet to identify as important factors to control for in similar investigations. Previous research on Facebook users most often incorporated gender, age, and race/ethnicity into their analyses (e.g., Ellison et al., 2007; Orr et al., 2009; Peluchette \& Karl, 2010) and occasionally education and income levels (e.g., Correa et al., 2010). Therefore, the present study will account for participant age, gender, and race/ethnicity.

Lastly, this study may suffer from a mono-method bias, as only one scale was used to represent each construct. Future research can utilize multiple measures in order to protect against measurement error and any potential bias inherent in using only one measure to capture the constructs under study.

\section{Definition of Terms}

Social networking sites (SNS). Boyd and Ellison (2007) define Social Networking Sites (SNS) as web sites providing users with a suite of services designed to create an online profile describing them, define a list of other users with whom a social connection has been established, and access the profiles and defined lists of other users 
within the web site. These services combine to form what these authors call a user's 'social networks,' which represent a web of interconnected individuals all with some shared social connection.

Interpersonal competency. In the present study interpersonal competency will be defined as one's ability to select, implement, and coordinate programs for social behavior, as well as how well one adjusts these programs of action in response to feedback from the social environment. These programs are comprised of the knowledge and practical procedures necessary for effective communication in a social environment, from choosing specific, impactful words, to clear and uninterrupted speech paired with expressive facial expressions and hand gestures.

Social self-efficacy. Social self-efficacy represents another way to operationalize interpersonal competence, as it seems to capture perceived confidence in one's abilities at interpersonal communication. Smith and Betz (2000) define social self-efficacy as "an individual's confidence in her/his ability to engage in social interactional tasks necessary to initiate and maintain interpersonal relationships" (Smith \& Betz, 2000, p. 286). This definition seems to be born out of applying Bandura's (1997) basic self-efficacy theory to the domain of social interaction. The present study will use this definition of social selfefficacy, as it parallels both Bandura's early theory about self-efficacy and more recent support in the psychology literature.

Attachment style. The term 'attachment style' in the present study will refer to the inner working model used by an individual when forming and participating in a close relationship, and the accompanying behavioral and emotional skills developed to accomplish associated relational activities (Bowlby, 1980; Fraley \& Shaver, 2000). This 
model can be characterized as having high or low levels along two dimensions:

attachment anxiety and attachment avoidance. When an individual exhibits low levels of anxiety and avoidance, they can be considered more securely attached, while high levels indicate more insecure attachment. These working models can be seen as a personal theoretical lens through which an individual sees themselves in a relationship and interprets the behavior of others, as well as forming expectations of self, others, and the relationship (Pietromonaco \& Barrett, 2000).

Five Factor Model trait taxonomy. John et al. (2008) define and describe the five traits in the FFM trait taxonomy as follows:

Extraversion. Factor 1 is called Extraversion and "implies an energetic approach toward the social and material world and includes traits such as sociability, activity, assertiveness, and positive emotionality" (p. 120).

Agreeableness. Factor 2 is called Agreeableness and "contrasts a prosocial and communal orientation toward others with antagonism and includes traits such as altruism, tender-mindedness, trust, and modesty" (p. 120).

Conscientiousness. Factor 3 is called Conscientiousness and "describes socially prescribed impulse control that facilitates task- and goal-directed behavior, such as thinking before acting, delaying gratification, following norms and rules, and planning, organizing, and prioritizing tasks" (p. 120).

Neuroticism. Factor 4 is called Neuroticism and "contrasts emotional stability and even-temperedness with negative emotionality, such as feeling anxious, nervous, sad, and tense" (p. 120). 
Openness. Factor 5 is called Openness and "describes the breadth, depth, originality, and complexity of an individual's mental and experiential life" (p. 120). I will use these descriptions to define the FFM factors throughout this study.

Facebook use. Prior methods of evaluating Facebook use focused solely on frequency and duration of activity on the site, however, Ellison et al. (2007) call for more comprehensive definitions that incorporate a user's emotional connection to and reliance on the site. In this study, Facebook use will be defined as follows: the extent to which users incorporate the site into daily social behavior, the intensity of users' emotional connections to the site, and the degree to which users actively engage with the site and its various tools for social behavior.

\section{Summary}

By closely examining the aspects of personality that impact Facebook use and how its use relates to social behavior and interpersonal communication, this study seeks to understand the role that this social media technology plays in social development of emerging adults. As this phenomenon arose quite recently, more research is needed to understand its impact on the social behavior of those young adults that use it most. Specifically, psychologists must investigate how incorporating this technology into a young adult's development, especially in the social domain, may impact interpersonal communication competency. In the same vein, this study seeks to understand the personality characteristics associated with Facebook use. This work may help young adults, their parents, practitioners, university administrators, and other researchers to make more informed decisions about using Facebook and social media. In addition, the present work may contribute significantly to the psychology and communication 
literatures about the relationships between Facebook use, personality variables, and interpersonal communication competency.

This dissertation has been organized into Five chapters. Chapter 2 reviews the literature related to Facebook's integration into the development and social behavior of emerging adults, how attachment style and FFM traits may impact Facebook use as well as interpersonal communication competency, and how social media use may impact interpersonal communication. Chapter 3 examines the quantitative methods employed in the present study in detail, reviewing the specifics of study design, sampling methods, measurement scales, procedures, and analyses. Chapter 4 presents the results from these analyses. Chapter 5 proceeds with a discussion of results, including how they related to prior research in this area, an examination of limitations in the present study, recommendations for future research, implications for theory, research, and practice, and general conclusions. Lastly an appendix will also be included that presents an independent manuscript based on the present study in preparation for submission to a peer-reviewed psychology journal. 


\section{CHAPTER II}

\section{REVIEW OF LITERATURE}

In the review of the relevant psychological literature that follows below, I hoped to establish the theoretical and empirical bases for the present study and provide a clear rationale for the specific hypotheses under investigation. In order to ground this study in a theoretical framework, I first review the development and basic concepts of both the emerging adulthood and attachment theories, supported by citations from the relevant scholarly literatures. Next I attempt to present, evaluate, and integrate research surrounding personality traits (specifically, attachment style and the Five Factor Model traits described in the previous chapter) in the context of social behavior, interpersonal communication competence and online social behavior, focusing on research examining interrelationships among these constructs. Next, I frame the interpersonal communication competence construct through the theoretical lens of communication theory, and provided empirical support for this definition. Lastly, I discuss the concept of social self-efficacy, using theory and empirical evidence to provide support for its role in interpersonal communication competence and social behavior. I end with a summary of the empirical and theoretical literature reviewed, synthesize this literature review into a clear rationale for the present research, and discuss limitations of my review, implications for this study, and potential future directions for research. 


\section{Theoretical Frameworks}

Emerging adulthood. Although many developmental theories postulate that true change begins to slow after reaching 18 years of age, new research suggests that young adults continue to show prominent developmental changes into their mid 20s (Arnett, 2000). Arnett's 'emerging adulthood' developmental theory grew out of three wellknown theories of development: Erikson's (1968), Levinson's (1978), and Keniston's (1971) theories, all of which extend past adolescence in some way to explain the development of young adults. However, Arnett (2000) argued that these theories fail to comprehensively and accurately capture the development of young adults, especially those in the present era. Indeed, Erikson's theory becomes less concrete and detailed after his adolescence stage, focusing on occupational identity and generativity for young adults (Erikson, 1968).

Arnett noted that the experience of young adults after high school is quite different in the $21^{\text {st }}$ century, as many are not content to simply decide upon a trade or career and in fact continue their search for a stable sense of self and place in the world (Arnett, 2004). In fact, Arnett's theory stressed the continued and intensive identity exploration that occurs after adolescence (Arnett, 2004) while previous theorists suggested that it slows significantly. Levinson combined adults from ages 17 to mid 30s into the same category and described their primary developmental tasks as building an established life and finding a place in the world. However, Arnett (2007) highlighted the "the ambivalence with which many emerging adults view their entry into adult responsibilities" (p. 24). Lastly, Arnett argued that Keniston's theory was encapsulated in 
his era of youth movements and politics, with an overemphasis on the struggle between a young adult and her society.

Arnett's (2000) theory suggested that young adults from approximately 18 to 25 years of age develop through an intense period of change as they work to form a stable sense of identity and explore meaningful relationships. He supported this trend by citing numerous sociological phenomena, such as the sharp increase in the median U.S. marriage age in the 1990s and 2000s, the marked increase in geographic mobility for U.S. adults between 19 and 29 years of age, and survey data on adults' perceptions of reaching adulthood (Arnett, 2004). He highlighted the observed instability of this age group as evidence of this intense change, as they exhibited pronounced diversity in living arrangements, primary life tasks (e.g., work, college attendance), and relationship status. He argues that this stage is unique from adolescence, in that these adults face a drastically different set of responsibilities, developmental tasks, and possibilities to explore. Through this theory's lens, emerging adults discover and begin to solidify their sense of self based on their own budding values, personality characteristics, and interests. In addition, they experiment with platonic and romantic relationships, seeking companionship with others that compliment their own emerging identities. Thus, this period is characterized by continued personal growth and development, resulting in "more enduring choices in love, work, and worldviews" (Arnett, 2000, p. 479). Other researchers support this conceptualization of young adults, suggesting that intrapersonal and interpersonal developmental activities continue past traditional adolescence into young adulthood (Montgomery, 2005). Arnett's theory forms the developmental theoretical framework for the present study, and will be one of the theories used as a lens 
through which to examine the associations between emerging adults' personality characteristics, interpersonal competency, and Facebook use.

Attachment theory. John Bowlby developed his theory of attachment in the 1940s and 1950s. This theoretical framework emphasized the importance of early relationships and nature of the connection between child and caretaker, which is most often the parent-child bond (Bowlby, 1969). Theories about attachment at the time were dominated by the psychoanalytic framework that focused on an infant's hunger drive being satisfied by the mother, and also the social learning perspective that emphasized how the pleasure of being fed becomes associated with the mother (Cassidy, 1999). After studying animal attachment behavior and later closely observing human parent-child interactions, Bowlby (1969) drew on evolutionary theory and postulated that an infant's need for connection had a biological basis developed through natural selection. Essentially, he postulated that an infant's proximity to its mother would aid in its survival, as the mother could offer protection, social interaction, teach skills, and feed her young. Thus, the infant would engage in what he called 'attachment behaviors' such as nursing at a breast, making sounds, crying, and smiling in order to facilitate this physical proximity and the accompanying behaviors (Bowlby, 1969). Unlike an instinct or a reflex, Bowlby theorized that these types of behaviors are organized into a system of attachment behaviors, as the set of behaviors exhibited by the child respond to stimuli and change depending on feedback (Ainsworth, Blehar, Waters, \& Wall, 1978; Cassidy, 1999). The goal of all this behavior is a strong mother-infant relationship, and all the consequences of the associated physical proximity (Bowlby, 1969). 
Emotions play a key role in Bowlby's (1973) theory, as maintaining the attachment bond is associated with positive affect and disruption of these bonds are associated with loss and sadness (Ainsworth et al., 1978). These emotional consequences may motivate an infant to maintain the attachment relationship (Cassidy, 1999). Combining both affective and cognitive material, Bowlby (1969) postulated that infants aggregate their experiences with attachment figures into mental representations of these figures. In this way, infants create what he called 'internal working models,' or representations of their attachment figures, such as their mother and father. In this way, infants can most effectively manifest attachment behaviors, learning from experience and mobilizing effective strategies to implement their attachment behavior system to best maintain their attachment bond (Cassidy, 1999). Informed by these early attachment relationships, the child builds an internal model for his or herself in relationships with others that persist through adolescence and adulthood (Bowlby, 1969; Zimmerman, 2004). Thus, although initially used to describe early relationships, attachment theory states that attachment style continues to dictate the formation and maintenance of adult relationships (Bowlby, 1980; Hazan \& Shaver, 1987; Fraley \& Shaver, 2000).

Bowlby (1969) theorized that these early attachment relationships help to form a child's enduring style of attachment, which can impact relationships and personality characteristics throughout later development and the life span. He focused on the quality of this initial child-caretaker bond, and emphasized the level of security that the child feels in the world and in exploration thereof (Bowlby, 1969). This level of security was theorized to persist as the child grew older, and applied to other important relationships throughout his or her life (Bowlby, 1969; Zimmerman, 2004). Kenny and Rice (1995) 
reviewed relevant research in applying attachment theory to the developmental challenges of what Arnett (2000) later conceptualized as the emerging adulthood stage. Essentially, they theorized that parental attachment plays an important role in the developmental processes of late adolescents in college, especially in their identity development, social behavior, and interpersonal relationships. Wei, Russel, and Zakalik (2005) stated that research supports the link between attachment and social competency as well as social self-efficacy, finding in their study that high attachment avoidance and anxiety were associated with lower levels of social self-efficacy. Healthier adult attachment has also been associated with better college adjustment (Lapsley \& Edgerton, 2002; Mattanah et al., 2004), psychosocial adjustment (DiTommaso et al., 2003; Engels et al., 2001; Hiester et al., 2009), greater self-esteem (Kenny \& Sirin, 2006), and increased interpersonal competence (DiTommaso et al., 2003; Engels et al., 2001; Ross \& Fuertes, 2010). A growing body of research supports the central role of attachment style in major developmental processes of emerging adults, so attachment theory will be used as an additional theoretical lens through which to view this investigation into the relationships between personality characteristics, interpersonal competency, and online social behavior in the present study.

Building on prior work with early (Ainsworth et al., 1978) and adult (Hazan \& Shaver, 1987) attachment relationships, Bartholomew and Horowitz (1991) present four descriptive categories of adult attachment styles, each with behavioral and emotional correlates for individuals in close relationships (See Figure 2). Adults with a secure attachment style have formed a positive model of themselves and others, and are generally comfortable and secure in close relationships. People with negative models of 
themselves and others are described as having a fearful-avoidant attachment style, and often describe simultaneously desiring and fearing intimacy and closeness. Those who have a negative model of themselves and a positive model of others are described as having a preoccupied attachment style, and have both a high need for intimacy and high anxiety about being abandoned. Lastly, those who have a negative model of others but a positive model of themselves are described as having a dismissing-avoidant attachment style, and are generally highly independent and uncomfortable in close relationships. Although the empirical support for these four attachment styles is stronger for the theoretically predicted views of self than views of others, overall this theoretical framework of adult attachment styles has sound support and is useful in understanding adult relationships (Pietromonaco \& Barrett, 2000).

Moving past Hazan and Shaver's (1987) category model of individual differences in adult attachment styles, and expanding on Bartholomew and Horowitz's (1991) fourcategory model, Brennan et al. (1998) proposed a two-component, dimensional model of attachment (see Figure 1). Their model defined two orthogonal dimensions, called 'anxiety' and 'avoidance,' on which an individual can vary from 'low' to 'high' on these two continuums, and this is how researchers often conceptualize attachment style today (Mikulincer \& Shaver, 2007; Rholes et al., 2008). The anxiety dimension reflects "the extent to which the attachment system is activated in times of environmental or relationship threat or stress" and the avoidance dimension "reflects the degree to which closeness with an attachment figure is desired" (Rholes et al., 2008, p. 120). For example, people with low avoidance and low anxiety are considered to be more securely attached, while a person with high avoidance and low anxiety would exhibit a dismissing-avoidant 
attachment style. In this way, Brennan et al. (1998) provided a more refined way of conceptualizing the four-category model of attachment on the two orthogonal, continuous dimensions of anxiety and avoidance.

In adhering to a defined search methodology, the specific actions outlined in Appendix A were followed to complete the search process for this literature review. The primary online bibliographic databases selected in this literature search were PsychINFO and ERIC, both hosted by CSA Illumina (ProQuest, 2011). An extensive search of the database thesauruses was conducted in order to identify the relevant descriptor terms and keywords for use in the search; all terms used are listed in Table 1. Next, I established practical screening criteria: a) only peer-reviewed sources were included in the literature search b) publication year for sources ranged from 1985 to 2011 c) articles were published in English. I chose this range of publication years for the included articles as this range will best capture the research linking the more modern conceptualizations of communication theory with more current manifestations of social behavior in the generations of young people developing into emerging adults. Arnett's (2000; 2004) theory claims that this developmental stage evolved from the unique set of evolving social circumstances and demographic factors that began changing noticeably from approximately the early to mid 1980's (Arnett, 2000). Thus, the research conducted throughout this time period is also most relevant to the present investigation centering on emerging adults. The defined search terms were combined in numerous searches in various combinations as outlined in the search strategy document detailed in Appendix B. Throughout this process, references cited in sources captured by the search were examined and relevant articles included in the search. Lastly, specific journals, review 
articles, and meta-analyses were reviewed for relevant sources and were included in the search.

Table 1

Descriptor and Keyword Terms Used in Literature Search Methodology

Terms

Computer mediated communication

Social interaction

Attachment behavior

Interpersonal relationships

Attachment theory

Social behavior

Interpersonal communication

Online social networks

Interpersonal interaction

Personality Traits

Personality development

Five Factor Personality Model

Psychosocial development

Social skills

Communication skills

Self-esteem

Self-efficacy

Social self-efficacy

\section{Facebook and Social Behavior of Emerging Adults}

Emerging adults are incorporating the Internet into major areas of their lives (Padilla-Walker, Nelson, Carroll, \& Jensen, 2010; Subrahmanyam \& Greenfield, 2008), especially in interpersonal communication and social behavior (Gordon et al., 2007), and often prefer online resources to offline resources (Ogan, Ozakca, \& Groshek, 2008). In fact, teenagers and emerging adults are increasingly incorporating the Internet and online social networking sites into essential psychosocial developmental tasks such as peer 
relations (Subrahmanyam et al., 2008), sexuality, and identity development (Manago et al., 2008; Subrahmanyam \& Greenfield, 2008). For example, Peluchette and Karl (2010) found that students made an active decision about what image to portray on their Facebook profiles, and that they accurately portrayed their intended image through the content that they chose to post on their account profiles. In this way, emerging adults are increasingly integrating the online environment and social networking sites specifically into important aspects of their development, especially in social behavior and interpersonal communication.

Boyd and Ellison (2007) defined Social Networking Sites (SNS) as web sites providing users with a suite of services designed to create an online profile describing them, define a list of other users with whom a social connection has been established, and access the profiles and defined lists of other users within the web site. Although each site manifests these features in a slightly different way, these factors are considered common across all SNS. These services combine to form what these authors call a user's "social networks," which represent a web of interconnected individuals all with some shared social connection. Facebook can be considered a SNS, as it offers users a forum for creating and presenting a personal profile that represents their identity. In addition, it emphasizes the interconnection of users' profiles, linking each person's page to others who share a social connection. Lastly, users can explore the profiles and social networks of other users. Facebook use was reconceptualized by Ellison et al. (2007) to incorporate a user's emotional connection to and reliance on the site, reemerging as a definition of Facebook use intensity. They defined this as the extent to which users incorporate the site into daily social behavior, the intensity of users' emotional connections to the site, and 
the degree to which users actively engage with the site and its various tools for social behavior.

Facebook has become the most widely used online social networking site for emerging adults, and is used primarily for social interaction (Ellison et al., 2007). Patchin and Hinduja (2010) found in their review of behavioral change in teenagers that most had moved on from social networking sites such as MySpace to join Facebook, in large part to address privacy concerns. In light of these recent developments, Subrahmanyam et al. (2008) joined other authors in calling for more research on this type of online communication and social behavior in order to understand its role in emerging adult development. Given the rapid development and use of SNS, however, authors lament a lack of research on how online social behavior impacts social skills development in adolescence (Subrahamanyam et al., 2008) as well as on personality traits that explain SNS use (e.g. Wilson, Fornasier \& White, 2010). But the literature seems to agree that the internet, and SNS like Facebook in particular, are increasingly involved in the psychosocial developmental processes of children and adolescents (Greenfield, 2004; Gross, 2004; Schmitt, Dayanim, \& Matthias, 2008) as well as emerging adults (Brown, 2006; Steinfeld et al., 2008; Subrahmanyam et al., 2008).

Many studies have looked at how personality traits such as self-esteem (e.g. Joinson, 2004) and Five Factor Model (FFM) characteristics (e.g. Amichai-Hamburger, Wainapel \& Fox, 2002; Amiel \& Sargent, 2004; Hamburger \& Ben-Artzi, 2000) influence internet use, but few have looked at the phenomenon of SNS and these traits' impacts on social behavior. John et al. (2008) defined the FFM traits as Extraversion (energetic and outgoing approach to the world, comfortable in social contexts, assertive 
and optimistic), Agreeableness (a prosocial approach to others and society, altruistic, and trusting), Conscientiousness (ability to control impulses, especially in social contexts, and law-abiding, organized, and planful), Neuroticism (negative outlook and unstable emotionally, characterized by anxiety and tension), and Openness (broadness in thinking and world view, characterized by acceptance and complexity). Therefore, the present study seeks to understand the relationship between stable personality traits such as attachment style, FFM traits, and Facebook use, as well as how personality traits and Facebook use are associated with interpersonal competence.

First I will discuss in depth each construct to be included in the analyses. Then I will review the body of literature, examining how each construct relates to Facebook use and interpersonal competency. Finally, I will summarize the relevant literature in an effort to justify the specific hypotheses to be tested in this study.

\section{Five Factor Model and Social Behavior}

The Five Factor Model (FFM; Digman, 1990; McCrae \& John, 1992; McCrae \& Costa, 2003) was developed as a way to describe adult personality, relying on the basic principles of trait psychology. McCrae and Costa (2003) defined traits as "dimensions of individual differences in tendencies to show consistent patterns of thoughts, feelings, and actions" (p. 25), and emphasized that traits emerge early on in development and endure throughout adulthood. If people exhibit more of a specific trait, they will be more likely to behave in ways that are congruent with that trait's essence, or to manifest the trait through their behavior. In this way, a trait can be thought of as a general disposition or a tendency to think, react, and act in given ways. This means that traits are consistent over 
time and across situations, as they are more stable than moods states, or habits which are specific behavioral patterns (John et al., 2008).

The FFM evolved out of natural language, as early personality psychologists identified thousands of trait terms used in English to describe people, their personalities, and their tendencies. Allport and Odbert (1936) narrowed a pool of 18,000 dictionary words to 4,000 that described personality traits. Cattell (1946) condensed this pool of descriptors into 12 dimensions, which became the basis for the Sixteen Personality Factor Questionnaire (16PF). Later work using Cattell's data and new data replicating Allport and Odbert's methods reached a comprehensive, five-factor model of personality traits that has been replicated in numerous studies (John et al., 2008). Initial research suggested that the FFM of personality has cross-cultural applicability (Stumpf, 1993), and more recent work concludes that it can be considered a universal model (McCrae \& Costa, 1997; McCrae \& Costa, 2003).

Robins, Fraley, Roberts and Trzesniewski (2001) demonstrated that these traits are relatively stable throughout young adulthood, although recent work suggests that these five traits change significantly across the entire lifespan (Srivastava, Joh, Gosling, $\&$ Potter, 2003). These authors found that all five traits of the FFM changed over time to some degree in their very large sample, with conscientiousness and agreeableness increasing with age for both genders, neuroticism and extraversion decreasing with age for women much more than men, and openness declining slightly with age for both genders. Sturaro, Denissen, van Aken, \& Asendorpf (2008) studied the FFM traits and relationship quality in emerging adults, finding that these traits and self-esteem were relatively stable throughout this developmental period. These results confirmed earlier 
work by Roberts and DelVecchio (2000) and Roberts, Walton and Viechtbauer (2006) that indicated rank-order stability in these traits over the lifespan but showed clear meanlevel change tied to chronological age. This recent meta-analysis by Roberts et al. (2006) suggested that FFM traits of conscientiousness and neuroticism as well as aspects of extraversion increase during young adulthood. In addition, the most recent article to investigate age differences in personality traits over time suggested that conscientiousness, agreeableness, and openness showed positive trends while neuroticism and extraversion generally displayed a negative trend from adolescence through emerging adulthood (Soto, John, Gosling \& Potter, 2010). The authors stated that these tendencies were mostly associated with greater levels of psychosocial maturity, however, the practical significance of these differences has yet to be determined. Although consensus has yet to be reached regarding the mutability of FFM traits, initial evidence suggests that they remain relatively consistent throughout this developmental period and may significantly impact online social behavior.

\section{Attachment and FFM Traits}

Since early work investigating the relationship between adult attachment style and FFM personality traits by Shaver and Brennan (1992) and Carver (1997), research methodology and measurement techniques have developed significantly. These early studies have been backed by later work that supports the positive correlation between secure attachment styles and extraversion and agreeableness, and negatively associated with neuroticism, while anxious and avoidant attachment styles were positively correlated with neuroticism and negatively correlated with extraversion and agreeableness (Backstrom \& Holmes, 2001; Picardi et al., 2005; Shaver \& Brennan, 
1992). However, more recent work has concluded that the attachment-FFM relationships are fairly consistent but weak and should be expected given the nature of these constructs (Picardi et al., 2005). As research on attachment and FFM personality traits in childhood suggests that attachment is an important predictor of these traits, especially extraversion, openness, and neuroticism (Hagekull \& Bohlin, 2003), I will incorporate the developmental nature of this relationship throughout the present study.

\section{Personality Traits and Interpersonal Competence}

In their review, Ozer and Benet-Martínez (2006) lamented the lack of research relating FFM personality traits to social competence; they cited support for personality traits impacting social skills which in turn affect relationship quality. They noted that the available research supports extraversion and neuroticism as the most important predictors of social outcomes, while Cuperman and Ickes (2009) provided support for extraversion and agreeableness as the most impactful FFM traits on social interaction. FFM traits do appear to influence a person's experience with social interactions (Ansell \& Pincus, 2004; Berry \& Hansen, 2000; McCrae, 1996), possibly through mechanisms such as affect and behavioral responses (Côté \& Moskowitz, 1998; Cuperman \& Ickes, 2009) and emotional reactivity (Denissen \& Penke, 2008). In addition, these FFM traits have been related to numerous aspects of interpersonal communication and interpersonal competence such as relationship satisfaction (Goodboy \& Booth-Butterfield, 2009; Ozer \& Benet-Martínez, 2006; Watson, Hubbard \& Wiese, 2000), satisfaction with sex (Fisher \& McNulty, 2008), conflict resolution (Wood \& Bell, 2008), and marital satisfaction (Donnellan et al., 2005; Karney \& Bradbury, 1995). 
Early work by Berry and Hansen (1996) suggested that extraversion and neuroticism were associated with the quality and quantity of social interactions, as higher extraversion and lower neuroticism were associated with increased quality and quantity of interpersonal communication. Berry and Hansen (2000) identified extraversion and agreeableness as the factors most associated with positive social interactions, with specific behavioral correlates identified such as focus of visual attending and body posture. This study benefited from a naturalistic approach and utilized observer ratings as well as self-report measures from participants. Barrett and Pietromonaco (1997) found that FFM traits predicted an individual's perceptions of naturally occurring social interactions throughout their weeks recorded through a daily diary record. For example, they found that higher levels of extraversion were associated with increasingly positive perceptions of their interpersonal interactions and an overall positive experience in social contexts. These results held true across a range of difference social variables, such as self-disclosure, self-esteem, and positive emotionality in interpersonal interactions.

In close relationships, White et al. (2004) found that neuroticism predicted lower relationship satisfaction, while extraversion and agreeableness predicted several positive relational outcomes. Similarly, recent work by Cuperman and Ickes (2009) found that extraversion and agreeableness were associated with more positive interpersonal interactions, while also associated with specific aspects of affect and social behaviors that were rated as facilitating interpersonal communication quality. Back et al. (2009) supported these results in finding that extraversion, neuroticism, and agreeableness reliably predicted actual behavior, which aligned with prior research as well. Thus, it 
appears that these three FFM traits are most associated with interpersonal communication competence.

\section{FFM Personality Traits and \\ Facebook Use}

Personality characteristics have been found to predict many different forms of communication, from cell phone use (Butt \& Phillips, 2008) to email and instant messaging use (Swickert, Hittner, Harris, \& Herring, 2002) and blogging activity (Guadagno, Okdie, \& Eno, 2008), while a summary of recent findings by Jackson et al. (2003) "suggest that personality characteristics may be important initially in determining the frequency of Internet use, and later in determining the nature of Internet use" (p. 86). However, some researchers have found that personality traits such as extroversion determine the extent and nature of internet use for social purposes (e.g. Tosun \& Lajunen, 2010). Investigating the relationship between Big Five personality characteristics and personal web page owners, Marcus, Machilek, and Schutz (2006) found that site visitors judged some of the page owner's FFM personality traits accurately, as, for example, “Openness to Experience could be inferred from personal Web sites with the highest validity of all five factors" (p. 1029). This finding was supported with social networking site profiles as well, as Back et al. (2010) found that these profiles accurately reflected actual Five Factor personality traits of the user, with extraversion and openness demonstrating the most accuracy. In addition, these authors controlled for idealization of self, and suggested that the observers were rating "real personality" of profile owners (p. 374). Schmitt, Dayanim, and Matthias' (2008) results confirmed that adolescents create personal web pages as expressions of their identities. Thus, self-presentation of 
personality traits on the web represents a manifestation of important social developmental processes and contributes to psychosocial development.

Based on early research investigating web usage, extraversion and neuroticism seem to have been the Five Factor traits most associated with web usage. In these early efforts, higher neuroticism was associated with less usage (Amiel \& Sargent, 2004; Tuten \& Bosnjak, 2001; Swickert et al., 2002) and higher extraversion associated with increased usage (Hamburger \& Ben-Artzi, 2000; Jackson et al., 2003; Tosun \& Lajunen, 2010). However, some authors have found the opposite trend, with introverted people using the internet more for social purposes (Amiel \& Sargent, 2004; Landers \& Lounsbury, 2006).

Much of this personality trait research has explored the role of extraversion/introversion on internet use (Amiel \& Sargent, 2004; Sheldon, 2008) and has recently been applied to SNS use specifically (e.g. Ross et al., 2009). Two general hypotheses have emerged with the rich-get-richer hypothesis (Kraut et al., 2002) postulating that extraverted individuals benefit most from online social communication (Peter, Valkenburg, \& Schouten, 2005; Sheldon, 2008), while the social compensation hypothesis states that introverted people benefit most from social internet use due to its anonymity, ease of social interaction due to lessened anxiety, social pressure, and fear of rejection (McKenna \& Bargh, 2000; Ward \& Tracey, 2004; Wolak, Mitchell, \& Finkelhor, 2003). Orchard and Fullwood's (2010) review of relevant literature found support for both of these hypotheses, however, Peter et al.'s (2005) work suggested that these models may be insufficient, and mediators like self-disclosure must be added to theoretical explanations to make them comprehensive in explaining social internet use. 
Correa et al. (2010) published a study with moderately strong methodology (i.e., large sample size $[\mathrm{n}=1482]$ matched on two census variables, less rigorous and abbreviated FFM scale, social media use scale constructed for the study) expanding upon recent research with college students (Ross et al., 2009; Wilson et al. 2010; Zywica \& Danowski, 2008) in establishing extraversion, neuroticism, and openness as the three traits most associated with SNS use specifically. Taken together, these studies' results suggest that higher extraversion, neuroticism, and openness were associated with increased SNS use. However, Ross et al.'s (2009) study suffered from a small sample size and a lack of methodological rigor in measurement, while Zywica and Danowski (2008) only included extraversion from the FFM. Wilson et al. (2010) found that extraversion and conscientiousness predicted hours of SNS use, but this study suffered from methodological weaknesses, such as a weak single item measure of SNS use hours, unclear use of a transformation on the dependent variable and interpretation thereof, a failure to adjust their overall alpha level given multiple model testing, and followed few of the guidelines for reporting statistics in published research (APA, 2008), such as improper reporting of regression results, a failure to report overall alpha level for testing, unclear methods section lacking detailed procedures and data analysis sections, a failure to report both unstandardized and standardized regression coefficients, and unclear description of measurement scales used. In fact, many of the more recent and specific research on personality traits and SNS use are published in the journals Cyberpsychology, Behavior, and Social Networking and Journal of Computer-Mediated Communication and often suffer from similar methodological weaknesses (e.g. Wilson et al., 2010) according to established guidelines. 
Sheldon (2008) and others lament the lack of research on the personality traits associated with Facebook users, while more recent research reflects mixed findings in this line of research. Results suggest both neutral and positive relationships between personality traits and SNS use (e.g., Wilson et al., 2010), however, many of these studies suffer from a lack of methodological rigor in measurement, sample characteristics, and methodology. Thus, research investigating personality traits and their relationship to Facebook use is sparse and limited at best, and must be expanded in order to reach a general consensus in this area of the field.

\section{Attachment Style and Interpersonal Competence}

Attachment style has been shown to impact one's style of relating to others and experience in close relationships (Hazan \& Shaver, 1987; Fraley \& Shaver, 2000), as the underlying attachment model guides future relationships formed throughout the lifespan (Berlin et al., 2008; Hazan \& Shaver, 1987; Mikulincer \& Shaver, 2007; Zimmerman, 2004). In addition, it has been linked to relationship satisfaction in romantic relationships (Fraley \& Shaver, 2000; Tucker, \& Anders, 1999), but this association may be mediated by communication style (Guerrero, Farinelli, \& McEwan, 2009). In line with this argument, attachment style has also been associated with interpersonal communication style, with more securely attached partners displaying more effective communication (Jang et al., 2002), along with other areas of interpersonal communication such as perceptions of social support (Bernardon, Babb, Hakim-Larson, \& Gragg, 2011; Collins \& Feeney, 2004; Mallinckrodt \& Wei, 2005).

Attachment theory provides a theoretical lens through which to view individual differences in interpersonal relationships and communication (Pietromonaco \& Barrett, 
1997). These authors suggest that even daily interpersonal interactions could be explained by individual attachment style, although most saliently within attachment relationships. Johnson (2003) notes the connection between attachment and communication styles, stating that securely attached people tend "to be more open and direct" and "disclose more and be more attuned to the communication of others" (p. 109). Pietromonaco, Greenwood, and Barrett (2004) supported this idea in their review of attachment's relationship to conflict communication in couples, finding that attachment style significantly predicted communication style and effectiveness. Similar results have been found for conversational skills, as Guerrero, Jones, and Burgoon (2005) showed that more securely attached people demonstrating more effective interpersonal communication while Cooley, Van Buren, and Cole (2010) found significant associations between social skills and attachment. Sibley and Overall (2008) supported these results with a theoretical argument that "the dynamics through which the attachment behavioral system affects relational representations may lead to more generalized behavioral tendencies that tend to apply across different relational contexts" and "regulate interpersonal responding in non-attachment contexts" (p. 1404).

Mallinckrodt (2000) proposed a model relating early attachment style to social competency and close relationships in adulthood. His Social Competencies and Interpersonal Processes (SCIP) model posits that secure early attachment relationships allow children to develop competency with interpersonal interaction that are critical for later close relationships in adulthood while insecure attachment eventually leads to social dysfunction (Mallinckrodt, 2000). Mikulincer and Shaver (2007) support this idea as well, as attachment style can "influence interpersonal skills" (p. 264). They explain this 
connection by stating that conflictual and unsupportive attachment relationships lead children to adopt inefficient strategies for seeking attachment (e.g., anxious hyperactivation), which can lead to poor interpersonal skills. There is ample support for how this process manifests with expressiveness, as avoidant attachment styles are significantly associated with deficits in interpersonal expression and disclosure (Mikulincer \& Shaver, 2007).

In the same vein, recent work has begun to explain why this association exists, pointing to the connection between attachment style and emotional communication (Guerrero et al., 2009). For example, these authors suggest that more securely attached individuals are more effective communicators, and therefore that attachment plays a role in interpersonal communication competency. However, this study suffered from a lack of methodological rigor in measurement and statistical analyses. Simpson, Collins, Tran, and Haydon (2007) found that early attachment played a significant role in predicting emotional expression and interpersonal competence throughout the lifespan and into close relationships of early adulthood. Mallinckrodt and Wei (2005) found that social self-efficacy and emotional awareness mediated the relationship of attachment and psychological distress and perceptions of social support.

This link between attachment style may hold true for the nonverbal aspects of interpersonal interaction as well, with Tucker and Anders (1998) finding that more securely attached adults displayed more nonverbal behaviors associated with intimacy and closeness and the opposite trend for insecurely attached individuals. This study suffered from a small sample size, however, and included only 61 romantic couples. Later work has found some support for this link between attachment style and nonverbal 
interpersonal behavior (Cooley, 2005; Schachner, Shaver, \& Mikulincer, 2005). For example, attachment may be related to interpersonal physical distance (Kaitz, Bar-Haim, Lehrer, \& Grossman, 2004), while research consistently supports the link between insecure attachment and deficits in accurately decoding and understanding facial expressions (Mikulincer \& Shaver, 2007).

More naturalistic studies have supported these trends as well, as more securely attached people may experience social interactions as more positive, disclose more readily, and feel more understood than insecurely attached people (Kafetsios \& Nezlek, 2002). Anders and Tucker (2000) explained this association by noting that in comparison with securely attached people, more anxious and avoidant individuals are less skilled in many areas of interpersonal communication, including "expressivity, disclosure, conversational regulation, conflict resolution skill, and interpersonal sensitivity" (p. 380). These authors suggested that interpersonal communication competency also helped to explain the link between attachment style and relational satisfaction.

Building on earlier work by Simon and Baxter (1993), Bippus and Rollin (2003) applied attachment style to platonic interpersonal relationships and found support for the idea that attachment was related to relationship maintenance behaviors. In this study, more securely attached people engaged in more pro-social behaviors in friendship relationships. Miller and Hoicowitz (2004) also reported a significant link between parental attachment and the length and quality of friendships in college, finding that avoidance in attachment to parents predicted friendship relational outcomes. Welch and Houser (2010) supported these findings, suggesting that more securely attached 
individuals reported greater satisfaction, self-disclosure, and hope in friendship relationships.

Observational research echoes these findings for adolescents (Furman, Simon, Shaffer, \& Bouchey, 2002), as Shomaker and Furman (2009) found that more secure parental representations were associated with higher friendship quality. Mayseless and Scharf's (2007) work with adolescents found that attachment style predicted participants' capacities for relational intimacy four years later in adulthood; this work was conducted in Israel and suffers from a small sample size. Other longitudinal research supports this idea that attachment style predicted relationship quality prospectively in young adults (Holland \& Roisman, 2010). This trend in results holds true for children and young adolescents, as Schneider, Atkinson, and Tardif's (2001) meta-analysis confirmed that parental attachment (mother-child specifically) is significantly related to peer friendship quality $(r=.24)$.

\section{Interpersonal Communication Competence}

Wilson and Sabee (2003) provided a comprehensive and detailed overview of the most prominent ways of defining communicative competence. In the present study, I defined interpersonal communication competency, or communicative competence, through the lens of a Hierarchical communications theory within the Theories of Message Production family of communications theories. This theoretical framework views interpersonal competency as consisting of "procedural knowledge at multiple levels of abstraction, including low-level knowledge," as competent communicators coordinate these multiple levels of action smoothly within a well-timed performance in a given social interaction (Wilson \& Sabee, 2003, p. 24). Relying on Green's (1997) later 
revisions of Action Assembly Theory, this Hierarchical model sees communicators as unconsciously developing an "associative network model" in long-term memory with each node in the network comprised of a procedural record of "knowledge underlying behavior" (Wilson \& Sabee, 2003, p. 26). These procedural records form "interconnected nodes representing features of actions, outcomes, and situations" (p. 26) that contain all the knowledge and procedures necessary to carry out social actions from specific muscle movements in the face, to more abstract plans for social behavior.

Competent communicators can effectively implement these programs for action, from general procedures for achieving social goals to the basic words, muscle movements, and ideas needed to achieve social communication goals. With increasing competence, individuals will be able to integrate these action programs together smoothly, stitching together a well-timed social performance that becomes effective communication. A competent communicator effectively integrates and implements stored programs (composed of knowledge and procedures) in order to communicate effectively. The individual might choose impactful words spoken clearly and without interruption, pairing them with an expressive gesture and a telling facial expression to communicate a specific meaning and emotional content. Thus, it is in the selection, implementation, and coordination of these programs for action, as well as how one adjusts these actions in response to feedback from the social environment, that determines one's level of interpersonal competency (Wilson \& Sabee, 2003).

Communication skills are essential to developing meaningful relationships (Bruch, Berko \& Haase, 1998) and interpersonal relationships play a major role in psychological wellbeing (Diener \& Ryan, 2009). Masten et al. (2004) stated that 
relationships are particularly important for young adults, and that how they approach them changes significantly as individuals progress from adolescence into adulthood. However, Larson, Whitton, Hauser, and Allen (2007) noted a distinct lack of research on the link between interpersonal competence and functioning in young adults. These authors found using a novel method of assessing social competence using peer ratings that higher interpersonal competence was associated with increased psychosocial functioning in a number of relevant domains (e.g., self-esteem, psychological distress). Deficits in social skills, have been connected to psychosocial problems (Segrin \& Flora, 2000), depression and anxiety, and lower levels of relational satisfaction (Hargie \& Dickson, 2006). Thus, interpersonal communication competency appears to be an important domain to understand and research in depth.

Buhrmester et al. (1988) in developing their interpersonal competency scale found higher ratings of competence were related in theoretically expected ways to social functioning, social self-esteem, shyness, loneliness, and social reticence. Interpersonal competence has even been studied in relation to the FFM personality traits, as Kanning's (2006) German translation of the ICQ found higher values in all social competence subscales as subjects reported higher extraversion, conscientiousness, agreeableness, openness, and lower neuroticism. Wolf, Spinath, Riemann, and Angleitner (2009) found significant relationships between FFM traits and self-monitoring, an important skill in social behavior. Ratings on the ICQ have been shown to be positively related to selfperceptions of level of engagement in conversations (Miller \& deWinstanley, 2002). Hargie and Dickson (2006) reported that many personality traits may play a role in interpersonal communication. For example, they present initial evidence that, compared 
to extroverted individuals, introverts tend to talk less frequently with less eye contact and more pauses in conversation.

Communication competence has been shown to play an important role in close relationships as well and attachment style may be significantly related to these social skills (Rholes et al., 2008). Individuals with higher levels of avoidance have difficulty becoming close to others (Bartholomew \& Horowitz, 1991) and disclosed less about themselves while anxiously attached individuals are more dissatisfied with interpersonal interactions (Bradford et al., 2002). In addition, anxious and avoidant people have lower expectations about the availability of emotional support from others in close relationships and report less satisfaction from the social support they actually receive (Anders \& Tucker, 2000). These results suggest that perceptions of support can significantly impact relationships and that attachment style may contribute significantly. Some researchers have even linked secure early attachments to greater interpersonal social skills in later childhood (Wood, Emmerson, \& Cowan, 2004), especially with close friendships (Schulman et al., 1994).

For college-aged emerging adults, friendships are often their most important relationships (Welch \& Houser, 2010). As media, and especially SNS, are increasingly involved in emerging adults' social interactions, researchers have begun to investigate how interpersonal communication via social media is impacted by personality variables such as attachment (Jin \& Peña, 2010). These authors found that communication via cellular phone was significantly related to attachment style, as avoidant college students used voice calls less in communicating with their romantic partner. Buote, Wood, and Pratt (2009) investigated the role of attachment style in online communication via SNS. 
They found that insecure individuals reported lower friendship quality, and that attachment style uniquely affected online and offline relationships. Taking all these results together, it appears important to investigate the role that interpersonal communication competency and personality traits play in the platonic relationships of emerging adults which often play out online.

\section{Interpersonal Communication Competence and Online Social Behavior}

Although no research has investigated the link between interpersonal communication competence and Facebook specifically, support for the link between social competence and online social behavior has recently begun to emerge in the literature. Ellison et al. (2007) found that Facebook use was positively associated with increased bridging and maintained social capital, or the "resources accumulated through the relationships among people" (p. 1145). These results suggest that Facebook use may be associated with positive relational outcomes, such as increases in social connectedness and integration into a college community. Mazer et al. (2008) investigated the relationship between self-disclosure and Facebook use, finding that teacher selfdisclosure on Facebook was associated with student learning outcomes and may encourage student communication and can build a stronger teacher-student relationship. In fact, computer-mediated communication may actually foster self-disclosure as internet users may be "better able to express and effectively convey important aspects of their real selves over the Internet” (McKenna et al., 2002, p. 29). These authors propose that individuals with decreased social skills may find forming relationships over the internet easier than in face-to-face interactions. Ledbetter (2010) supports these results as well, 
finding that communication competence plays a role in an individual's attitude towards online self-disclosure.

However, Valkenburg and Peter (2008) stated that as of 2008, only three studies have investigated the association between online communication and interpersonal communication competence, while their results suggested a positive association between online communication and social competence in the real world. Caplan (2005) found that social skills were related to online social behavior, with decreased social skills with selfpresentation being associated with increased interaction online. Similarly, Engelberg and Sjoberg's (2004) results suggested that decreased social competence was associated with increased internet communication for social purposes. Lastly, Harman et al. (2005) results suggest that time spent online in general was not associated with changes in level of social skills for the children under study, but that misrepresentation of one's identity online was related to poor social skills. Thus, although still inchoate and nascent, there is growing evidence supporting the link between interpersonal communication competence, social interaction skills, and online social behavior and communication.

\section{Social Self-Efficacy}

Social self-efficacy is another way to conceptualize a person's perceptions of their own interpersonal communication competence. Bandura's (1997) theory of self-efficacy has received widespread attention and empirical support from counseling psychologists (Gore, 2006) as a prominent aspect of his social cognitive theory (Bandura, 1986). He postulates that beliefs about one's own abilities to be successful within a given domain of tasks (e.g., math exams, making career decisions) impacts performance in and motivation to complete those activities (Bandura, 1986). These expectations about our own abilities 
to be successful form our self-efficacy beliefs in a domain, which significantly influences our decision to initiate a behavior, motivation to spend energy completing the behavior, and dedication to overcome obstacles in order to successfully complete that behavior (Bandura, 1986). In this way, how we think about our own skills in a given area influences how we actually use associated behavioral skills.

Bandura (1997) theorized that the strength or level of self-efficacy beliefs would contribute significantly to a person's motivation to complete a given task and their persistence therein. He identified four means for strengthening or weakening selfefficacy: emotional arousal, verbal persuasion, vicarious experiences, and performance accomplishments (Bandura, 1997). Performance accomplishments act essentially as a feedback loop, in that perceived success with performing a task will strengthen selfefficacy expectations for that task; this also forms the most effective method of impacting self-efficacy (Bandura, 1997). Vicarious experiences take the form of social modeling, in that observing another person being successful with a task increases our own self-efficacy expectations for the same task. Verbal persuasion often takes the form of support and encouragement from respected peers or attachment figures, and serves to bolster our own self-efficacy beliefs. Lastly, our psychological state or level or emotional arousal can impact self-efficacy beliefs as negative or positive emotions can affect our thought process and thus our self-efficacy beliefs.

Sherer et al. (1982) published the term 'social self-efficacy' shortly after Bandura created his self-efficacy theory, and used it to describe a component factor in developing their general self-efficacy scale. However, this scale's disappointing psychometrics (e.g., $\alpha=.71$ and weak factor analysis results), wide scope which conflicts with self-efficacy's 
domain specificity, and the lack of research on social self-efficacy with adult populations makes this construct largely underexplored until recently (Fan, Meng, Gao, Lopez, \& Liu, 2010; Smith \& Betz, 2000). Therefore, Smith and Betz (2000) developed a novel social self-efficacy scale in order to measure one's self-efficacy in the specific domain of social behavior, or one's confidence in being successful in social interactions. It was designed to capture a person's confidence in their social skills in various domains and was shown to be significantly negatively related to measures of social anxiety and shyness as might be expected. Thus, social self-efficacy represents another way to operationalize interpersonal competence, as it seems to capture perceived confidence in one's abilities at interpersonal communication.

Social self-efficacy has been linked to psychosocial functioning (Hermann \& Betz, 2004; Smith \& Betz, 2002) and relational competence (Caprara, Gerbino, Paciello, Di Giunta, \& Pastorelli, 2010) and may play an important role in the development of interpersonal resources "needed to cope successfully with transition into adulthood" (p. 44). In studying college students, Wei et al. (2005) found that social self-efficacy mediates the relationship between attachment and psychosocial functioning. Corcoran and Mallinckrodt (2000) also found that social self-efficacy mediates the empirically supported relationship between attachment and conflict management skills in adults. Mallinckrodt and Wei (2005) supported these results, as their survey study of 430 college students suggested that both attachment anxiety and avoidance were negatively associated with social self-efficacy. Wei et al. (2005) explained this association through attachment theory, stating that negative working models of self in anxiously attached individuals explain decreased confidence in interpersonal interactions. In addition, they 
explained that avoidant individuals have learned through early attachment relationships that self-disclosure risks the pain of rejection and so expect less from self-disclosure and become overly self-reliant.

A number of studies have linked attachment styles directly to social skills and interpersonal competence (DiTommaso et al., 2003; Engels et al., 2001). DiTommaso et al. (2003) found that attachment was related to specific social skills, especially emotional expressivity; in addition, the results also suggested that more securely attached individuals exhibit a more balanced set of social skills, while insecurely attached individuals showed disproportionate levels of social skills. Wright and Perrone (2010) found that attachment was significantly related to social self-efficacy, results supported by recent research which suggested that high levels of anxiety and avoidance are related to decreases in social competency (Mallinckdrot \& Wei, 2005; Wei et al., 2005). Thus, attachment has consistently been found to be associated with interpersonal competence, but future research must investigate how other stable personality traits are related as well.

\section{Summary of Conclusions and Support for Research}

A systematic, explicit, comprehensive and reproducible literature search was performed following a defined methodology. The results were synthesized and integrated using both emerging adulthood and attachment theory as two developmental theoretical lenses. Although potentially limited by selection criteria, search strategy, and errors in synthesizing sources, this review attempted to yield a comprehensive overview of the relevant published scholarly literature related to attachment, FFM personality traits, interpersonal communication competency, social self-efficacy, and Facebook use. 
Many psychological theories of development see adolescence and the transition into young adulthood as primarily concerned with questions of identity, interpersonal relationships, finding a sense of place in the world, and occupational roles (e.g., Erikson, 1968; Levinson, 1978; Keniston, 1971). Arnett's (2000) emerging adulthood theory has become a useful way to conceptualize the development of young adults in the modern era, focusing on the period after the transition from adolescents into young adulthood. Attachment theory (Bowlby, 1969) provides another useful theoretical lens through which to view developmental processes, especially those concerned with interpersonal relationships. This more enduring style of attachment developed in the context of early relationships has consequences for later interpersonal connections throughout life (Kenny \& Rice, 1995; Zimmerman, 2004). Attachment has links to relationship satisfaction (Tucker \& Anders, 1999), communication style (Jang et al., 2002; Johnson, 2003), and interpersonal competency (DiTommaso et al., 2003; Guerrero \& Jones, 2005; Mallinckrodt, 2000; Mikulincer \& Shaver, 2007; Ross \& Fuertes, 2010; Wei et al., 2005). Thus, attachment style seems to play an important role in relationships and interpersonal communication, both key developmental tasks of emerging adults.

As emerging adults are increasingly integrating social media into their daily lives and developmentally significant tasks (Greenfield, 2004; Subrahmanyam et al., 2008), more research must seek to understand how personality factors are related to Facebook use and interpersonal competency (Brown, 2006; Thayer \& Ray, 2007). Facebook has become the most salient example of this integration (Patchin \& Hinduja, 2010) and researchers have begun to investigate how personality traits are related to its use (e.g. Amiel \& Sargent, 2004). As friendships are often the most important relationships for 
this population (Welch \& Houser, 2010), researchers have begun to investigate the role of personality variables such as attachment (Buote et al., 2009) and FFM traits (Ross et al., 2009) in online social behavior.

FFM personality traits do appear to be associated with interpersonal competence (Ansell \& Pincus, 2004), although some lament the lack of literature investigating this relationship (Ozer \& Benet-Martinez, 2006). Much previous research has established the link between these traits and relationship satisfaction (White et al., 2004) or positive experiences with social interactions (Cuperman \& Ickes, 2009), but little has looked at the link to social competence. This pattern of results seems to apply to online social behavior as well, most notably on SNS (Ross et al., 2009) as FFM traits such as extraversion, neuroticism, and openness seem to explain the intensity and frequency of Facebook use (Correa et al., 2010). Much more research is needed on this link (Sheldon, 2008), and future research must use methodologically rigorous studies to better understand this relationship.

\section{Limitations of Literature Review}

This literature review may suffer from a number of limitations. In creating an a priori methodology for conducting this research literature review, I established a number of criterion for inclusion that may have limited the sources available for review. In this way, using the two selected databases may have limited the number of sources available. The search used a defined list of descriptors and keywords and employed specific strategies such as reference branching and examining literature reviews, all of which may have unintentionally excluded sources relevant to the research questions. In addition, the search methodology's established practical exclusion criteria that all sources gathered 
through the online bibliographic databases had to be published after 1985 in peerreviewed, English journals may have unnecessarily excluded sources. Additionally, this review may have suffered from the 'file drawer' phenomenon, in that many studies that do not demonstrate significant results remain unpublished and become what is known as 'grey literature.' This selection bias in available research may have biased the results of this review. Lastly, investigator error may have contributed to limiting the comprehensiveness of this literature review. However, precautions were included in the search methodology at the outset, such as detailed documentation of the search process and consulting with colleagues in the field to ensure that the most relevant sources were included in synthesizing the search results. Thus, overall this literature review provides an adequate census of the relevant published scholarly sources germane to the research questions outlined in Chapter 1 of the present work.

\section{Implications and Future Directions}

Research appears to be lacking in a number of areas relevant to emerging adults' personality traits associated with Facebook use and interpersonal competency. As the research is still emerging, little is known about the personality characteristics associated with the nature and intensity of Facebook use. Although initial links between attachment and interpersonal competency and social self-efficacy have been suggested (e.g. Mallinckrodt \& Wei, 2005; Wright \& Perrone, 2010), more research is needed to fully understand this connection. As Facebook use continues to become more seamlessly integrated into the daily lives of emerging adults, the relationship between interpersonal competency, social self-efficacy, and online social behavior through SNS use must be more thoroughly explored. 


\section{CHAPTER III}

\section{METHODS}

The present investigation utilized a cross-sectional design that examined the interrelationships between personality traits and interpersonal communication competence as well as online social behavior. I examined how stable personality traits previously shown to affect social relationships and behavior, specifically attachment and FFM traits, were associated with interpersonal communication competence and online social behavior manifested in Facebook use. I recruited undergraduate college student participants via email to complete a web-based survey comprised of multiple scale measures as described below. Johnson's (2005) review of web-based survey protocol validity suggested that web-based personality measures are approximately similar to paper-and-pencil measures as long as appropriate steps are taken to prevent invalid subject response patterns. In the present study, I employed the recommended methods for detecting multiple submissions, same-response category inattentiveness, protocol consistency, and patterns of missing data. The measurement scales included in the present study were used to operationalize the constructs of interest under investigation, as attachment theory and the FFM trait taxonomy support the conceptualization of attachment and FFM traits as latent constructs. In addition, the Hierarchical communication theory introduced in chapter 2 supports the idea that interpersonal competence can be represented as a latent construct and operationalized by measuring utility with (interpersonal competence) and confidence in social interaction and 
relationship maintenance skills (social self-efficacy and interpersonal competence). Therefore, this study investigated relationships among latent constructs in an attempt to contribute to the established literature by creating a model that explains the interrelationships between personality traits, interpersonal competence, and online social behavior.

Based on the review of relevant literature, I hypothesized a primary theoretical model and an alternate model relating attachment and FFM traits to interpersonal competence and Facebook use (See Figure 3 and Figure 4; models specified in detail below in the Data Analyses section). In order to test this primary theoretical model, I employed structural equation modeling (SEM) procedures in order to determine the viability of these theorized relationships between unobserved, latent variables. Latent variables are used to represent hypothetical constructs based in theory (Kline, 2011), such as the construct of adult attachment style. It cannot be observed directly and there is no perfect measure of this construct, therefore in this example, researchers can use observable variables as indirect measures of constructs (Kline, 2011). Therefore, I used observable scale data (obtained from the measures described below) as indirect measured indicators of the constructs of interest in this study. These indirect indicators or measured variables are not perfect measures of the constructs they attempt to represent and are impacted by measurement error. Thus, I used SEM in order to account for the measurement error inherent in the scales used in this study, as SEM presents an effective way of testing the relationships between latent constructs while accounting for measurement error inherent in operationalizing those constructs (Byrne, 2006). 
Of Jöreskog's (1993) three strategic frameworks for using SEM, I followed the Model Generating (MG) approach, first testing an a priori primary theoretical model for fit to the data, then comparing this model to alternate theoretical models, and, only if no a priori model is retained, using a combination of theory and results from the data to respecify and evaluate a new model. This approach is useful in arriving at a statistically possible model specifying interrelationships among constructs of interest that is also meaningful in practice (Byrne, 2006). As recent research investigating the interrelationships among all the variables of interest in the present study was sparse at best, I used the model generating approach in order to generate a new theoretical model of interrelationships, instead of Jöreskog's (1993) Strictly Confirmatory and Alternative Models approaches to using SEM. Thus, in the present research I conducted a nonexperimental cross-sectional study using SEM to investigate the statistical plausibility and practical meaning of theoretical models specifying interrelationships between the following latent constructs: adult attachment style, FFM personality traits (extraversion and neuroticism), interpersonal communication competence, and Facebook use.

\section{Participants}

All of the participants recruited for this study were first year undergraduate students between the ages of 17 and 22. I recruited participants via email from a medium sized $(N=14,000)$ Rocky Mountain region university, and all data were collected over the internet using a web-based survey through the company SurveyMonkey (SurveyMonkey, 2011). As monetary incentives have been shown to increase web-based survey response rate (Shih \& Fan, 2008), the first 25 participants earned a $\$ 5$ iTunes gift card and every participant was entered in a raffle for a chance to win a \$100 Visa Gift 
Card. Approximately 2250 first year students were contacted about study participation through their university email address. First, I sent potential participants an email (see Appendix C) inviting them to participate in the study, along with a hyperlink to the study web site where they were presented with the IRB-approved informed consent letter (see Appendix D). Participants indicated their voluntary informed consent by writing their name on the same page below the consent letter, and clicking an 'okay' button which linked to the study survey. The survey consisted of the specific measures detailed below, adapted to a web-based survey format. Data were collected from each participant's set of responses to the survey items and stored on SurveyMonkey.com's secure servers until being downloaded and imported into a statistical software package and stored on a secure network hard drive accessible by the researcher's university computer.

A recent pilot study with similar research questions investigated in the same population of students using very similar recruitment methods (Jenkins-Guarnieri et al., 2012) obtained data from a sample of 463 participants and found a mean age of 18.36 , with $75.8 \%$ females, and $76.9 \%$ identifying as Caucasian, $10.2 \%$ as multiracial, $8.9 \%$ as Hispanic/Latino, and 2.2\% as African American. This study's participant demographic profile closely matched the overall demographic profile for the university, although females were overrepresented by $12 \%$ in the study sample. For the present study, I expected to obtain a comparable sample, as the recruitment and data collection methods will be quite similar. 


\section{Instrumentation}

Demographics. Five questions asked participants to input their age (specific number), gender (male or female), what race/ethnicity they identify as (Caucasian, Hispanic/Latino, African American, Asian, Native American, Pacific Islander, Multiple races/ethnicities, or Other: specify), year in college $\left(1^{\text {st }}\right.$ year, $2^{\text {nd }}$ year, $3^{\text {rd }}$ year, $4^{\text {th }}$ year, more than 4 years), current relationship status (single, in a committed dating relationship, engaged/married, or divorced) and if they currently have a Facebook account (yes or no).

Facebook Intensity. Early computer-mediated communication research cited the importance of focusing on how people communicate through computers, instead of analyzing how individuals interact with computers. Previous ways of conceptualizing Facebook usage have focused solely on factual numbers such as number of 'friends' on a profile and minutes spent on the site each day. Ellison et al. (2007) developed a new measure of Facebook use intensity in order to capture a more comprehensive picture of Facebook usage that incorporated a user's emotional connection to the site and how much a user incorporates the site into daily social behavior. Instead of focusing solely on duration or frequency of use, this measure captures active engagement with the site and how much a user integrates Facebook into their social life (Ellison et al., 2007).

Ellison et al.'s (2007) scale is comprised of 8 items, two of which focus on factual information associated with use, while six items center on emotional attachment to and integration of the site's use. The first two questions ask participants about weekly minutes spent logged on and about number of "Facebook friends," for which they can choose between 9 options of custom ranges adapted for each question (e.g., " $0=10$ or less, $1=11-50$ "). For the remaining six questions, participants indicate their level of 
agreement or disagreement with each item using a 5-point Likert-type rating scale ranging from 1 ("Strongly Disagree") to 5 ("Strongly Agree"). These questions include: "Facebook has become part of my daily routine," "I feel I am part of the Facebook community," and "I feel out of touch when I haven't logged onto Facebook for a while." As the answer scales have different ranges of anchors (e.g., 1-9 and 1-5), participant responses are standardized before being included in statistics such as means. For the mean score, higher numbers indicate greater engagement with and investment in Facebook use. Ellison et al. (2007) in their original study with college-aged adults found a Cronbach's $\alpha$ reliability coefficient estimate of .83 and provided initial evidence for this measure's validity by comparing this scale's scores to measures of social capital and specific uses of Facebook; more support is still emerging. It has been used in recent years with college age students (e.g., Ross et al., 2009; Valenzuela, Park, \& Kee, 2009) as a measure of engaged use and continues to be used in social psychology research. The measurement model for the construct of Facebook Use Intensity consisted of three indicators: 3 of the 8 original items with the highest factor loadings from an EFA analysis performed on this scale's data were used as indicators. Yang, Nay and Hoyle (2010) provided support for this scale-shortening approach for use with SEM analyses, and suggested selecting items with the highest factor loadings with medium sample sizes $(N=$ 350). Marsh, Hau, Balla and Grayson's (1998) simulation studies support this approach as well, and suggested that item-level indicators may perform as well as parcels of items, especially when the number of parcels was low. 
Attachment. Adult attachment was measured using The Experiences in Close Relationships-Revised scale (ECR-R; Fraley, Waller \& Brennan, 2000) using the anxiety and avoidance subscales composed of 18 items each. Thus, this scale conceptualizes attachment as two orthogonal continuums of attachment anxiety and attachment avoidance on which an individual can range from low to high (Fraley \& Shaver, 2000; Rholes et al., 2008). For all 36 items, participants rate their level of agreement or disagreement with each question on a 7-point Likert-type scale ranging from 1 ("Strongly Disagree") to 7 ("Strongly Agree"). For the anxiety subscale, questions focus on participants' level of anxiety related to being abandoned in relationships. Sample items for the attachment anxiety construct include: "I worry that I won't measure up to other people," "I rarely worry about my partner leaving me," and "I'm afraid that I will lose my partner's love." For the avoidance subscale, items center on how avoidant a person is in his/her behaviors in relationships. Sample items for the attachment avoidance construct include: "I am nervous when partners get too close to me," "I find it easy to depend on romantic partners," and "I get uncomfortable when a romantic partner wants to be very close." Recent work supports the scale's construct validity and use with college age adults (Fairchild \& Finney, 2006), strong score stability over a 6-week interval and a twofactor structure similar to the original ECR (Sibley \& Liu, 2004). In addition, Sibley, Fischer and Liu (2005) found support for its convergent and discriminant validity, and demonstrated adequate internal consistency estimates (Cronbach's $\alpha$ estimates of .93 for the anxiety subscale and .94 for the avoidance subscale). High scores on the measure's subscales, representing the two attachment anxiety and avoidance dimensions, indicate more insecure attachment while low scores indicate more secure attachment. The 
measurement model of the attachment construct consisted of two indicators: the means scores of the Anxiety and Avoidance subscales.

Five Factor Model Personality traits. The Five Factor Model (FFM; Digman, 1990; McCrae \& John, 1992) has become a widely accepted personality trait taxonomy (McCrae \& Costa, 2003). It has been described as a comprehensive system for understanding individual personality traits, with Ozer and Riese (1994) stating that "Just as latitude and longitude permit the precise description of any location on earth, the FFM promises the hope of similarly locating personality dispositions" (p. 361). Much work has established its generalizability (McCrae \& Costa, 2003), even across cultures (Stumpf, 1993), while Robins, Fraley, Roberts, and Trzesniewski (2001) demonstrated these traits' stabilities across the ages typical of the four years of undergraduate work.

Developed by John, Donahue and Kentle (1991) as a measure of FFM traits, the Big Five Index (BFI; John et al., 2008) can be used in research to capture relative levels of the FFM traits: Neuroticism, Openness, Extraversion, Conscientiousness, and Agreeableness. This measure consists of 44 items with 8 to 10 items for each of the 5 trait subscales. Participants rate their level of agreement with each question, using a 5-point Likert-type scale ranging from 1 ("Disagree Strongly") to 5 (“Agree Strongly"). All the items begin with the stem "I see myself as someone who..." and some sample endings include: "is talkative," "worries a lot," "is reserved," and "is helpful and unselfish with others." Higher subscale mean scores indicate that the participant exhibits more of the FFM trait captured by a given subscale. John et al. (2008) demonstrated adequate internal consistency estimates that range from .75 to .90 with U.S. adults and Benet-Martínez and John (1998) found estimates ranging from .79-.88 in a large sample $(N=711)$ of college 
students. The BFI has been shown to have convergent and divergent patterns with other FFM scales that suggest strong convergent and concurrent validity, and discriminant validity, as well as high validity correlations between self and peer ratings of the FFM traits (John et al., 2008). In addition, this scale was developed and has been used extensively with college aged adults (John et al., 2008; Srivastava et al., 2003). The measurement model for the Extraversion and Neuroticism construct consisted of the item-level indicators for these two respective subscales: 4 of the 8 original items with the highest factor loadings as indicators for Extraversion and 4 of the original 8 items with the highest factor loadings as indicators for Neuroticism. Yang et al. (2010) provide support for this scale-shortening approach for use with SEM analyses, and suggested selecting 4 to 6 items with the highest factor loadings with medium sample sizes $(N=$ 350). Marsh et al. (1998) simulation studies support this approach as well, and suggested that item-level indicators may perform as well as parcels of items, especially when the number of parcels was low.

Interpersonal communication competence. Interpersonal communication competence was measured with The Interpersonal Competence Scale (ICS; Buhrmester, et al., 1988) in assessing skill and competence with interpersonal communication. It is composed of 40 items arranged into five subscales that are associated with five constructs integral to interpersonal competence: Initiation (initiating relationships), Emotional Support (providing advice and emotional support), Disclosure (appropriate disclosure of personal information), Negative Assertion (asserting challenges and displeasure with others), and Conflict Management (skills involved in managing conflict in relationships). Participants rate their perceived level of ability and comfort with each item's content, and 
use a 5-point Likert-type scale ranging from 1 ('I'm poor at this; I'd feel so uncomfortable and unable to handle this situation that I would avoid it if possible") to 5 ("I'm very good at this; I'd feel very comfortable and could handle this situation easily"). High subscale mean scores indicate increased facility and comfort with the area of interpersonal competence captured by a given subscale. Buhrmester et al. (1988) demonstrated internal consistency coefficients ranging from Cronbach's $\alpha$ estimates of .77 to .87 for the 5 subscales used with college students. They also provided initial support for its factor structure as well as concurrent and discriminant validity by comparing ICS scores to data obtained with other scales of social functioning designed to capture related domains of social interaction, such as assertion and disclosure competency. In addition, they compared self-ratings on the ICS subscales to peer ratings of the participant's interpersonal competence and found moderate convergence levels. The measurement model for the construct of interpersonal communication competency originally consisted of the mean scores of each of the five ICS subscales as well as the PSSE mean score (described below). However, evaluation of the measurement model for this construct (Byrne, 2006) suggested that the PSSE be removed as an indicator based on large univariate Lagrange Multiplier statistics and high error covariances between the PSSE mean score and indicators for the Extraversion construct. Therefore, the final measurement model for Interpersonal Competency consisted of the five ICS subscale mean scores, with an error covariance between the Emotional Support and Conflict Resolution indicators. 
Social self-efficacy. Smith and Betz (2000) expanded upon previous research in creating their Scale of Perceived Social Self-Efficacy (PSSE) to measure an individual's sense of their self-efficacy in social relationships. Another viable way to conceptualize and operationalize perceived interpersonal communication competence, social selfefficacy captures self-beliefs and self-confidence specific to social behavior. This scale was developed with college students and consists of items designed to capture a participant's confidence in the social interaction skills involved in beginning and sustaining interpersonal relationships. The PSSE contains 25 items covering interaction skills in six different areas from social assertiveness to making friends, and participants rate their confidence in their ability to successfully complete the item's task on a 5pointLikert-type scale ranging from 1 ("No confidence at all”) to 5 ("Complete confidence"). Sample items include: "Ask a potential friend out for coffee," "Join a lunch or dinner table where people are already sitting and talking," and "Ask someone for help when you need it." Higher mean scores on this scale indicate greater self-efficacy with social behavior involved in initiating and maintaining social relationships.

Smith and Betz's (2000) original study demonstrated adequate internal consistency for their scale data (Cronbach's $\alpha=.94$ ), test-retest reliability (coefficient of .82 for a 3-week interval), and provided initial support for its validity. They found support for concurrent validity in that PSSE scores demonstrated a strong positive relationship with other measures of social self-efficacy. They found support for construct validity as well, as PSSE scores displayed a strong positive relationship with related measures such as global self-esteem while showing a negative relationship with social anxiety. In addition, PSSE scores were associated with measures of confidence in skills 
relevant to the Enterprising Holland's code (Holland, 1973), while less strongly related to confidence in Investigative and Realistic code skills. Thus, this scale is appropriate for use with college students and has demonstrated adequate psychometrics.

\section{Procedures}

Participant recruitment. Before collecting data, I completed an application for approval to conduct this study from the Internal Review Board in the Office of Sponsored Programs at the university where this research was conducted (see Appendix F for IRB approval letter). Data for this study were collected from participants entirely online through the web-based survey program SurveyMonkey (SurveyMonkey, 2011). First, I generated a list of email addresses belonging to first year students at the university where this research was conducted using an institutional database web-based application for running data reports, called Insight. Next I emailed an invitation (see Appendix C) to participate in the study to all first year students as of the Fall 2011 semester, including a link to the study's web-based survey hosted on the SurveyMonkey web site. When potential participants clicked on this link, they were directed to the study's online survey introduction page and invited to review the study's informed consent document before deciding to participate.

Informed consent process. The informed consent process required by the IRB was completed entirely online as well. After reaching the introduction page and clicking a button labeled 'continue,' the next page displayed the IRB-approved informed consent letter (see Appendix D) describing the study in detail, outlining all that would be involved in study participation, and reviewing any risks involved in participation. After reading the informed consent letter, potential participants could choose to participate in 
the study by clicking on a button labeled 'I Agree To Participate' in order to proceed to the study survey items or on a button labeled 'I Decline To Participate' in order to exit the study survey. After completing the study survey, participants were offered the opportunity to input their email address in a text box on the final page of the survey in order to be entered into a drawing to win the incentive for participation. As an incentive to participate, the first 25 participants received a $\$ 1$ iTunes gift card and all participants received an entry into a random drawing from among all the study participants for a $\$ 100$ Visa Gift Card. Finally, each participant was presented with a paragraph designed to debrief them on the nature and purpose of the study (see Appendix E).

Study survey. The study's survey was hosted entirely online by the web-based survey program SurveyMonkey (SurveyMonkey, 2011). First I adapted each of the study's measures described above for the web-based format, typing in each scale item and creating a Likert-type scale response option format that mimicked the paper-andpencil version of each scale. When this process was complete, I generated a web address for the study survey through the SurveyMonkey program and copied this address into the invitation email sent to all potential study participants. After clicking on this link and completing the informed consent process, participants were presented with the web-based adaptation of each of the study's measures. Participants indicated their responses on the Likert-type scales by clicking radio check boxes on the web-based survey adaptation that corresponded to Likert scale numbers, closely paralleling the experience of completing the scales in their paper-and-pencil versions. After completing the study survey, participants were offered the opportunity to input their email address in a text box on the 
final page of the survey in order to be entered into a drawing to win the incentive for participation.

Survey response rate and study sample size. Shih and Fan's (2008) metaanalysis on survey methodology found that the mean response rate for web-based surveys was approximately $34 \%$ and that incentives and follow-up reminder emails can significantly improve response rate. A pilot study conducted with similar research questions and subject recruitment methods in the same population showed an overall response rate of approximately $18 \%$ for a similar web-based survey (Jenkins-Guarnieri et al., 2012). Thus, I expected a similar response rate in the present study for a total sample of approximately 400 subjects. Most applications of SEM require a fairly large sample size $(N>200)$ (Kline, 2011), so participant recruitment and final sample size will be important elements of this study.

Jackson's (2003) more conservative guidelines for determining adequate sample size in SEM analyses that has received recent empirical support (Kline, 2011), suggested an $N: q$ ratio of 10:1 to be considered adequate; $N$ represents the number of cases or participants and $q$ represents the number of parameters to be estimated in the SEM model of interest. Forty-six parameters were estimated in the primary theoretical model, meaning that sample size following this approach should exceed 460 participants. As moderately large sample sizes such as this may not be practically feasible, Kline (2011) established a minimum adequate sample size of 200 for most SEM analyses, and this guideline was adopted as the minimum sample size considered adequate for the present study. This aligns with recent guidelines by Weston and Gore (2006) for Counseling 
Psychologists that stipulate a minimum sample size of 200 for any SEM analysis, and recommend larger sample sizes whenever possible.

\section{Data Analysis}

After the data collection stage of this study, a spreadsheet containing all data were downloaded from the web-based program and imported into the statistical software package PASW Statistics 17, Release Version 17.0.2 (SPSS Inc., 2009). SEM analyses were conducted following Kline's (2011) guidelines for the appropriate steps in an SEM analysis that align with Jöreskog's (1993) MG approach to SEM: 1) specify models, 2) assess model identification, 3) operationalize constructs with appropriate measures, and collect and screen the data for factors that may impact the analyses (e.g., assumptions underlying SEM, outliers, collinearity), 4) estimate model, 5) respecify model as necessary, 6) report results of model fit, interpret parameter estimates, consider equivalent or alternative models (and repeat the steps as necessary).

In the first step, I created the primary theoretical model detailed in Figure 3, based on the comprehensive literature review conducted in Chapter II. Ample support was found for the interrelationships between attachment style, FFM traits, and interpersonal communication competence, as well as between these variables and SNS use. However, to the best of my knowledge not one study has sought to investigate the interrelationships between all of these variables. These models essentially represent my hypotheses in visual form by indicating interrelationships in a structural regression model (Kline, 2011). These models are basically comprised of a set of equations that "define the model's parameters, which correspond to presumed relations among observed or latent variables” (Kline, 2011, p. 92). In following Kline's (2011) recommendations, I also 
created an alternative model detailed in Figure 4 which reflects re-specified changes to the original model that are theoretically plausible as well given the relevant literature reviewed.

In the primary theoretical model, I hypothesized the pattern of interrelationships among attachment style, Extraversion and Neuroticism, interpersonal competence, and Facebook use intensity. The primary model postulated that attachment was an exogenous variable that directly and positively impacts interpersonal competence (e.g., more securely attached adults, or those scoring lower on the anxiety and avoidance continuums of attachment style, also displayed increased interpersonal competence) (Anders \& Tucker, 2000; Bippus \& Rollin, 2003; Cooley, 2005; Mallinckrodt, 2000), and extraversion (Backstrom \& Holmes, 2001; Carver, 1997), directly and negatively affecting neuroticism (Backstrom \& Holmes, 2001; Carver, 1997; Hagekull \& Bohlin, 2003) as well as indirectly impacting interpersonal competence (Guerrero et al., 2009; Johnson, 2003; Mikulincer \& Shaver, 2007; Rholes et al., 2008) and interpersonal factors related to Facebook use (Bradford et al., 2002; Schulman et al., 1994) through these two FFM traits (Picardi et al., 2005). In addition, I found ample research support for the direct impact of neuroticism negatively and extraversion positively affecting interpersonal competency (Berry \& Hansen, 1996; Cuperman \& Ickes, 2009; Ozer \& Benet-Martinez, 2006) and Facebook use intensity (Amiel \& Sargent, 2004; Back et al., 2010; Correa et al., 2010), as well as indirectly affecting Facebook use intensity through the mediating variable of interpersonal competence (Caplan, 2005; Engelberg \& Sjoberg, 2004; Harman et al., 2005; Ledbetter, 2010). In the primary alternative nested model (see Figure 4), the direct and positive affect of extraversion and the direct and negative effect of neuroticism 
on Facebook use intensity are removed to make interpersonal competency a fully mediating variable between extraversion, neuroticism, and attachment on Facebook use intensity.

In the second step, I evaluated all of the models for their identification status. A model can be considered identified if "it is theoretically possible for the computer to derive a unique estimate of every model parameter" (Kline, 2011, p. 93), which in following Kline's (2011) guidelines requires that models must have at least 0 degrees of freedom and that every latent variable be assigned a metric. The models that I created all can be considered to be over-identified, because they contain less free parameters to be estimated than observations. To meet the second criteria for identification, I utilized a unit loading identification constraint on one of each latent variable's direct effect for one of its indicators in order to set the metric, a commonly used technique in SEM (Kline, 2011). Essentially, this makes one indicator a reference variable for each latent variable. In the third step, I selected psychometrically strong measurement scales for each of the hypothetical constructs and adapted them for the study's web-based survey format described above. One of the most frequently used methods for operationalizing a construct and a frequently used variable in the social sciences can be seen as having "a continuous interval-level underlying distribution and a discontinuous ordinal-level observed (measured) distribution" (O’Brien, 1985, p. 265). For example, the psychological trait of extraversion theoretically has a continuous distribution from an absence of this trait to full salience of this trait. However, in order to operationalize and measure this trait, scientists can use an ordinal Likert-type scale as an observable indicator of this latent variable (Yang-Wallentin, Jöreskog \& Luo, 2010). In choosing 
measures for use in this study, I took care to select scales with ample support for construct and criterion validity as well as internal consistency for resulting data collected in samples similar to the one used in the present study. Psychometrically strong measures have been highly recommended for SEM analyses in order to yield practically useful model interpretations (Kline, 2011). The score validity for each of the study's measures is described above in the instrumentation section, along with previously obtained reliability estimates for data collected with these measures. In addition, I calculated a Cronbach's alpha coefficient reliability estimate for the data obtained with each of the study's scales (see Table 3). 
Table 3

Descriptive Statistics for All Continuous Variables

\begin{tabular}{|c|c|c|c|c|c|c|c|c|c|c|c|c|c|c|c|c|c|c|c|c|c|c|}
\hline & 1 & 2 & 3 & 4 & 5 & 6 & 7 & 8 & 9 & 10 & 11 & 12 & 13 & 14 & 15 & 16 & 17 & 18 & 19 & $\alpha$ & $\bar{m}$ & $\begin{array}{c}\text { St. } \\
\text { Dev }\end{array}$ \\
\hline 1. Anx & - & & & & & & & & & & & & & & & & & & & .94 & 3.13 & 1.30 \\
\hline 2. Avoid & .448 & - & & & & & & & & & & & & & & & & & & .94 & 2.98 & 1.24 \\
\hline 3. BFI36 & -.126 & -.191 & - & & & & & & & & & & & & & & & & & - & 4.0 & .980 \\
\hline 4. BFI21 & -.158 & -.180 & .590 & - & & & & & & & & & & & & & & & & - & 3.09 & 1.21 \\
\hline 5. BFI1 & -.086 & -.200 & .646 & .607 & - & & & & & & & & & & & & & & & - & 3.95 & 1.04 \\
\hline 6. BFI31 & -.218 & -.146 & .473 & .648 & .410 & - & & & & & & & & & & & & & & - & 3.13 & 1.19 \\
\hline 7. BFI9 & .167 & .110 & -.210 & -.126 & -.163 & -.207 & - & & & & & & & & & & & & & - & 2.45 & 1.08 \\
\hline 8. BFI19 & .223 & .079 & -.172 & -.200 & -.123 & -.270 & .463 & - & & & & & & & & & & & & - & 3.25 & 1.24 \\
\hline 9. BFI14 & .297 & .122 & -.148 & -.228 & -.145 & -.294 & .402 & .472 & - & & & & & & & & & & & - & 3.11 & 1.07 \\
\hline $\begin{array}{c}10 . \\
\text { BFI24 }\end{array}$ & .277 & .066 & -.189 & -.081 & -.119 & -.159 & .448 & .331 & .300 & - & & & & & & & & & & - & 2.26 & 1.04 \\
\hline $\begin{array}{c}11 . \\
\text { ICQInit }\end{array}$ & -.211 & -.352 & .596 & .448 & .506 & .396 & -.200 & -.224 & -.181 & -.116 & - & & & & & & & & & .90 & 3.53 & .82 \\
\hline & -.166 & -.333 & .167 & .171 & .238 & .106 & -.056 & -.051 & -.050 & -.036 & .474 & - & & & & & & & & .92 & 4.20 & .71 \\
\hline & -.338 & -.375 & .283 & .290 & .228 & .270 & -.120 & -.197 & -.160 & -.178 & .586 & .415 & - & & & & & & & .84 & 3.47 & .78 \\
\hline $\begin{array}{c}14 . \\
\text { ICQDisc }\end{array}$ & -.218 & -.584 & .360 & .265 & .340 & .260 & -.140 & -.135 & -.121 & -.115 & .664 & .560 & .619 & - & & & & & & .86 & 3.50 & .77 \\
\hline $\begin{array}{c}15 . \\
\text { ICQCon }\end{array}$ & -.171 & -.346 & .159 & .109 & .192 & .084 & -.102 & -.086 & -.124 & -.110 & .510 & .726 & .478 & .648 & - & & & & & .83 & 3.76 & .65 \\
\hline $\begin{array}{c}16 . \\
\text { PSSE }\end{array}$ & -.260 & -.375 & .601 & .495 & .517 & .440 & -.252 & -.233 & -.172 & -.202 & .775 & .405 & .526 & .589 & .437 & - & & & & .96 & 3.56 & .74 \\
\hline 17. FB5 & .103 & -.084 & .152 & .119 & .078 & .040 & -.004 & .083 & .149 & .042 & .097 & .072 & .031 & .051 & -.003 & .071 & - & & & - & 3.64 & 1.28 \\
\hline 18. FB7 & .029 & -.116 & .167 & .127 & .132 & .065 & -.089 & .046 & .027 & -.017 & .174 & .112 & .103 & .134 & .103 & .151 & .547 & - & & - & 3.20 & 1.18 \\
\hline 19. FB4 & .019 & -.048 & .183 & .129 & .094 & .089 & -.076 & .012 & .017 & -.041 & .143 & .071 & .158 & .121 & .023 & .061 & .572 & .574 & - & - & 3.31 & 1.15 \\
\hline
\end{tabular}

Note. $N=456$. Bold type indicates $p<.01$

Anx = ECR-R Attachment Anxiety subscale mean, Avoid = ECR-R Attachment Avoidance subscale mean; ICQInit = Interpersonal Competency Questionnaire

Initiating subscale mean, ICQEmo = Emotional Support subscale mean, ICQNeg = Negative Assertion subscale mean, ICQDisc = Disclosure subscale mean,

ICQCon $=$ Conflict Management subscale mean; PSSE = Perceived Social Self-Efficacy scale mean; FB = Facebook Use Intensity scale. 
Next I proceeded to collect the data as described earlier and imported it into the statistics software program. Data preparation and screening included screening for any potential problems with collinearity, assessing the range for each scale's data to check for data entry errors and analyzing standardized residuals plots to assess for outliers, assessing for multivariate normality and specification errors as the assumptions underlying SEM, and addressing missing data using the listwise deletion method. I attempted to screen these data for any evidence of collinearity, a potential cause of nonpositive definite data matrices, which adversely affects most estimation algorithms in SEM (Kline, 2011). Squared multiple correlations between each variable and the others included in the analysis were calculated and inspected for values larger than .90 , as those larger than this criterion may suggest significant collinearity problems (see correlation matrix in Table 3), and variance inflation factors (VIF) were inspected for any values greater than 10, which may suggest the presence of redundancy among variables or extreme collinearity (Kline, 2011). I assessed these data for multivariate normality by evaluating the univariate distributions of all continuous variables to check for the normality assumption required by SEM (including skew and kurtosis), along with the scatter plots for each variable to check for the linearity and homoscedasticity assumptions of data analyzed using SEM, and skew and kurtosis greater than the absolute values of 2 and 7, respectively, were considered significant (Hoyle, 1995). I addressed any missing data using the listwise deletion method in order to avoid underestimation of error variances associated with single-imputation methods (Kline, 2011). Lastly, I checked for gender differences in using a multivariate analysis of variance (MANOVA) designed with the gender as the independent variable and each of the study's scale means as 
dependent variables in order to test for statistically significant differences between participant gender in the measurement scale data.

To conduct the SEM analysis, evaluate model fit, and interpret parameter estimates, I used the program EQS, Release 6.1 (Bentler, 2008). After importing, preparing, and screening the data as described above, I began by specifying my primary and alternate theoretical models in the EQS program. Then I followed a two-step process for conducting SEM analyses by first analyzing and estimating the fit to the data with the measurement models and then analyzing and estimating the measurement and structural models together (Kline, 2011). In this approach, the researcher first conducts confirmatory factor analysis (CFA) on each scale and its indicators in order to evaluate the fit of the observed indicators to the latent constructs (Weston \& Gore, 2006). In this way, the full theoretical model can be treated as a CFA measurement model so that the researcher can evaluate and focus on the measurement aspects of the model (Kline, 2011). In the second step, the researcher conducts model estimation and evaluation of the full structural model, which focuses on the theoretical relationships among latent variables and test for the significance of the structured paths (Weston \& Gore, 2006). The primary theoretical model can also then be compared to the alternate models using the chi-squared difference test, which evaluates potential statistical significance of "decrement in overall fit as free parameters are eliminated or the improvement in fit as free parameters are added" (Kline, 2011, p. 215). In essence, the chi-squared difference test assesses the statistical significance of change in model fit upon adding or removing structural paths (Weston \& Gore, 2006). Thus I repeated the remaining steps that follow, first for the measurement model and then for the full structural models. 
In the fourth step, I estimated the primary theoretical model detailed in Figure 3, and evaluated the results for overall model fit, assessed the practical meaning of parameter estimates, and interpreted parameter relationships. The most common default method for estimating parameters is based on the Maximum Likelihood (ML) estimation method, the assumptions of which include that the variables included as observations approximate normal distributions and that the variables are continuous in nature (Byrne, 2006). A number of simulation studies have found that Maximum Likelihood (ML) estimation when treating ordinal data as ordinal instead of as continuous produces more accurate estimates of parameters and standard errors (e.g., Babakus, Ferguson, \& Jöreskog, 1987) but can potentially produce biased fit statistics. Johnson and Creech (1983) echoed these results in their study suggesting that the categorization errors that often accompany the use of ordinal data create bias in SEM models with multiple indicators, although they did not find a great deal of distortion in parameter estimates. These conclusions and recommendations by researchers seem to hold true proportionally to the degree of non-normality in the data: when ordinal data begins to deviate from the ML estimator's normality assumption results become increasingly biased (DiStefano, 2002).

However, estimation methods that seem to best address ordinal type data such as Weighted Least Squares (WLS) often have exacting restrictions that detract from their usefulness (e.g., high number of subjects) (Byrne, 2006). Bentler and Chih-Ping (1987) suggested that ML can be used with ordinal data that approximates a normal distribution as long as multiple fit indicators are used to assessment global fit. Green, Akey, Fleming, Hershberger and Marquis' (1997) results support the use of ML with ordinal data when 
the scales contain a greater number of categories and the distributions of resulting data approximate normal distributions. The chi-squared statistic appears to become biased primarily when the data display significant non-normality (Hutchinson \& Olmos, 1998; Muthen \& Kaplan, 1992). Therefore, I will treat the data as continuous and use ML to estimate my theoretical model if the data collected display reasonable normality, and treat the data as ordinal and use Robust ML with the Satorra-Bentler chi-squared statistic (Satorra \& Bentler, 1988) if the data displays significant nonnormality, following recommended guidelines for significant skew and kurtosis by Hoyle (1995).

Approximate fit indices are another method for evaluating the fit between a hypothesized model and observed relationships in the data. They are different from standard test statistics in that they are not used to test a hypothesis, but are treated as continuous statistics reflecting the degree of fit between model and data. The Comparative Fit Index (CFI; Bentler, 1990) and the Non-Normed Fit Index (NNFI; Bentler \& Bonett, 1980) have been shown to be less affected by nonnormality in data (Hutchinson \& Olmos, 1998) when using ML estimation and are used to assess the "goodness of fit" between the structural model and the null model (Kline, 2011). They range from 0 to 1, with higher values indicating better fit. Hutchinson and Olmos (1998) also recommended using the Steiger-Lind root mean square error of approximation (RMSEA; Steiger, 1990) and the Standardized Root Mean Square Residual (SRMR; Bentler, 1995; Jöreskog \& Sörbom, 1986), as they were less affected by sample size or model size and complexity. Although still scaled from 0 to 1 , these two approximate fit indices are used to indicate "badness of fit" between the model and the data where lower values indicate less misfit between model and data. The RMSEA can be considered a 
parsimony-adjusted index, meaning that its value decreases with greater number of degrees of freedom (Kline, 2011).

Beauducel and Wittmann (2005) investigated fit statistics in models with a small degree of misspecification, as is often found in social psychology research using scales, such as with personality trait measures. This study was meant as an adjunct to the classic work by $\mathrm{Hu}$ and Bentler (1999), which is commonly used as a reference for fit statistic cutoff criterion, and suggested a raised incremental fit statistics' cutoff criteria of .95 for goodness of fit indexes (e.g., CFI \& NNFI). Beauducel and Wittmann (2005) describe how Hu and Bentler (1999) used higher secondary loadings in their models, which is often not the case for those found in personality trait scale psychometrics which are often significantly lower given the complexity of the hypothetical constructs under study (e.g., neuroticism). These new results suggest that incremental fit indices may be less likely to accept models in personality research contexts, as "there will always be some small distortion of simple structure" (Beauducel \& Wittmann, 2005, p. 72) and when the loadings are small (e.g., .40 or .50) as is the case with many trait measurement scales. Thus, they recommend using the RMSEA and SRMR, as well as their use in combination as outlined by $\mathrm{Hu}$ and Bentler (1999), when conducting research on personality traits using scale data.

Following Kline's (2011) recommendations for evaluating model fit, I calculated the model chi-squared statistic along with its degrees of freedom and $p$ value. A nonsignificant chi-squared statistic would indicate perfect model fit of the observed covariances (Kline, 2011; Weston \& Gore, 2006). However, in studies with fairly large sample sizes, this exact fit method for evaluating model fit using the chi-squared statistic 
is often overly sensitive and biased by a number of factors including multivariate nonnormality and sample size (Kline, 2011). I also calculated the matrix of correlation residuals and described this pattern of residuals for the overall model in order to assess for patterns in relationships among variables that may suggest misspecification. Next, I assessed the following approximate fit statistics suggested by Kline: RMSEA, Bentler Comparative Fit Index (CFI; Bentler, 1990), Standardized Root Mean Square Residual (SRMR; Bentler, 1995; Jöreskog \& Sörbom, 1986), and the Non-Normed Fit Index (NNFI; Bentler \& Bonett, 1980). I utilized the suggested cutoff criterion for these fit statistics: $>.95$ for the NNFI and CFI, $<.08$ for the SRMR, and close to .06 for the RMSEA (Beauducel \& Wittmann, 2005; Hu \& Bentler, 1999). However, Weston and Gore (2006) suggested that $N N F I$ and $C F I$ values greater than .90 can be considered adequate to good for smaller samples $(N<500)$, and so these less stringent criteria will also be considered in final model evaluation. Any differences between models evaluated for improvement of fit will be assessed using the chi-squared difference test (Kline, 2011; Weston \& Gore, 2006).

In the fifth step, I used the same methods described above to estimate the primary and secondary alternate models and evaluate them for overall fit and interpretability of parameter estimates; I followed Cohen's (1988) guidelines for interpretation of parameter estimate values. If no model could be retained, then I used a combination of theoretical rationale and results from the SEM analysis to re-specify the initial primary theoretical model in order to improve fit to the data and generate a meaningful model demonstrating the interrelationships among the constructs (Kline, 2011). 
In the sixth and final step, I followed established guidelines (e.g., Kline, 2011; Weston \& Gore, 2006) in reporting the results in Chapter 4 from this multi-step SEM analysis. These results included the overall model fit statistics described above and used in evaluating the fit of the model to the data as well as unstandardized and standardized parameter estimates first for the measurement model and then for the full structural models along with their accompanying $t$ statistics and standard errors. In addition, I reported all chi-squared statistics used in chi-squared difference tests used to compare decrement or improvement in fit between the models. Lastly, I reported all specific model modifications made in re-specifying the primary theoretical model and all results from the data used in making these decisions (e.g., modification indices). 


\section{CHAPTER IV}

\section{RESULTS}

Of the 630 Participants who completed the study informed consent process, 619 reported having a Facebook.com account and were included in the study. Two participants (ages 29 and 30) were then excluded as they were not considered to be emerging adults (Arnett, 2000), which yielded 617 participants that were included in the study. Based on this final sample, 439 reported being female $(71.2 \%)$ and 177 reported being male (28.7\%); gender was not reported for one participant. The mean age of the sample was $18.43(S D=1.041$; range of $17-26)$, and $72.9 \%$ identified as Caucasian, 11\% Multiple races/ethnicities, 9.2\% Hispanic, 4.5\% African American, 1.3\% Asian American, .5\% Native American, and .3\% Pacific Islander. Due to attrition from participants deciding to exit the web-based survey before completing it by closing their web browser, data from 456 participants were available for all the study variables using listwise deletion, as missing data were not considered missing completely at random.

\section{Selection of Indicators Using Exploratory Factor Analysis}

I first submitted all the items comprising the BFI Extraversion (8 items) and Neuroticism (8 items) subscales to two separate exploratory factor analyses (EFA) in order to select the four items from each subscale with the highest loadings as indicators for subsequent CFA analyses. According to guidelines published by Mundfrom, Shaw, and $\mathrm{Ke}(2005)$ for an EFA with a variables-to-factors ratio of 6, low communality, and a coefficient of congruence $K>.98$ (meets "excellent" criteria), the sample size clearly 
meets and exceeds the minimum requirement of 200 participants. Descriptive statistics and correlations among all the continuous variables used in the CFA/SEM analyses are displayed in Table 3. For the Extraversion subscale, data were available from 588 participants after listwise deletion of missing data due to omitted responses, and I utilized a maximum likelihood extraction method while forcing the extraction of 1 factor. All items displayed skew and kurtosis values within acceptable ranges (skew $<2$, kurtosis $<$ 7) (Hoyle, 1995), there was no evidence of collinearity in these data, and both the KaiserMeyer-Olkin measure $(K M O=.870)$ and Bartlett's Test of Sphericity $(p<.001)$ supported the factorability of these data (Tabachnick \& Fidell, 2001). Factor 1 had an Eigenvalue of 4.060 and accounted for $50.752 \%$ of the variance, the factor matrix coefficients for the included items are shown in Table 2. Based on these analyses, BFI items 36, 21, 1, and 31 were used as indicators for the Extraversion latent construct in subsequent CFA/SEM analyses.

For the BFI Neuroticism subscale, data were available from 584 participants after listwise deletion of missing data due to omitted responses, and I utilized a maximum likelihood extraction methods and forced the extraction of 1 factor. There was no evidence of collinearity in these data, all of these items displayed skew and kurtosis values within acceptable ranges ( skew $<2$, kurtosis $<7$ ), and both the Kaiser-MeyerOlkin measure $(K M O=.828)$ and Bartlett's Test of Sphericity $(p<.001)$ supported the factorability of these data (Tabachnick \& Fidell, 2001). Factor 1 had an Eigenvalue of 3.389 and accounted for $42.358 \%$ of the variance; the factor matrix coefficients for the included items are shown in Table 2. Based on these analyses, BFI items 9, 19, 14, and 
24 were used as indicators for the Neuroticism latent construct in subsequent CFA/SEM analyses.

Table 2

Factor Coefficients for Items Comprising Extraversion, Neuroticism, and Facebook Use

\begin{tabular}{cccccc}
\hline \multicolumn{2}{c}{ Extraversion } & \multicolumn{2}{c}{ Neuroticism } & \multicolumn{2}{c}{ Facebook Use } \\
\hline Item & \multicolumn{1}{c}{ Item } & FB5 & $\mathbf{. 8 5 8}$ \\
\hline BFI36 & $\mathbf{. 7 8 8}$ & BFI9 & $\mathbf{. 7 1 3}$ & FB3 & $\mathbf{. 8 4 8}$ \\
BFI21 & $\mathbf{. 7 7 9}$ & BFI19 & $\mathbf{. 6 7 0}$ & FB7 & $\mathbf{. 6 9 7}$ \\
BFI1 & $\mathbf{. 7 6 1}$ & BFI14 & $\mathbf{. 6 2 9}$ & FB4 & $\mathbf{. 6 7 9}$ \\
BFI6 & $\mathbf{. 6 4 1}$ & BFI24 & $\mathbf{. 5 9 7}$ & FB6 & $\mathbf{. 6 4 8}$ \\
BFI16 & $\mathbf{. 6 2 5}$ & BFI29 & $\mathbf{. 5 7 3}$ & FB8 & $\mathbf{. 5 9 5}$ \\
BFI11 & $\mathbf{. 6 1 7}$ & BFI39 & $\mathbf{. 5 3 9}$ & FB2 & $\mathbf{. 5 4 4}$ \\
BFI26 & $\mathbf{. 6 0 8}$ & BFI34 & $\mathbf{. 4 6 6}$ & FB1 & $\mathbf{. 2 6 6}$
\end{tabular}

Note. $N=588$ for Extraversion items; $N=584$ for Neuroticism items; $N=614$ for the Facebook Use items. For the Extraversion construct, items 36, 21, 1, and 31 were used as indicators; for the Neuroticism construct, items 9, 19, 14, and 24 were used as indicators; for the Facebook Use construct items 5, 7, and 4 were used as indicators.

To select the three items with the highest loadings for the Facebook Use Intensity scale for use as indicators of the latent construct Facebook use in later SEM analyses, this scale's 8 items were subjected to an EFA using maximum likelihood extraction methods. Using available data from 614 participants due to omitted responses, both the KaiserMeyer-Olkin measure $(K M O=.866)$ and Bartlett's Test of Sphericity $(p<.001)$ 
supported the factorability of these data (Tabachnick \& Fidell, 2001), while all skew and kurtosis values for these items fell within acceptable ranges (skew $<2$, kurtosis $<7$ ) and there was no evidence of collinearity. Only 1 factor was extracted, had an Eigenvalue of 4.053, and explained approximately $50.657 \%$ of the variance; the factor matrix coefficients for these items are shown in Table 2. Although the a priori model specified that the first two more factual items from this scale would be used as indicators, as well as the mean of the remaining six items, these results suggested that the first two items were actually the weakest items measuring the construct of Facebook use in this sample. In addition, the statement contents for items 3 and 5 were essentially redundant, and so item 3 was excluded as a potential indicator. Given these results, the highest loading items 5, 7, and 4, were used as indicators for Facebook use in subsequent CFA/SEM analyses.

\section{Measurement Model Confirmatory \\ Factor Analysis Results}

After selecting the indicators for the Extraversion, Neuroticism, and Facebook Use constructs, I followed Byrne's (2006) guidelines in conducting confirmatory factor analyses to evaluate the fit of the observed indicators to the data for the measurement model for each latent construct. Each CFA was conducted using Robust methods ML, while treating the data as continuous, and fit was assessed using the ideal, conservative guidelines described in Chapter III $\left(\chi^{2} / d f<3, N N F I\right.$ and $C F I>.95, S R M R<.08$, and RMSEA close to .06), and the less stringent guidelines suggested by Weston and Gore (2006) (NNFI and CFI > .90); the results for each model are displayed in Table 4 and Table 5. The Attachment construct was not subjected to a CFA due to the model being under-identified, however, these two subscales have previously been used successfully in 
structural models to measure this latent construct (Wright \& Perrone, 2010), and this measure has previously demonstrated excellent psychometrics when used with samples of college-aged adults (Fairchild \& Finney, 2006; Sibley \& Liu, 2004; Sibley et al., 2005). 
Table 4

Overall Model Fit Statistics for Measurement Models

\begin{tabular}{|c|c|c|c|c|c|c|c|c|c|}
\hline Latent Construct & Model & $\chi^{2}$ & $\chi_{S B}^{2}$ & $d f$ & $\chi^{2}$ difference & RMSEA & $S R M R$ & $C F I_{S B}$ & $N N F I_{S B}$ \\
\hline \multirow[t]{2}{*}{ Extraversion } & 1 & $70.227^{*}$ & $55.218^{*}$ & 2 & - & .213 & .050 & .940 & .821 \\
\hline & 2 & 1.817 & 1.723 & 1 & $68.41^{*}$ & .035 & .007 & .999 & .999 \\
\hline Neuroticism & 1 & $12.277^{*}$ & $9.327^{*}$ & 2 & - & .078 & .028 & .982 & .947 \\
\hline \multirow[t]{3}{*}{$\begin{array}{l}\text { Interpersonal } \\
\text { Competency }\end{array}$} & 1 & $263.682 *$ & $178.195^{*}$ & 9 & - & .203 & .078 & .870 & .783 \\
\hline & 2 & $117.405^{*}$ & $82.529 *$ & 5 & $146.277^{*}$ & .185 & .059 & .915 & .830 \\
\hline & 3 & 8.898 & 6.948 & 4 & $108.507 *$ & .040 & .015 & .997 & .992 \\
\hline Facebook Use & 1 & 1.40 & 1.313 & 1 & - & .023 & .032 & .999 & .998 \\
\hline \multicolumn{10}{|c|}{$\begin{array}{l}\text { Note. } N=584 \text { for Extraversion; } N=600 \text { for Neuroticism; } N=455 \text { for Interpersonal Competency; } N=612 \text { for Facebook Use. } * \\
\text { indicates } p<.01 . \chi^{2} S B=\text { Satorra-Bentler scaled chi-squared; } R M S E A=\text { root mean square error of approximation; } S R M R=\text { standardized } \\
\text { root mean square residual; } C F I=\text { comparative fit index; } N N F I=\text { non-normed fit index. Extraversion model } 2 \text { added an error } \\
\text { covariance between items BFI36 and BFI1. Interpersonal Competency model } 2 \text { removed the PSSE mean score as an indicator, and } \\
\text { model } 3 \text { added an error covariance between the Emotional Support and Conflict Resolution subscale mean scores. }\end{array}$} \\
\hline
\end{tabular}


Table 5

Maximum Likelihood Estimates of Factor Loadings and Residuals for Measurement Models

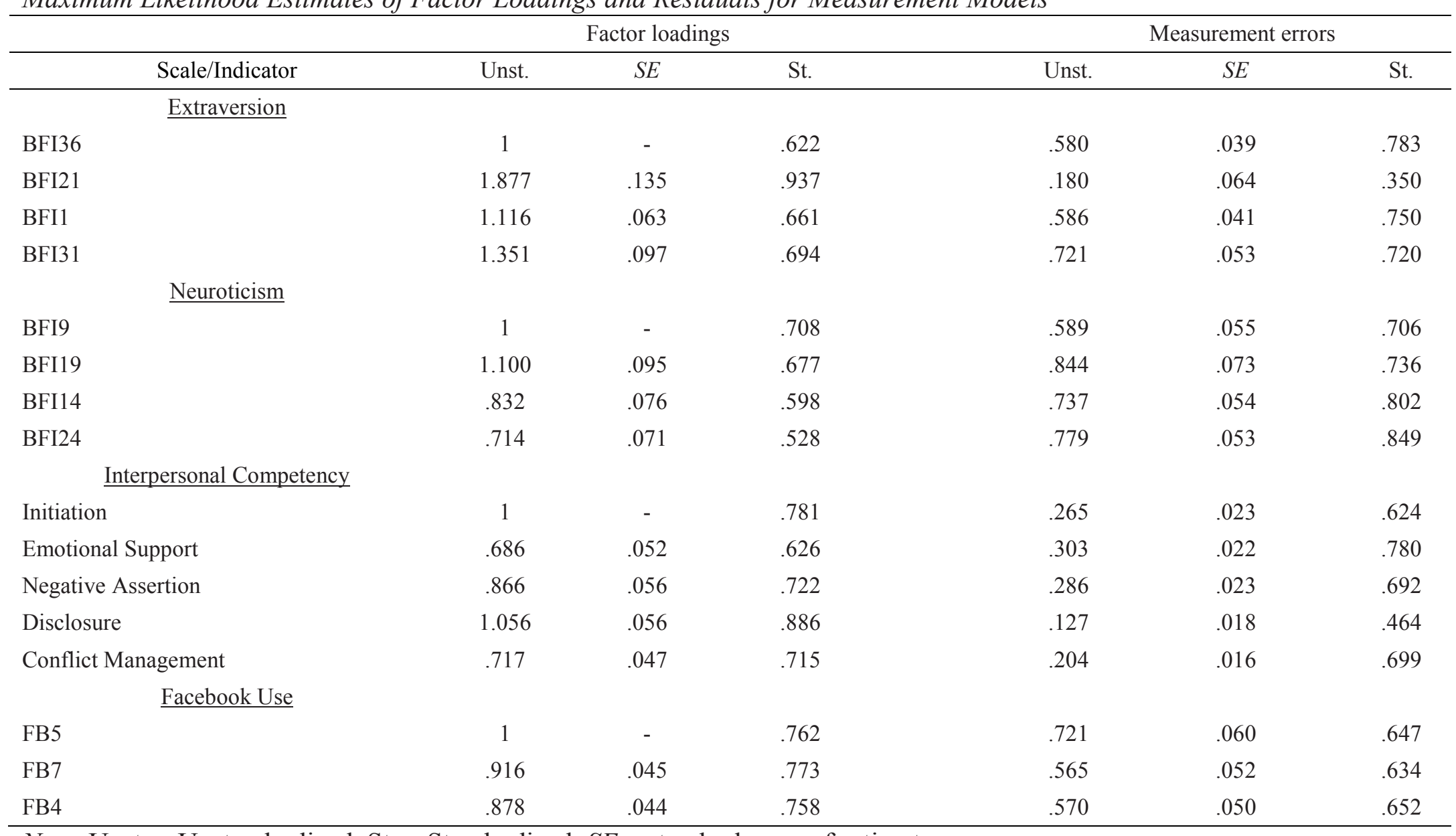

Note. Unst. = Unstandardized, St. $=$ Standardized, $S E=$ standard error of estimate. 
Using the available data from 588 participants using listwise deletion due to omitted responses, the 4-indicator measurement model for the latent construct of Extraversion was submitted to a CFA. Three cases were removed due to large relative contributions to normalized multivariate kurtosis (cases 63, 90, 156), as they exhibited "strikingly different" estimates produced by EQS compared to all the other cases analyzed (Byrne, 2006, p. 199). The largest standardized residual from these data was .099 , and parameter estimates were all statistically significant and practically meaningful, which suggested good component fit; overall measurement model fit statistics are shown in Table 4. The results of model 1 suggested poor fit to the data, and so model modifications were made based on large univariate Lagrange Multiplier test statistics and low $R^{2}$ values for specific items, which suggested the addition of an error covariance between BFI items 36 and 1. Model 2 freed this parameter and was rerun with the same specifications as model 1 . These results suggested that this measurement model demonstrated good fit to the data, with approximate fit statistics falling within acceptable ranges: $R M S E A=.035(90 \%$ confidence interval of $.001-.122)$ and $\mathrm{CFI}=.999$. The $\chi^{2}{ }_{S B}$ was not statistically significant $(p=.189)$, and suggested good exact model fit. The added error covariance parameter was statistically significant $(p<.05)$ and the unstandardized estimate was .246 with a standard error of .033 .

Using the available data from 600 participants due to omitted responses, the 4indicator measurement model for the latent construct of Neuroticism was submitted to a CFA. The largest standardized residual from these data was .052, and parameter estimates were all statistically significant and practically meaningful which suggested good component fit; overall model fit statistics are shown in Table 4. The results of 
model 1 suggested good fit to the data, with the majority of approximate fit statistics falling within acceptable ranges: $R M S E A=.078(90 \%$ confidence interval of $.033-.132)$ and $C F I=.982$. However, the $\chi^{2}{ }_{S B}$ was statistically significant $(p=.009)$, and suggested inexact model fit. Taken together, these results suggest adequate to good fit for this measurement model's fit to the data.

Using the available data from 458 participants due to omitted responses, the 6indicator measurement model for the latent construct of Interpersonal Competency was submitted to a CFA. Three cases were removed due to their unusually large relative contributions to normalized multivariate kurtosis (cases 156, 339, and 436), as they exhibited "strikingly different" estimates produced by EQS compared to all the other cases analyzed (Byrne, 2006, p. 199). The largest standardized residual from these data was .256 , and parameter estimates were all statistically significant and practically meaningful which suggested good component fit; overall model fit statistics are shown in Table 4. The results of model 1 suggested poor fit to the data, and so model modifications were made based on large univariate Lagrange Multiplier test statistics, which suggested the removal of the PSSE mean score as an indicator due to its association with the ICQ Initiation subscale mean and low performance as an indicator due to a low $R^{2}$ value. Model 2 used only the five ICQ subscale mean scores as indicators with the same specifications as model 1 . The results of model 2 suggested poor fit to the data, and so model modifications were made based on an unusually large univariate Lagrange Multiplier test statistics, which suggested the addition of an error covariance between the Emotional Support and Conflict Resolution subscale mean scores. The results from model 3 suggested that this measurement model demonstrated good fit to the data, with 
approximate fit statistics falling within acceptable ranges: RMSEA $=.040(90 \%$ confidence interval of $.001-.098), C F I=.997$, and the freed error covariance parameter was statistically significant (unstandardized estimate for this freed parameter was statistically significant $[p<.05]$ with an unstandardized estimate of .125 and a standard error of .015). The $\chi_{S B}^{2}$ was not statistically significant $(p=.063)$, and suggested good exact model fit.

Using the available data from 616 participants due to omitted responses, the 3indicator measurement model for the latent construct of Facebook Use was submitted to CFA. Four cases were removed due to large relative contributions to normalized multivariate kurtosis (cases 73, 156, 462, and 585), as they exhibited "strikingly different" estimates compared to all the other cases analyzed (Byrne, 2006, p. 199). The largest standardized residual from these data was -.048 , and parameter estimates were all statistically significant and practically meaningful which suggested good component fit; overall model fit statistics are shown in Table 4. The results from model 1 suggested that this measurement model demonstrated good fit to the data, with approximate fit statistics falling within acceptable ranges: $R M S E A=.023(90 \%$ confidence interval of $.001-.113)$, $C F I=.999$, and a $\chi_{S B}^{2}$ which was not statistically significant $(p=.257)$, and suggested good exact model fit.

\section{Structural Equation Model Results}

After assessing the fit of the measurement models, the full structural model was submitted to structural equation modeling (SEM) analyses using the measurement models specified above (using the modified measurement models where indicated). Data were available from 456 participants using listwise deletion due to omitted responses, which 
far surpassed the minimum requirement of 200 for most SEM applications (Kline, 2011), and was the approximate ideal sample size of 460 for the original theoretical model calculated from Jackson's (2003) more conservative formula for computing sample size with SEM analyses. The revised full structural equation model (see Figure 5) was submitted to SEM analyses using the previously established measurement models, using Robust ML and treating these data as continuous. The largest standardized residual from these data was .352 , skew (ranged from -.925 to .591 ) and kurtosis (ranged from -1.068 to .302) statistics all fell within acceptable ranges, and 2 cases were removed due to large relative contributions to normalized multivariate kurtosis (cases 43 and 156) based on "strikingly different" estimates produced by EQS compared to all the other cases analyzed (Byrne, 2006, p. 199). Structural regression model results for this model are displayed in Figure 6. Most parameter estimates were statistically significant and practically meaningful which suggested good component fit, however, the structural paths between Neuroticism and Interpersonal Competency, Neuroticism and Facebook Use, and Interpersonal Competency and Facebook use were not significant. The results of model 1 suggested poor fit to the data (see Table 6), and so model modifications were made based on large univariate Lagrange Multiplier test statistics and Wald test statistics, which suggested the removal of these three structural paths and the addition of two error covariances between the Attachment Avoidance and ICQ Disclosure subscale mean scores as well as the Emotional Support and Conflict Resolution subscale mean scores. 


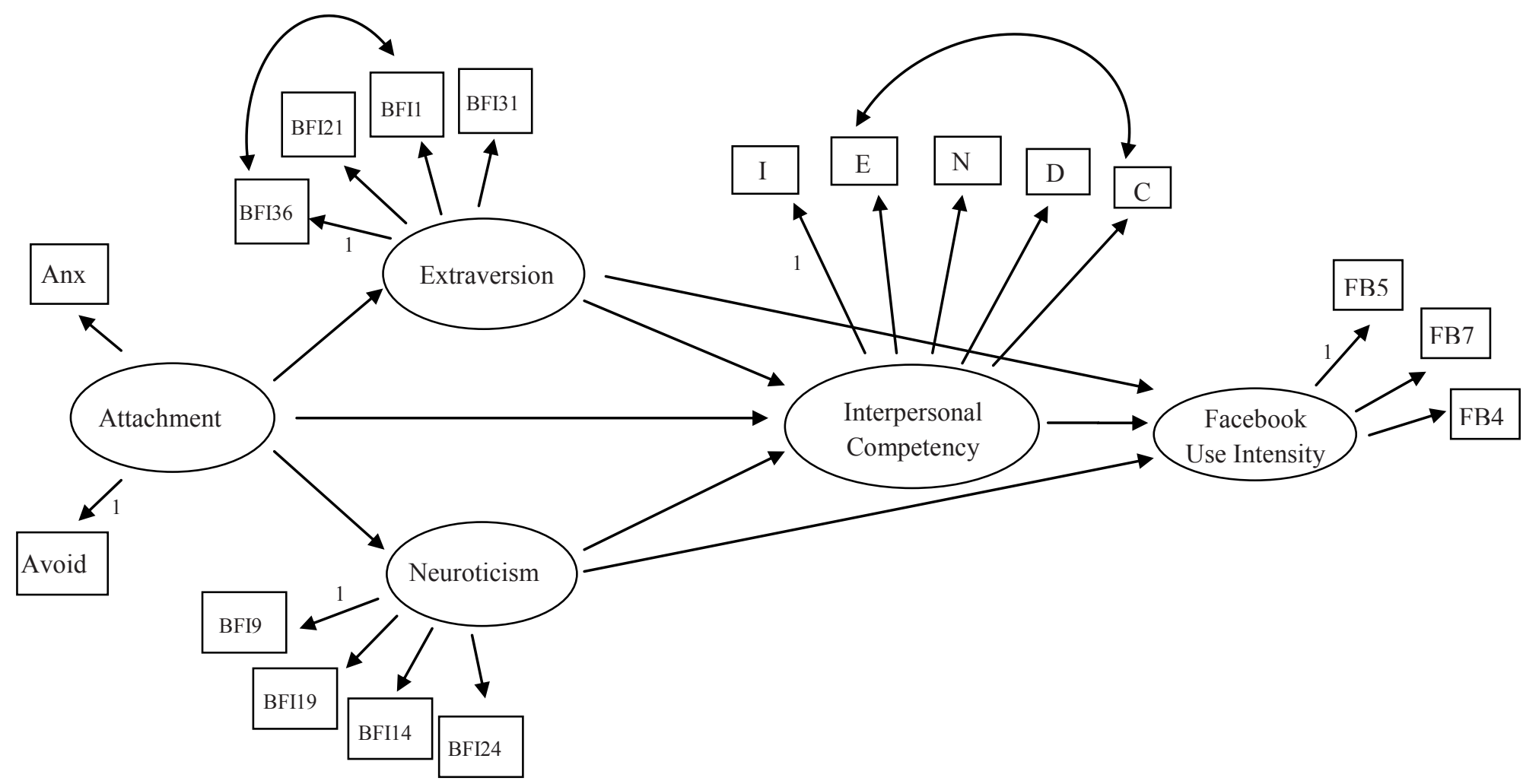

Figure 5. Respecified Full Structural Model.

Note. Anx $=$ Attachment Anxiety subscale; Avoid = Attachment Avoidance subscale; E1-E4 = BFI Extraversion subscale items; N1$\mathrm{N} 4=$ BFI Neuroticism items; $\mathrm{Fr}=$ Standardized item capturing number of Facebook friends; Min = Standardized item capturing minutes spent weekly on Facebook; Conn = Mean of six standardized items capturing a user's attachment to Facebook; I = ICS Initiation subscale; $\mathrm{E}=$ ICS Emotional Support subscale; $\mathrm{N}=$ ICS Negative Assertion subscale; $\mathrm{D}=$ ICS Disclosure subscale; $\mathrm{C}=\mathrm{ICS}$ Conflict Management subscale. 


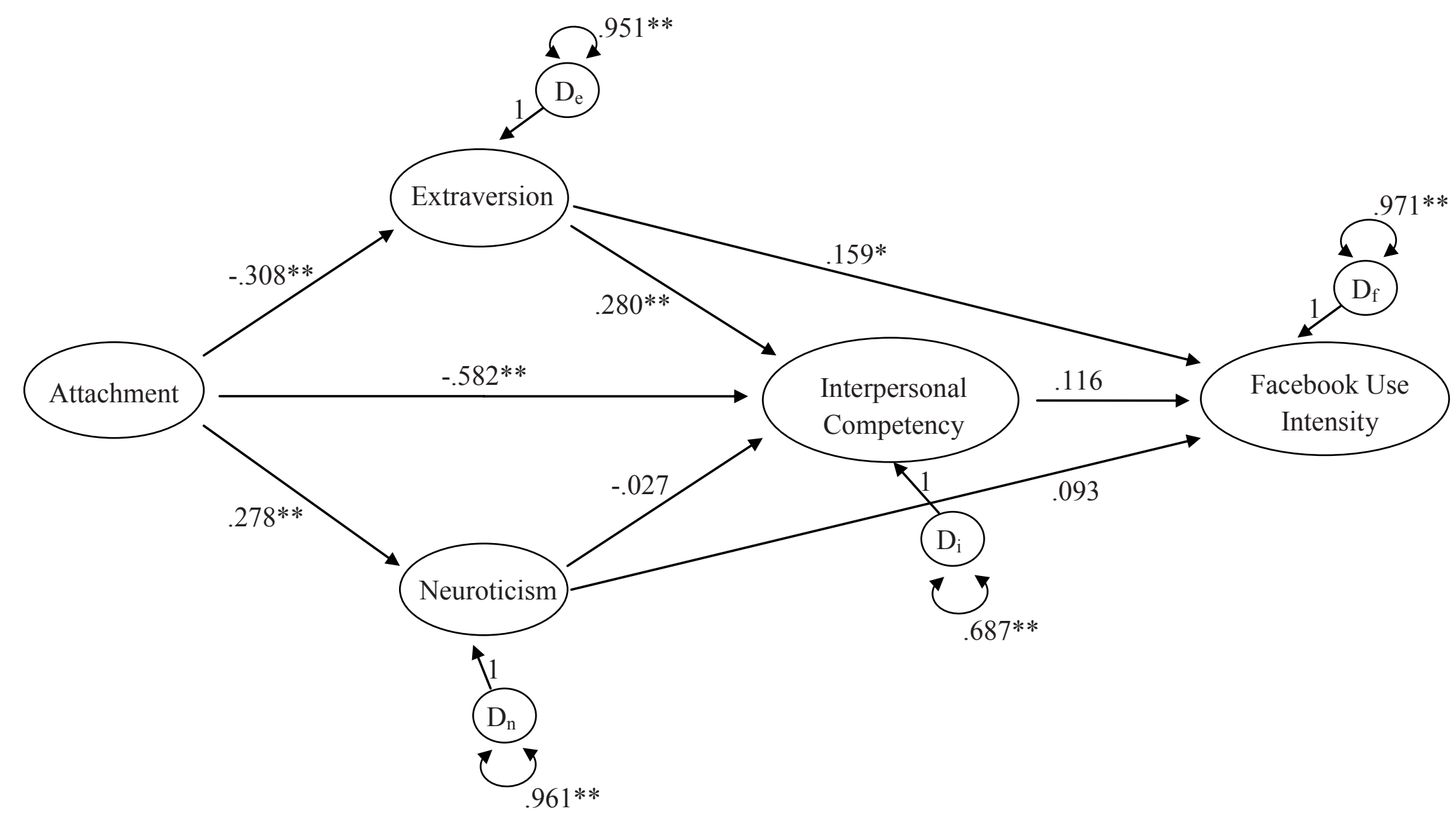

Figure 6. $N=$ 453. Primary structural model 1. Estimates are reported as standardized parameters. Standardized estimates for disturbances are proportions of unexplained variance. * indicates statistically significant at the .01 level; ** indicates statistically significant at the .001 level. 
Model 2 was submitted to SEM analysis with these additional two freed parameters and the three structural paths removed. The results of model 2 are displayed in Figure 7, and suggested marginal fit to the data (see Table 6), and so model modifications were made based on unusually large univariate Lagrange Multiplier test statistics, which suggested the addition of two error covariances between the BFI item 36 and the ICQ Initiation subscale mean score, as well as between BFI items 31 and 21. In addition, one case was removed due to its unusually large relative contributions to normalized multivariate kurtosis (case 339). The results from Model 3 are displayed in Figure 8 , and suggested adequate to good fit to the data (see Table 6). The $\chi^{2}$ statistic for exact model fit can be overly sensitive and biased by a number of model characteristics (Kline, 2011), and thus I used the revised criteria of $\chi^{2} / d f<3$ (Iacobucci, 2010). Although the $\chi_{S B}^{2}$ was statistically significant, suggesting inexact fit, the $\chi^{2}{ }_{S B} / d f$ ratio of 2.85 was $<$ 3, and therefore met the revised criteria. The RMSEA was .064 (90\% confidence interval of .056-.072), which meets the criteria of being close to .06. The SRMR was .070, which meets and exceeds the criteria of being less than .08, the CFI was .926, and the NNFI was 910. Although these values were less than the predetermined cutoff criteria of $>.95$ for these fit statistics, they still meet Hu and Bentler's (1999) criteria for being close to .95 for adequate fit. In addition, Weston and Gore (2006) suggested using less stringent criteria for samples less than $500(C F I>.90, N N F I>.90)$. Given the complexity of the model, the number of parameters to be estimated, and taking all the fit statistics together, this final primary model (model 3, Figure 8) demonstrated adequate to good overall fit to the data. In addition, this model demonstrated good component fit, as all parameter estimates were statistically significant and practically meaningful (see Table 7). 
Table 6

Overall Model Fit Statistics for the Primary Structural Regression Model

\begin{tabular}{cccccccccccc}
\hline Model & $\chi^{2}$ & $\chi^{2}{ }_{S B}^{2}$ & $d f$ & $\chi^{2}$ difference & RMSEA & $90 \%$ CI & SRMR & $C F I_{S B}$ & $N N F I_{S B}$ \\
\hline 1 & $527.836^{*}$ & $491.280^{*}$ & 125 & - & .080 & $.073-.088$ & .081 & .884 & .858 \\
2 & $460.430^{*}$ & $430.818^{*}$ & 127 & $67.406^{*}$ & .073 & $.065-.080$ & .073 & .904 & .884 \\
3 & $382.828^{*}$ & $360.162^{*}$ & 126 & $77.602^{*}$ & .064 & $.056-.072$ & .070 & .926 & .910 \\
\hline
\end{tabular}

Note. $N=453 . *$ indicates $p<.01 . C I=$ Confidence Interval. $\chi_{S B}^{2}=$ Satorra-Bentler scaled chi-squared; $R M S E A=$ root mean square error of approximation; $S R M R=$ standardized root mean square residual; $C F I=$ comparative fit index; $N N F I=$ non-normed fit index. Model 2 added one freed error covariance parameter between the Attachment Avoidance and ICQ Disclosure subscale mean scores, as well as removing the three structural regression path parameters between Neuroticism and Interpersonal Competency, Neuroticism and Facebook use, and Interpersonal Competency and Facebook Use. Model 3 added two freed error covariance parameters between BFI item 36 and the ICQ Initiation subscale mean score, as well as between BFI items 31 and 21. 
Table 7

Maximum Likelihood Estimates of Structural Paths for the Final Primary and Alternate Models

\begin{tabular}{|c|c|c|c|}
\hline Parameter & Unstandardized & $S E$ & Standardized \\
\hline \multicolumn{4}{|l|}{ Primary Model } \\
\hline Attachment $\rightarrow$ Extraversion & -.314 & .063 & -.366 \\
\hline Attachment $\rightarrow$ Neuroticism & .330 & .065 & .395 \\
\hline Attachment $\rightarrow$ Interpersonal Competency & -.330 & .053 & -.437 \\
\hline Extraversion $\rightarrow$ Interpersonal Competency & .358 & .047 & .407 \\
\hline Extraversion $\rightarrow$ Facebook Use & .269 & .067 & .220 \\
\hline \multicolumn{4}{|l|}{$\underline{\text { Alternate Model }}$} \\
\hline Attachment $\rightarrow$ Extraversion & -.307 & .061 & -.366 \\
\hline Attachment $\rightarrow$ Neuroticism & .319 & .064 & .386 \\
\hline Attachment $\rightarrow$ Interpersonal Competency & -.304 & .059 & -.416 \\
\hline Extraversion $\rightarrow$ Interpersonal Competency & .348 & .048 & .399 \\
\hline Interpersonal Competency $\rightarrow$ Facebook Use & .225 & .080 & .160 \\
\hline
\end{tabular}

Note. $N=453$. All parameter estimates statistically significant at $p<.05 . S E=$ standard error of estimate. 


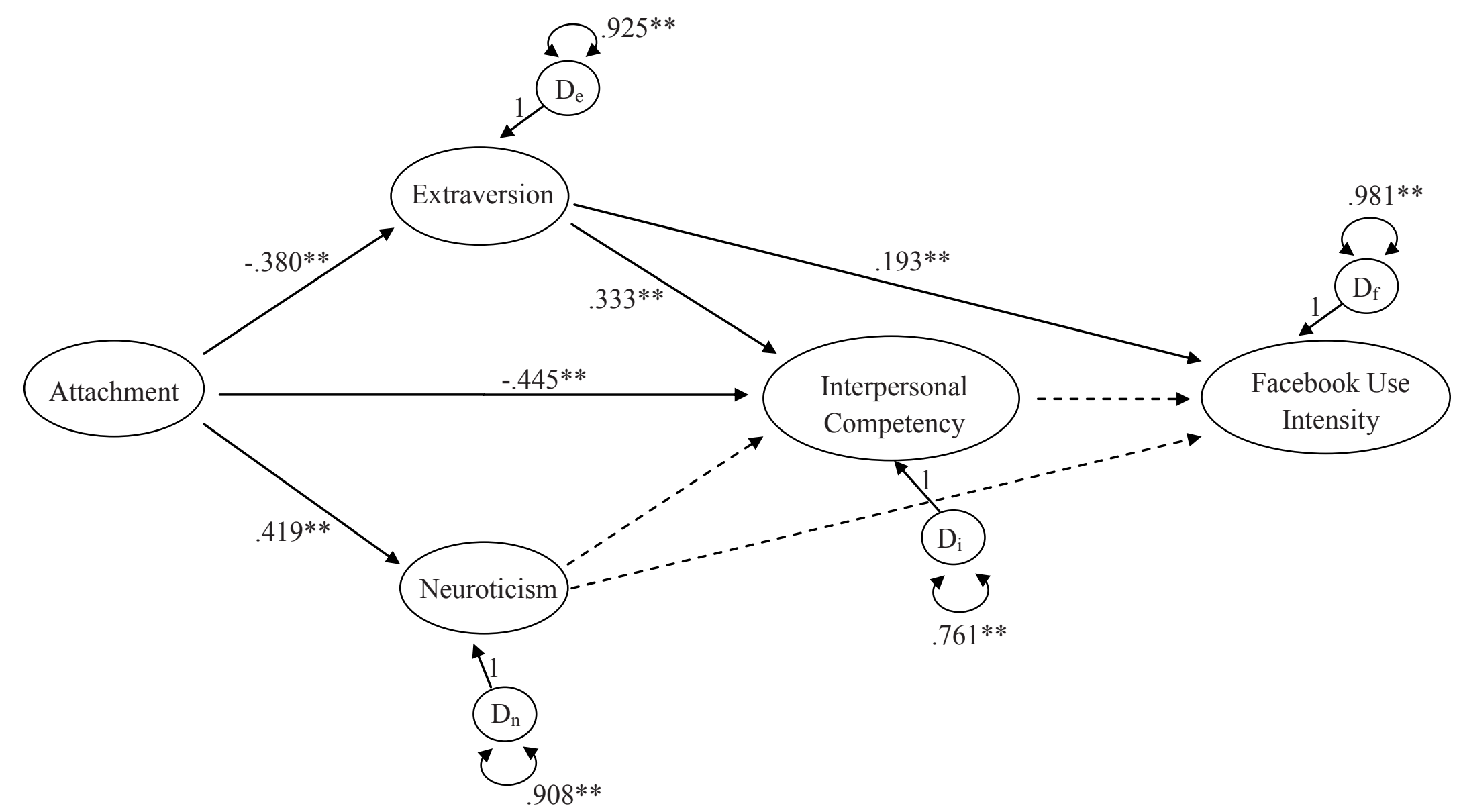

Figure 7. $N=$ 453. Primary structural model 2. Estimates are reported as standardized parameters. Standardized estimates for disturbances are proportions of unexplained variance. * indicates statistically significant at the .01 level; ** indicates statistically significant at the .001 level. 


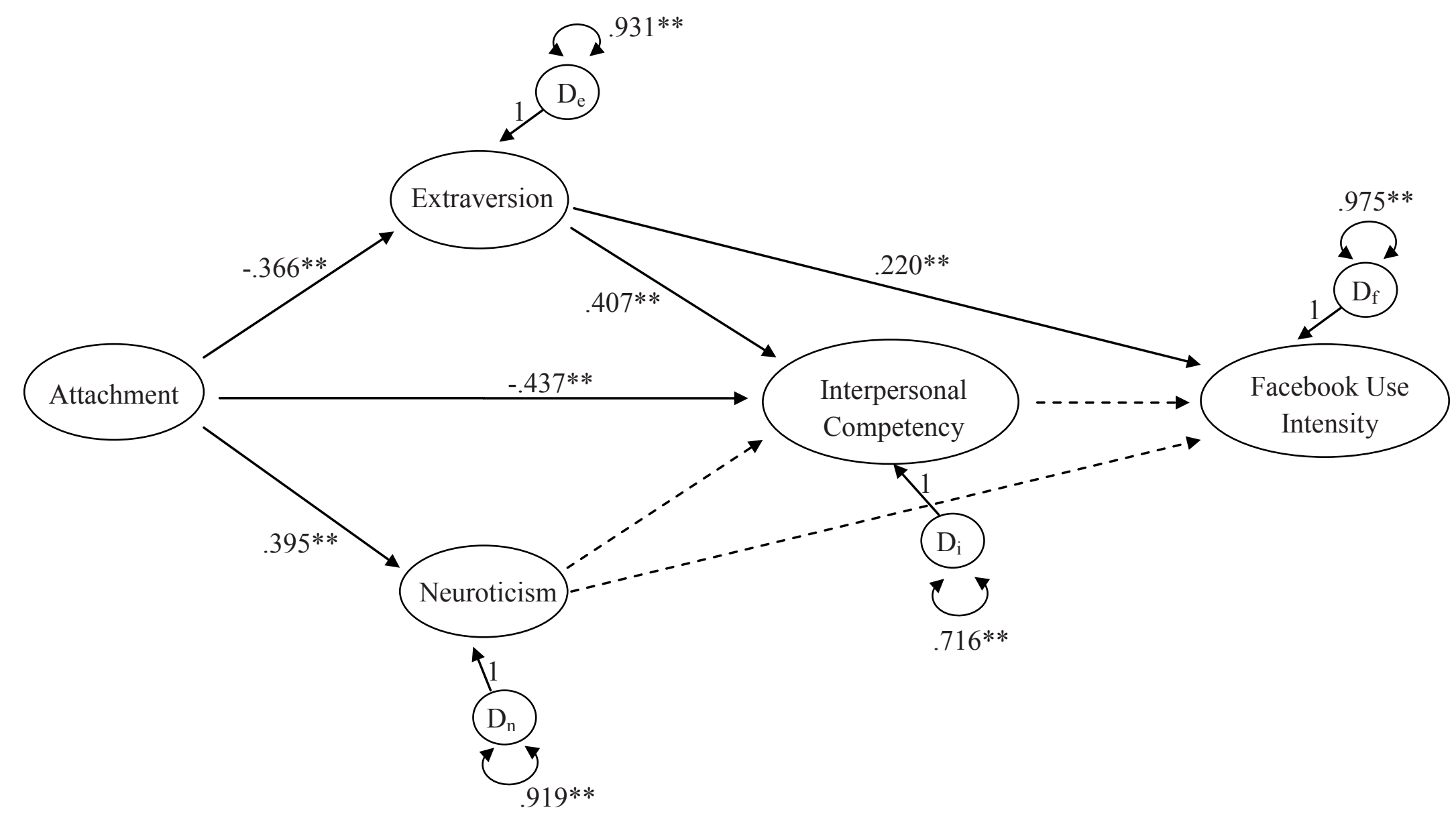

Figure 8. $N=$ 453. Final primary structural model 3. Estimates are reported as standardized parameters. Standardized estimates for disturbances are proportions of unexplained variance. * indicates statistically significant at the .01 level; ** indicates statistically significant at the .001 level. 


\section{Model Interpretation}

The alternate a priori model (see Figure 9) was similar to the primary a priori model, but excluded the structural paths from Extraversion and Neuroticism to Facebook Use. This alternate model was submitted to SEM analyses using the same measurement model specified above (estimating the same four error covariances that were estimated in the final primary a priori model) using Robust ML while treating the data as continuous. All skew and kurtosis statistics fell within acceptable ranges (skew $<2$, kurtosis $<7$ ), the largest standardized residual from these data was .357, and 2 cases were removed (43 and 156) based on Byrne's (2006) criteria for significant contributions to multivariate kurtosis. Data from 454 participants were available after addressing missing data using listwise deletion. All parameter estimates were statistically significant and practically meaningful (see Table 7), except for the path from Neuroticism to Interpersonal Competency, and suggested good component fit (see Figure 9). Overall fit statistics for this structural regression model fell within acceptable ranges: $\chi^{2}(125)=393.711, \chi_{S B}^{2}=$ 369.438, RMSEA $=.066(90 \%$ Confidence Interval: $.058-.073), S R M R=.073, C F I=$ $.922, N N F I=.905$. Given the complexity of the model, the number of parameters to be estimated, and considering all of the fit statistics together, this alternative model demonstrated adequate to good overall fit to the data. 


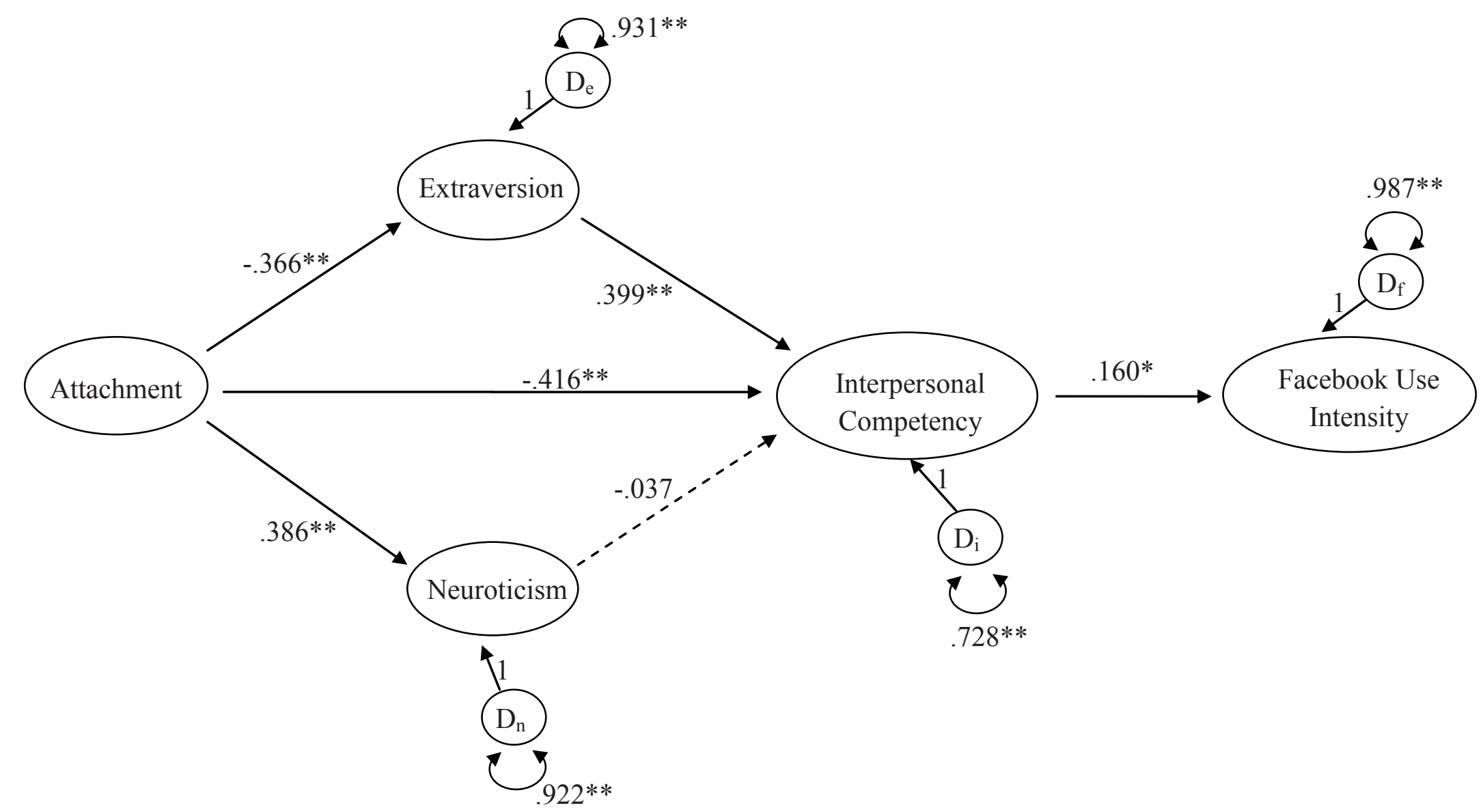

Figure 9. $N=453$. Alternate structural model. Estimates are reported as standardized parameters. Standardized estimates for disturbances are proportions of unexplained variance. * indicates statistically significant at the .05 level. ** indicates statistically significant at the .001 level. 
Interpretations of the final primary and alternate models were conducted using Cohen's (1988) guidelines on effect size applied to the standardized path coefficients, with absolute values of $<.10$ suggesting a small effect size, approximately .30 suggesting a medium effect size, and $>.50$ suggesting a large effect size. In the final primary model (model 3, Figure 8), insecure attachment had a medium, negative direct effect (-.366) on Extraversion, with about $13.4 \%$ of the variance in Extraversion explained $\left(R^{2}=.134\right)$ by attachment, a medium, positive direct effect (.395) on Neuroticism, with about $15.6 \%$ of the variance explained by attachment, and a medium, positive direct effect (.437) on Interpersonal Competency, with $19.1 \%$ of the variance explained by attachment. In addition, insecure attachment had indirect effects on Interpersonal Competency and Facebook Use through the mediating variables of Extraversion and Neuroticism. Lastly, Extraversion had a medium, positive direct effect (.407) on Interpersonal Competency, and a small to medium, positive direct effect (.220) on Facebook Use. It follows that Attachment has an indirect effect on Facebook Use through Extraversion as a mediating variable. Neuroticism did not have any direct effects, and did not appear to act as a mediating variable. Given these path estimates, approximately $48.7 \%$ of the variance in Interpersonal Competency was explained and $4.8 \%$ of the variance in Facebook Use was explained in this model.

In the final alternate model, insecure attachment had a medium, negative direct effect (-.366) on Extraversion, a medium, positive direct effect (.386) on Neuroticism, and a medium, negative direct effect (-.416) on Interpersonal Competency. Extraversion had a medium, positive direct effect (.399) on Interpersonal Competency, which had a small, direct effect (.160) on Facebook Use. Therefore, Attachment had an indirect effect 
on Facebook Use through the mediating variables of Extraversion and Interpersonal Competency. Neuroticism did not have any direct effects, and did not act as a mediating variable. This model explained approximately $2.5 \%$ of the variance in Facebook Use. 


\section{CHAPTER V DISCUSSION}

Given the increase in internet use among young adults (Zickuhr, 2010), especially as a means of communication (Correa et al., 2010) and for social purposes (Pempek et al., 2009; Ross et al., 2009) through online social media such as Facebook.com (Cheung, Chiu, \& Lee, 2011), new research must seek to understand the characteristics of these social media users and the potential impact of this use on their development, especially in the social domain (Brown, 2006). Similarly, Thayer and Ray (2006) call for more research on how increased internet use may impact the relationships and communication skills of users. As SNSs have become one of the most common manifestations of social behavior and communication online, researchers are beginning to investigate their role in the social lives of everyday users (Steinfield et al., 2008). Others encourage further research on SNSs with the emerging adult population that uses them most, as this medium is fairly new and as yet has not been studied in depth (Ross et al., 2009), especially in relation to social behavior (Raacke \& Bonds-Raacke, 2008). The young adult population uses Facebook more than any other age group (Zickuhr, 2010), and is increasingly incorporating its use into their social lives and daily routines (Brown, 2006; Ellison et al., 2007). Thus, the present study examined the interrelationships among characteristics of college-aged social media users shown to be associated with online social behavior through the developmental lens of Arnett's (2000) emerging adulthood theory as well as the attachment theoretical framework (Bowlby, 1969). 


\section{Study Rationale and Purpose}

The specific goal of the present research was to develop a model that explains the interrelationships among early-forming and stable personality characteristics, interpersonal competence, and Facebook use. This study investigated how personality traits commonly associated with relationship quality, relationship satisfaction, and interpersonal communication are associated with each other, perceived interpersonal competence, and the intensity of Facebook use. Building on previous work (e.g., JenkinsGuarnieri et al., 2012; Ross et al., 2009), this investigation included adult attachment style and the FFM traits Extraversion and Neuroticism. Thus far, no research has been conducted with the emerging adult population on the interrelationships among these personality traits, interpersonal competency, and intensity of online social behavior manifested through Facebook.

Based on the comprehensive literature review, there was clear theoretical support for attachment directly and positively affecting interpersonal competence (Anders \& Tucker, 2000; Bippus \& Rollin, 2003; Cooley, 2005; Mallinckrodt, 2000) and Extraversion (Backstrom \& Holmes, 2001; Carver, 1997), directly and negatively affecting Neuroticism (Backstrom \& Holmes, 2001; Carver, 1997; Hagekull \& Bohlin, 2003) as well as indirectly impacting interpersonal competence (Guerrero et al., 2009; Johnson, 2003; Mikulincer \& Shaver, 2007; Rholes et al., 2008) and interpersonal factors related to Facebook use (Bradford et al., 2002; Schulman et al., 1994) through these two FFM traits (Hagekull \& Bohlin, 2003; Picardi et al., 2005). In addition, I found ample research support for the direct impact of Neuroticism being negatively and Extraversion being positively related to interpersonal competency (Berry \& Hansen, 1996; Cuperman 
\& Ickes, 2009; Ozer \& Benet-Martinez, 2006) and Facebook use intensity (Back et al., 2010; Correa et al., 2010), as well as indirectly associated with Facebook use intensity through the mediating variable of interpersonal competence (Caplan, 2005; Engelberg \& Sjoberg, 2004; Harman et al., 2005; Ledbetter, 2010). The alternate model (see Figure 4 and 9) posited equally plausible relationships given the available research on these constructs, with the direct effects between Extraversion and Neuroticism and Facebook use removed to make interpersonal competency a full mediator between the personality traits and Facebook use in this model. Therefore, the following research questions were created to evaluate two theoretical models that explained the interrelationships among attachment, Extraversion and Neuroticism, interpersonal competency, and Facebook use intensity:

Q1 Does a primary theoretical explanatory model (see Figure 3) adequately fit the observed relationships in the data, conceptualized with attachment directly and positively affecting extraversion and interpersonal competency, directly and negatively impacting neuroticism while indirectly affecting Facebook use intensity through these mediating variables, with extraversion positively and neuroticism negatively and directly impacting interpersonal competency and Facebook use intensity while indirectly affecting Facebook use intensity through interpersonal competency, and with interpersonal competency directly and positively affecting Facebook use intensity?

Q2 Does the primary theoretical model demonstrate statistically better fit to the observed interrelationships between these constructs in the data than the alternate model (see Figure 4) which removes the direct effects of Extraversion and Neuroticism on Facebook use, making interpersonal communication competency a full mediator between personality traits and Facebook use intensity? 


\section{Attachment Style}

In evaluating the final primary a priori model (see Figure 8), the results from these data supported the theoretical links between attachment style and the FFM personality traits Extraversion and Neuroticism. Similar to both earlier work (e.g., Carver, 1997) and later work (e.g., Backstrom \& Holmes, 2001) supporting similar results, the present study found significant relationships between attachment style and these two FFM personality traits. Specifically, the results indicated that insecure attachment style was positively associated with Neuroticism and negatively associated with Extraversion, with approximately equal strengths in both of these relationships. In addition, insecure attachment style was negatively related to interpersonal competency, results which align well with previous research linking more secure attachment and greater competence with effective communication skills (Cooney et al., 2010; Jang et al., 2002; Pietromonaco et al., 2004), even when focusing on nonverbal communication (Tucker \& Anders, 1998) and when using distinctly naturalistic methods (Kafetsios \& Nezlek, 2002). Additionally, more secure attachment has been shown to be related to concepts closely related to interpersonal competency, such as perceptions of social support (Bernardon et al., 2011) and relationship satisfaction (Welch \& Houser, 2010). These results also follow theoretical predictions based on Bowlby's (1969) attachment theory, as attachment style was postulated to be significantly related to interpersonal skills as well as confidence and comfort in forming close relationships. For example, less securely attached individuals would be expected to have less interpersonal competence and exhibit greater difficulties in forming close relationships (see below for a full discussion of theoretical implications). Lastly, these data demonstrated indirect effects of 
Attachment on interpersonal competency and Facebook Use through Extraversion and Neuroticism as mediating variables.

\section{Five Factor Model Personality Traits}

The results indicated that only Extraversion was significantly related to interpersonal competency and Facebook use intensity, while Neuroticism did not exhibit significant relationships with other constructs in these data. In the final primary model (see Figure 8), Extraversion was positively related to both interpersonal competency and Facebook Use, with the former association approximately twice as strong as the latter. This parallels research investigating the interrelationships among these constructs, as Extraversion has previously been shown to be associated with interpersonal competency (Cuperman \& Ickes, 2009; Ozer \& Benet-Martínez, 2006). For example, higher Extraversion and lower Neuroticism have been related to increased quality and quantity of interpersonal communication (Berry \& Hansen, 1996). Similarly, research by Back et al. (2009) demonstrated that Extraversion, Neuroticism, and Agreeableness were reliably associated with interpersonal behavior. In the same vein, these two FFM traits have been shown to be associated with online social behavior, with higher Extraversion associated with increased usage (Jackson et al., 2003; Tosun \& Lajunen, 2010). Thus, the present study's results support the positive links between Extraversion and interpersonal competency and Facebook use intensity.

However, the present study's results also suggested that Neuroticism did not have a direct effect on interpersonal competency when first accounting for insecure attachment style. This suggests that attachment style may be the more influential construct in predicting interpersonal competence and online social behavior, and should be accounted 
for when investigating the predictors of these constructs. Although ample empirical support was found for the link between Neuroticism and interpersonal competency (Back et al., 2009; Berry \& Hansen, 1996; Cuperman \& Ickes, 2009; White et al., 2004) and Facebook use intensity (Correa et al., 2010; Ross et al., 2009), this support did not account for attachment style and thus may have excluded this relevant variable from analyses. Given the significant link between Attachment and Neuroticism (see Table 3), these results suggest that Attachment may explain significant portions of the variance in interpersonal competency and Facebook use. In this way, the variance in interpersonal competency and Facebook use explained by Neuroticism may actually be better explained by Attachment, implying that Attachment represents a significant portion of the variance in Neuroticism.

\section{Interpersonal Competency}

Results from these SEM analyses suggested that in the final primary model, interpersonal competency was not related to Facebook use, although Extraversion's direct effect on Facebook use may account for this finding. In the alternate model with the direct paths between Extraversion, Neuroticism and Facebook use removed, most of the same relationships emerged with similar strengths as in the primary model. However, when the path between Extraversion and Facebook use was removed, interpersonal competency acted as a mediator between Extraversion, attachment style and Facebook use, with a significant, positive, and small effect of interpersonal competency on Facebook use. These results suggested that attachment style and Extraversion may have indirect relationships with Facebook use through the mediating variable of interpersonal competency (see Figure 8 and Figure 9). However, the links between Extraversion and 
Facebook use and interpersonal competency and Facebook use seemed to be mutually exclusive in these data: initially the final primary model (see Figure 8) displayed a significant relationship between Extraversion and Facebook use and a nonsignificant relationship between interpersonal competency and Facebook use, while the final alternative model displayed a significant relationship between interpersonal competency and Facebook use when the path between Extraversion and Facebook use was removed (see Figure 9). Therefore, the question still remains as to whether Extraversion or interpersonal competency acted as the primary mediator between Attachment style and Facebook use. In addition, there may be some underlying third construct/variable related to interpersonal interaction that explained the variance in these relationships. Further research is needed in this area to examine these interrelationships and to investigate the specific links and their relative strengths.

\section{Overall Model Interpretation}

Based on the results of the final primary and alternate models, the present study's results suggested that emerging adults with higher levels of insecure attachment reported lower levels of Extraversion, higher levels of Neuroticism, and less developed interpersonal competency. In addition, those who reported higher Extraversion also indicated greater interpersonal competency and Facebook Use Intensity, although interpersonal competency may serve as a mediating variable between attachment style and Extraversion. Interestingly, and in contrast with prior research, higher Neuroticism was not associated with changes in perceptions of interpersonal competency or Facebook Use Intensity. This finding may be explained by this study's inclusion of attachment style in the model, which may account for the nonsignificant direct effects of Neuroticism. 


\section{Research Implications}

Given the current measurement instruments available for capturing social media use and Facebook use specifically, further research is needed to develop new measures to assess this construct with strong validity evidence and psychometrics. Perhaps because the social media phenomenon is still relatively nascent, much of the recent research published on social media and Facebook has utilized inadequate measurement instruments to operationalize associated constructs such as intensity of use, investment in use, and frequency of use (Jenkins-Guarnieri, Wright, \& Johnson, 2012). This body of research often used single items as indicators (e.g., Wilson et al., 2010), scales developed for the same study with inadequate psychometric statistics reported (e.g., Ross et al., 2009), and single item behavioral frequency measures such as the average number minutes per week of active use (e.g., Baker \& Oswald, 2010), which has been questioned as a complete and representative measure of social media use (Ellison et al., 2007; Jenkins-Guarnieri, et al., 2012). In addition, some researchers advocate for measuring beyond behavioral frequency of use, and in addition capturing emotional connection to use and incorporation of use into social routines (Ellison et al., 2007). With improved instrumentation, researchers may be able to use psychometrically stronger measures of latent constructs with evidence of validity, utilizing multiple scales or multiple subscales as indicators instead of single item indicators as was used in the present study's design. Thus, further research is needed to develop novel measures of social media use and related constructs in order to progress research in this domain.

In the same vein, future research could also utilize improved methods for measuring the Attachment style construct by separating this variable into its two 
component pieces of attachment anxiety and attachment avoidance. Designing a different measurement model in order to measure and operationalize the Attachment construct as accurately as possible with its two components may help to clarify the relationships found in the present study's models. In addition, this study's results support the inclusion of the attachment construct when examining the interrelationships among constructs related to interpersonal competency and online social behavior. Including the variable of attachment yielded results that diverged from previous research in this area, suggesting that Attachment may be an especially relevant variable in investigations seeking to explain the personality characteristics related to social media use and Facebook use specifically. Future research should incorporate Attachment as a relevant variable to be included in the earlier steps of similar models, given the strong theoretical and empirical support for its early emergence in infancy and early childhood (Bowlby, 1969). Furthermore, additional research is needed to confirm the present study's results suggesting that the Neuroticism construct is irrelevant to social behavior when also accounting for Attachment style. Lastly, researchers could include other theoretically relevant constructs in examining similar interrelationships, such as self-esteem, relationship self-efficacy, and other FFM traits.

Previous research has shown that a number of specific demographic variables may be associated with internet use, and the present study did not incorporate multiple demographic variables into analyses. Future research could clarify which among these demographic variables are associated with Internet use, and specifically with online social behavior or social media use. This may help to refine study design and analyses, and make results more generalizable. Future research could investigate the measurement 
invariance of social media use scales in order to determine whether the data obtained from social media use scales have the same meaning for different populations of users with varying demographic characteristics (Kline, 2011). In essence, these investigations would seek to understand whether the individual items, overall structure of items and factors, and even the rating scales used operate equivalently for different groups of people. For example, it may be the case that the present study's results are more applicable to female emerging adults than males due to differences in how these two groups responded to the scales. Thus, future research should investigate the potential role of demographic variables in explaining the interrelationships among the constructs related to social media use and interpersonal competency. Additionally, future research on the personality characteristics of online social media users may benefit from accounting for these types of demographic variables that may influence SNS use.

Although the present study's results suggested that interpersonal competency may act as a mediating variable between attachment style, Extraversion and Facebook use, further research must replicate these results with similar populations of participants. In addition, future research could examine whether this mediating role is supported in different populations, as well as the specific mechanisms of this mediation. By examining different model constructions, researchers may reach a better understanding of how these constructs are interrelated, as well as glean insight into other relevant constructs that may play a significant role in explaining these interrelationships.

\section{Theoretical Implications}

Through the lens of Bowlby's (1969) Attachment theory, the present study's results align well with the basic tenets of this theoretical framework. This theory as well 
as later empirical work both support the important role of Attachment style in the formation and maintenance of relationships throughout the lifespan (Hazan \& Shaver, 1987; Fraley \& Shaver, 2000; Zimmerman, 2004), suggest that Attachment style is related to formative personality characteristics (Backstrom \& Holmes, 2001; Hagekull \& Bohlin, 2003; Shaver \& Brennan, 1992), and link Attachment to later developmental processes associated with social behavior and interpersonal competency of adults in college (Kenny \& Rice, 1995). Similarly, the present study’s results suggest that Attachment style was related to Extraversion and Neuroticism, two personality traits from the FFM found to be significantly related to interpersonal competency and online social behavior (Ozer \& Benet-Martínez, 2006). Specifically, the data from the present study suggested that more insecure attachment was associated with greater levels of Neuroticism and lesser levels of Extraversion. Viewed through a theoretical lens, these results parallel Bowlby's (1969) explanations of behavior that more secure attachment is associated with greater comfort and capability in social interactions. Extraversion is defined in this same way, with higher levels associated with greater comfort and capability in interpersonal interactions. Attachment theory also posits that more secure attachment is linked with more positive emotional states and greater life satisfaction in general, and this mirrors the practical definition of lower levels of Neuroticism (John et al., 2008).

Based on the present study's data, higher levels of insecure attachment displayed a strong negative relationship with interpersonal competency, which fits well with Attachment theory's suggestion that more secure attachment yields greater comfort in and skills with close relationships. According to the theory, more secure attachment leads 
to adopting more adaptive internal working models, which a person then uses to build and maintain strong, close interpersonal relationships (Bowlby, 1969). Additionally, securely attached individuals benefit from increased learning of social skills and emotional regulation that can benefit a person throughout the lifespan in social interactions. The results suggesting that Attachment may be indirectly related to Facebook use align with the theoretical framework as well, in that online social behavior can be seen as an extension of offline interpersonal social behavior (Ellison et al., 2007), and so similar relationships as those found between Attachment and interpersonal interactions would be expected in the online social environment as well.

Arnett's $(2000 ; 2004)$ emerging adulthood theoretical framework, which suggests that college-aged adults, like those who participated in the present study, continue to develop throughout this era of their life and discover a more stable sense of self based on their own budding values, personality characteristics, and interests. In addition, they focus intently on platonic and romantic relationships, and engage in intrapersonal and interpersonal developmental activities (Montgomery, 2005) in seeking companionship with others that compliment their own emerging identities (Arnett, 2000). The present study's results align with Arnett's theory in that the explanatory model based on these data also demonstrated strong links between personality characteristics and interpersonal competency. Specifically, the relatively strong relationship between Extraversion (a trait in the FFM closely associated with social behavior) and interpersonal competency mirror this theoretical framework's suggestion of strengthening connections between developing personality traits and interpersonal relationships for emerging adults. The same type of relatively strong link can be seen between Attachment and interpersonal competency in 
the model as well, offering more support of the strengthening the theoretical importance of intrapersonal traits with interpersonal ramifications as described in Arnett's theory. Emerging empirical evidence has suggested that some of the developmental activities of emerging adults (Arnett, 2000) may be occurring through online mediums (Brown, 2006). For example, a recent study highlighted how a process commonly associated with identity development was reflected on participants' Facebook pages: users expressed "salient and highly elaborated" ethnic identities through their Facebook pages just as they would in the real world (Grasmuck et al., 2009, p. 179). Constructing an online profile page can be seen as a purposeful act, one that reflects a user's identity and self in a social environment (Manago et al., 2008). Similarly, developmental processes associated with emerging adulthood such as identity formation (Peluchette \& Karl, 2010) and social behavior (Gordon et al., 2007) often manifest online through SNS such as Facebook. In this way, emerging adults express themselves and represent aspects of their personality through online mediums with distinctly social motivations.

Just as Arnett's (2000) theory and empirical research support the idea that personality traits are connected to online social behavior, the present study's results suggested direct relationships between Extraversion and interpersonal competency and Facebook use intensity and indirect relationships between Attachment and Facebook use intensity. Although much research is needed in this area to clarify the specific relationships between personality characteristics and online social behavior through social media, results based on these data support the potential links suggested by the emerging adulthood theoretical framework. 


\section{Practice Implications}

A number of practice implications emerged for counseling psychologists in light of the present study's results. Given the significant role of Attachment in the model based on these data, practitioners in this field should acknowledge the influence of attachment style on personality traits, interpersonal competency, and online social media use when working with clients. This implication necessitates the exploration of early relationships and success with attachment behaviors in order to understand behavioral tendencies and interpersonal difficulties that may arise in the course of therapy. In this way, clinicians may be able to identify motivations behind social behaviors and contributing factors to interpersonal strife that are based on insecure attachment and plan treatment accordingly. Therapists may follow a similar approach in examining the role of personality traits as well, given the significant roles of Neuroticism and Extraversion in the present study's results. For example, clinicians can target potential negatively biased interpretations of events that may lead to decreased competence in interpersonal interactions, as increased Neuroticism is associated with a tendency toward negative emotionality, sadness, nervousness, and tension (John et al., 2008), thus making potentially negatively biased information processing more likely. In these ways, practice implications for counseling psychologists based on the present study's results suggest that practitioners incorporate the potential role of Attachment, personality traits, and interpersonal competency in related issues that arise in clinical work.

Given the increasing prominence of online social media in the daily lives of adults, counseling psychologists may need to increasingly interface with social media in their clinical work. For example, many organizations, such as the Veterans Health 
Administration, are relying on social media as an effective outreach strategy and an entry point to access mental health care. In light of these trends and the present study's results, counseling psychologists should acknowledge the role of attachment style, personality traits, and level of interpersonal competency in determining the effectiveness of online social media as an access point for care for clients.

Given the study's results suggesting the potential influence of Attachment, Extraversion, and interpersonal competency in Facebook use intensity, clinicians may wish to assess clients' levels of these constructs when planning how best to communicate with and engage clients about their mental health treatment. As certain personality traits may be associated with less engagement with social media, clinicians could incorporate clients levels of these traits in order to better predict their likelihood of integrating social media into their daily lives. With these potential clues, clinicians may be better able to plan communication strategies regarding treatment. For example, clients with more insecure attachment and lower levels of Extraversion may benefit more from direct phone contact than from online social media contact for communication, treatment scheduling, and outreach efforts. Thus, the present study's results may be useful in helping clinicians plan more effective communication about treatment planning and scheduling.

\section{Limitations}

As can be expected given the fairly recent popularity of SNS and Facebook specifically, the communication and psychology literatures display a dearth of research on the personality characteristics related to Facebook use and its potential effects on interpersonal relationships and interpersonal competency. In addition, my extensive literature review found that most work in this area was found in the communications 
literature, in journals such as Cyberpsychology \& Behavior, Computers in Human Behavior, and the Journal of Computer-Mediated Communication. Although some studies focusing on these issues are being published in psychology journals, such as the Journal of Applied Developmental Psychology, further research from the perspective of the psychological sciences are needed to better understand the psychological constructs associated with the nature and extent of Facebook use, as well as its potential impact on psychosocial functioning. Therefore, the present study may suffer from a sparse research base and underdeveloped theoretical foundation from which to launch a carefully constructed investigation and thereby contribute meaningfully to research in this area.

The generalizations of study findings are limited to the unique demographic characteristics of the sample used, and may only apply to emerging adult populations in college. The study sample consisted primarily of first year, first time undergraduate college students from a medium $(N=13,000)$, Rocky Mountain region university. In addition, the sample included few individuals identifying as ethnic/racial minorities, and substantially more females answered the study's invitation email and completed the online study survey, which could also complicate generalizations made from this study's findings. Lastly, the data were collected from a nonrandom sample, as potential participants voluntarily chose to participate in this research. Given this inclusion method, personality traits associated with participation may also have influenced the results by biasing the way that they responded to the study survey.

Kraut et al. (2002) identified control variables known to influence internet use, variables which may influence online social behavior as well (i.e., age, gender, race, income, education, and the size of one's place of upbringing; urban or rural). However, 
when reviewing the literature, no research has sought to identify variables known to influence Facebook use specifically. The present study attempted to incorporate background and contextual variables shown to influence internet use and social behavior, however, its current design may have failed to account for demographic variables that research has yet to identify as important factors to control for in similar investigations. Previous research on Facebook users most often incorporated gender, age, and race/ethnicity into their analyses (e.g., Ellison et al., 2007; Orr et al., 2009) and occasionally education and income levels (e.g., Correa et al., 2010). Given the lack of clarity and cohesiveness in these findings, the present study did not attempt to account for these types of background characteristics of users that may impact Facebook use, an aspect of this study's design that may limit the generalizability of these results as well. Lastly, this study may suffer from a mono-method bias, as only scale data were used to represent each construct. Future research can utilize multiple measures in order to protect against measurement error and any potential bias inherent in using only one type of measure to capture the constructs under study.

\section{Conclusions}

Despite a number of limitations, the present study established a well-fitting model explaining the interrelationships among relevant personality constructs, interpersonal competency and Facebook use. Specifically, more secure attachment was related to higher Extraversion, lower Neuroticism, and increased perceptions of interpersonal competency. Higher levels of Extraversion were related to increased interpersonal competency and Facebook use, while interpersonal competency may act as a mediator between attachment style and Extraversion and Facebook use. Interestingly, Neuroticism 
did not appear to have significant relationships with other constructs under study after accounting for attachment style. This study highlights the importance of attachment style and its role in explaining FFM personality traits, interpersonal competency, and Facebook use. Paralleling Bowlby's (1969) original attachment theory, these results suggest that individuals with more secure attachment will feel more comfortable and capable in interpersonal relationships and social behavior, and by implication online social behavior. These results are especially relevant for emerging adults in college, and future research may investigate whether these interrelationships hold true for other segments of the U.S. population. 


\section{REFERENCES}

Ainsworth, M. S., Blehar, M. C., Waters, E., \& Wall, S. (1978). Patterns of attachment: A psychological study of the strange situation. Oxford, England: Lawrence Erlbaum. Retrieved from www.csa.com

Allport, G.W. \& Odbert, H.S. (1936). Trait-names: A psycho-lexical study. Psychological Monographs, 47, 211-215.

Amichai-Hamburger, Y., \& Vinitzky, G. (2010). Social network use and personality. Computers in Human Behavior, 26, 1289-1295. doi:10.1016/j.chb.2010.03.018

Amichai-Hamburger, Y., Wainapel, G., \& Fox, S. (2002). "On the internet no one knows I'm an introvert": Extroversion, neuroticism, and internet interaction. CyberPsychology \& Behavior, 5, 125-128. doi:10.1089/109493102753770507

Amiel, T., \& Sargent, S. L. (2004). Individual differences in internet usage motives. Computers in Human Behavior, 20, 711-726. doi:10.1016/j.chb.2004.09.002

Anders, S. L., \& Tucker, J. S. (2000). Adult attachment style, interpersonal communication competence, and social support. Personal Relationships, 7, 379389. doi:10.1111/j.1475-6811.2000.tb00023.x

Ansell, E. B., \& Pincus, A. L. (2004). Interpersonal perceptions of the five-factor model of personality: An examination using the structural summary method for circumplex data. Multivariate Behavioral Research, 39, 167-201. doi:10.1207/s15327906mbr3902_3 
APA Publications and Communications Board Working Group on Journal Article Reporting Standards. (2008). Reporting standards for research in psychology: Why do we need them? what might they be? American Psychologist, 63, 839-851. doi:10.1037/0003-066X.63.9.839

Arnett, J. J. (2000). Emerging adulthood: A theory of development from the late teens through the twenties. American Psychologist, 55, 469-480.

Arnett, J. J. (2004). Emerging adulthood: The winding road from the late teens through the twenties. New York, NY, US: Oxford University Press. Retrieved from www.csa.com

Arnett, J. J. (2007). Suffering, selfish, slackers? myths and reality about emerging adults. Journal of Youth and Adolescence, 36, 23-29. doi:10.1007/s10964-006-9157-z

Aveyard, H. (2007). Doing a literature review in health \& social care. New York: Open University Press. Retrieved from www.csa.com

Babakus, E., Ferguson Jr., C. E., \& Jöreskog, K. G. (1987). The Sensitivity of Confirmatory Maximum Likelihood Factor Analysis to Violations of Measurement Scale and Distributional Assumptions. Journal of Marketing Research (JMR), 24, 222-228. Retrieved from EBSCOhost.

Back, M. D., Schmuckle, S. C., \& Egloff, B. (2009). Predicting actual behavior from the explicit and implicit self-concept of personality. Journal of Personality and Social Psychology, 97, 533-548. doi:10.1037/a0016229

Back, M. D., Stopfer, J. M., Vazire, S., Gaddis, S., Schmukle, S. C., Egloff, B., \& Gosling, S. D. (2010). Facebook profiles reflect actual personality, not self- 
idealization. Psychological Science, 21, 372-374.

doi:10.1177/0956797609360756

Backstrom, M., \& Holmes, B.M. (2001). Measuring adult attachment: A construct validation of two self-report instruments. Scandinavian Journal of Psychology, 42, 79-86.

Baker, L. R.,\& Oswald, D. L. (2010). Shyness and online social networking services. Journal of Social and Personal Relationships, 27, 873-889. doi: $10.1177 / 0265407510375261$

Bandura, A. (1986). Social foundations of thought and action: A social cognitive theory. Englewood Cliffs, NJ: Prentice-Hall.

Bandura, A. (1997). Self-efficacy: The exercise of control. New York: Freeman.

Barelds, D. P. H. (2005). Self and partner personality in intimate relationships. European Journal of Personality, 19, 501-518. doi:10.1002/per.549

Barrett, L. F., \& Pietromonaco, P. R. (1997). Accuracy of the five-factor model in predicting perceptions of daily social interactions. Personality and Social Psychology Bulletin, 23, 1173-1187. doi:10.1177/01461672972311005

Bartholomew, K., \& Horowitz, L. M. (1991). Attachment styles among young adults: A test of a four-category model. Journal of Personality and Social Psychology, 61, 226-244. doi:10.1037/0022-3514.61.2.226

Baumeister, R. F., Campbell, J. D., Krueger, J. I., \& Vohs, K. D. (2003). Does high selfesteem cause better performance, interpersonal success, happiness, or healthier lifestyles? Psychological Science in the Public Interest, 4, 1-44. doi:10.1111/1529-1006.01431 
Beauducel, A., \& Wittmann, W. W. (2005). Simulation study on fit indexes in CFA based on data with slightly distorted simple structure. Structural Equation Modeling, 12, 41-75. doi:10.1207/s15328007sem1201_3

Benet-Martínez, V., \& John, O. P. (1998). Los cinco grandes across cultures and ethnic groups: Multitrait-multimethod analyses of the big five in spanish and english. Journal of Personality and Social Psychology, 75, 729-750. doi:10.1037/00223514.75.3.729

Bentler, P. M. (1990). Comparative fit indexes in structural models. Psychological Bulletin, 107, 238-246. doi:10.1037/0033-2909.107.2.238

Bentler, P. M. (1995). EQS structural equations program manual. Encino, CA: Multivariate Software.

Bentler, P. M. (2008). EQS 6 structural equations program manual. Encino, CA: Multivariate Software.

Bentler, P. M., \& Bonett, D. G. (1980). Significance tests and goodness of fit in the analysis of covariance structures. Psychological Bulletin, 88, 588-606. doi:10.1037/0033-2909.88.3.588

Bentler, P. M., \& Chih-Ping, C. (1987). Practical Issues in Structural Modeling. Sociological Methods \& Research, 16, 78. Retrieved from EBSCOhost.

Berlin, L. J., Cassidy, J., \& Appleyard, K. (2008). The influence of early attachments on other relationships. In J. Cassidy, \& P. R. Shaver (Eds.), Handbook of attachment: Theory, research, and clinical applications (2nd ed., pp. 333-347). New York, NY, US: Guilford Press. Retrieved from www.csa.com 
Bernardon, S., Babb, K. A., Hakim-Larson, J., \& Gragg, M. (2011). Loneliness, attachment, and the perception and use of social support in university students. Canadian Journal of Behavioural Science/Revue Canadienne Des Sciences Du Comportement, 43, 40-51. doi:10.1037/a0021199

Berry, D. S., \& Hansen, J. S. (1996). Positive affect, negative affect, and social interaction. Journal of Personality and Social Psychology, 71, 796-809. doi:10.1037/0022-3514.71.4.796

Berry, D. S., \& Hansen, J. (2000). Personality, nonverbal behavior, and interaction quality in female dyads. Personality and Social Psychology Bulletin, 26, 278-292. doi: $10.1177 / 0146167200265002$

Bippus, A. M., \& Rollin, E. (2003). Attachment style differences in relational maintenance and conflict behaviors: Friends' perceptions. Communication Reports, 16, 113-123. Retrieved from www.csa.com

Bowlby, J. (1969). Attachment and loss: Vol. 1. Attachment. New York: Basic Books. Bowlby, J. (1980). Attachment and loss: Vol. 3. Loss: Sadness and depression. New York: Basic Books.

Boyd, D. M., \& Ellison, N. (2007). Social network sites: Definition, history, and scholarship. Journal of Computer-Mediated Communication, 13, 210-230.

Bradford, S. A., Feeney, J. A., \& Campbell, L. (2002). Links between attachment orientations and dispositional and diary-based measures of disclosure in dating couples: A study of actor and partner effects. Personal Relationships, 9, 491-506. doi:10.1111/1475-6811.00031 
Brennan, K. A., \& Shaver, P. R. (1993). Attachment styles and parental divorce. Journal of Divorce \& Remarriage, 21, 161-175. doi:10.1300/J087v21n01_09

Brennan, K. A., Clark, C. L., \& Shaver, P. R. (1998). Self-report measurement of adult attachment: An integrative overview. In J. A. Simpson, \& W. S. Rholes (Eds.), Attachment theory and close relationships. (pp. 46-76). New York, NY, US: Guilford Press. Retrieved from www.csa.com

Brown, J. (2006). Emerging adults in a media-saturated world. In J. Arnett, \& J. Tanner (Eds.), Emerging adults in America: Coming of age in the 21st century (pp. 279-299). NY: American Psychological Association.

Bruch, M.A., Berko, E.H., \& Haase, R.F. (1998). Shyness, masculine ideology, physical attractiveness, and emotional impressiveness: Testing a meditational model of men's interpersonal competence. Journal of Counseling Psychology, 45, 84-97.

Buhrmester, D., Furman, W., Wittenberg, M. T., \& Reis, H. T. (1988). Five domains of interpersonal competence in peer relationships. Journal of Personality and Social Psychology, 55, 991-1008. doi:10.1037/0022-3514.55.6.991

Buote, V. M., Wood, E., \& Pratt, M. (2009). Exploring similarities and differences between online and offline friendships: The role of attachment style. Computers in Human Behavior, 25, 560-567. doi:10.1016/j.chb.2008.12.022

Butt, S., \& Phillips, J. G. (2008). Personality and self reported mobile phone use. Computers in Human Behavior, 24, 346-360. doi:10.1016/j.chb.2007.01.019

Byrne, B. M. (2006). Structural equation modeling with AMOS: Basic concepts, applications, and programming. Mahwah, NJ, US: Lawrence Erlbaum Associates Publishers. Retrieved from www.csa.com 
Caplan, S. E. (2005). A social skill account of problematic internet use. Journal of Communication, 55, 721-736. doi:10.1111/j.1460-2466.2005.tb03019.x

Caprara, G. V., Gerbino, M., Paciello, M., Di Giunta, L., \& Pastorelli, C. (2010). Counteracting depression and delinquency in late adolescence: The role of regulatory emotional and interpersonal self-efficacy beliefs. European Psychologist, 15, 34-48. doi:10.1027/1016-9040/a000004

Carver, C. S. (1997). Adult attachment and personality: Converging evidence and a new measure. Personality and Social Psychology Bulletin, 23, 865-883. doi:10.1177/0146167297238007

Cassidy, J. (1999). The nature of a child's ties. In J. Cassidy and P.R. Shaver (Eds.), Handbook of attachment: Theory, research, and clinical applications (pp. 3-20). New York: Guilford Press. Retrieved from www.csa.com

Cattell, R. B. (1946). The description and measurement of personality. NY: Harcourt. Cheung, C. M. K., Chiu, P., \& Lee, M. K. O. (2011). Online social networks: Why do students use facebook? Computers in Human Behavior. Advance online publication. doi:10.1016/j.chb.2010.07.028

Cohen, J. (1988). Statistical power analysis for the behavioral sciences (2nd ed.). New York: Academic.

Collins, N. L., \& Feeney, B. C. (2004). Working models of attachment shape perceptions of social support: Evidence from experimental and observational studies. Journal of Personality and Social Psychology, 87, 363-383. doi:10.1037/00223514.87.3.363 
Cooley, E. L. (2005). Attachment style and decoding of nonverbal clues. North American Journal of Psychology, 7, 25-33. Retrieved from www.csa.com

Cooley, E. L., Van Buren, A., \& Cole, S. P. (2010). Attachment styles, social skills, and depression in college women. Journal of College Counseling, 13, 50-62.

Retrieved from www.csa.com

Corcoran, K. O., \& Mallinckrodt, B. (2000). Adult attachment, self-efficacy, perspective taking, and conflict resolution. Journal of Counseling \& Development, 78, 473483. Retrieved from www.csa.com

Correa, T., Hinsley, A. W., \& de Zúñiga, H. G. (2010). Who interacts on the web?: The intersection of users' personality and social media use. Computers in Human Behavior, 26, 247-253. doi:10.1016/j.chb.2009.09.003

Côté, S., \& Moskowitz, D. S. (1998). On the dynamic covariation between interpersonal behavior and affect: Prediction from neuroticism, extraversion, and agreeableness. Journal of Personality and Social Psychology, 75, 1032-1046. doi:10.1037/00223514.75.4.1032

Cuperman, R., \& Ickes, W. (2009). Big five predictors of behavior and perceptions in initial dyadic interactions: Personality similarity helps extraverts and introverts, but hurts "disagreeables". Journal of Personality and Social Psychology, 97, 667684. doi:10.1037/a0015741

Denissen, J. J. A., \& Penke, L. (2008). Neuroticism predicts reactions to cues of social inclusion. European Journal of Personality, 22, 497-517. doi:10.1002/per.682

Diener, E., \& Ryan, K. (2009). Subjective well-being: A general overview. South African Journal of Psychology, 39, 391-406. Retrieved from www.csa.com 
Digman, J. M. (1990). Personality structure: Emergence of the five-factor model. Annual Review of Psychology, 41, 417-440.

DiStefano, C. (2002). The impact of categorization with confirmatory factor analysis. Structural Equation Modeling, 9, 327-346.

DiTommaso, E., Brannen-McNulty, C., Ross, L., \& Burgess, M. (2003). Attachment styles, social skills and loneliness in young adults. Personality and Individual Differences, 35, 303-312. doi:10.1016/S0191-8869(02)00190-3

Donnellan, M. B., Larsen-Rife, D., \& Conger, R. D. (2005). Personality, family history, and competence in early adult romantic relationships. Journal of Personality and Social Psychology, 88, 562-576. doi:10.1037/0022-3514.88.3.562

Ellison, N. B., Steinfield, C., \& Lampe, C. (2007). The benefits of facebook "friends:" social capital and college students' use of online social network sites. Journal of Computer-Mediated Communication, 12, 1143-1168. doi:10.1111/j.10836101.2007.00367.x

Engelberg, E., \& Sjöberg, L. (2004). Internet use, social skills, and adjustment. CyberPsychology \& Behavior, 7, 41-47. doi:10.1089/109493104322820101

Engels, R. C. M. E., Finkenauer, C., Meeus, W., \& Deković, M. (2001). Parental attachment and adolescents' emotional adjustment: The associations with social skills and relational competence. Journal of Counseling Psychology, 48, 428-439. doi:10.1037/0022-0167.48.4.428

Erikson, E. H. (1968). Identity: Youth and crisis. New York: Norton.

Fairchild, A. J., \& Finney, S. J. (2006). Investigating validity evidence for the experiences in close relationships-revised questionnaire. Educational and 
Psychological Measurement, 66, 116-135. doi:10.1177/0013164405278564

Fan, J., Meng, H., Gao, X., Lopez, F. J., \& Liu, C. (2010). Validation of a U.S. adult social self-efficacy inventory in chinese populations. The Counseling Psychologist, 38, 473-496. doi:10.1177/0011000009352514

Fink, A. (2005). Conducting research literature reviews: From the internet to paper (2nd ed.). Thousand Oaks, CA: Sage Publications. Retrieved from www.csa.com

Fisher, T. D., \& McNulty, J. K. (2008). Neuroticism and marital satisfaction: The mediating role played by the sexual relationship. Journal of Family Psychology, 22, 112-122. doi:10.1037/0893-3200.22.1.112

Fraley, R. C, \& Shaver, P. R. (2000). Adult romantic attachment: Theoretical developments, emerging controversies, and unanswered questions. Review of General Psychology, 4, 132-154.

Fraley, R. C., Waller, N. G., \& Brennan, K. A. (2000). An item response theory analysis of self-report measures of adult attachment. Journal of Personality and Social Psychology, 78, 350-365. doi:10.1037/0022-3514.78.2.350

Funder, D. C., \& Colvin, C. R. (1991). Explorations in behavioral consistency: Properties of persons, situations, and behaviors. Journal of Personality and Social Psychology, 60, 773-794.

Furman, W., Simon, V. A., Shaffer, L., \& Bouchey, H. A. (2002). Adolescents' working models and styles for relationships with parents, friends, and romantic partners. Child Development, 73, 241-255. doi:10.1111/1467-8624.00403 
Goodboy, A. K., \& Booth-Butterfield, M. (2009). Individual differences in romantic partners' desire for less closeness. North American Journal of Psychology, 11, 209-218. Retrieved from www.csa.com

Gordon, C. F., Juang, L. P., \& Syed, M. (2007). Internet use and well-being among college students: Beyond frequency of use. Journal of College Student Development, 48, 674-688. doi:10.1353/csd.2007.0065

Gore, P. A., Jr. (2006). Academic self-efficacy as a predictor of college outcomes: Two incremental validity studies. Journal of Career Assessment, 14, 92-115. doi:10.1177/1069072705281367

Gosling, S. D., Rentfrow, P. J., \& Swann, W. B., Jr. (2003). A very brief measure of the big-five personality domains. Journal of Research in Personality, 37, 504-528. doi:10.1016/S0092-6566(03)00046-1

Grasmuck, S., Martin, J., \& Zhao, S. (2009). Ethno-racial identity displays on facebook. Journal of Computer-Mediated Communication, 15, 158-188. doi:10.1111/j.10836101.2009.01498.x

Green, J. O. (1997). A second generation action assembly theory. In J. O. Greene (Ed.), Message production: Advances in communication theory. (pp. 151-170). Mahwah, NJ, US: Lawrence Erlbaum Associates Publishers. Retrieved from www.csa.com

Green, S.B., Akey, T.M., Fleming, K.K., Hershberger, S.L., \& Marquis, J.G. (1997). Effect of the number of scale points on chi-square fit indices in confirmatory factor analysis. Structural Equation Modeling: A Multidisciplinary Journal, 4, 108 - 120. DOI: $10.1080 / 10705519709540064$ 
Greenfield, P. M. (2004). Developmental considerations for determining appropriate internet use guidelines for children and adolescents. Journal of Applied Developmental Psychology. Special Issue: Developing Children, Developing Media: Research from Television to the Internet from the Children's Digital Media Center A Special Issue Dedicated to the Memory of Rodney R.Cocking, 25, 751-762. doi:10.1016/j.appdev.2004.09.008

Gross, E. F. (2004). Adolescent internet use: What we expect, what teens report. Journal of Applied Developmental Psychology. Special Issue: Developing Children, Developing Media: Research from Television to the Internet from the Children's Digital Media Center A Special Issue Dedicated to the Memory of Rodney R.Cocking, 25, 633-649. doi:10.1016/j.appdev.2004.09.005

Guadagno, R. E., Okdie, B. M., \& Eno, C. A. (2008). Who blogs? personality predictors of blogging. Computers in Human Behavior, 24, 1993-2004. doi:10.1016/j.chb.2007.09.001

Guerrero, L. K., Farinelli, L., \& McEwan, B. (2009). Attachment and relational satisfaction: The mediating effect of emotional communication. Communication Monographs, 76, 487-514. doi:10.1080/03637750903300254

Guerrero, L. K., Jones, S. M., \& Burgoon, J. K. (2000). Responses to nonverbal intimacy change in romantic dyads: Effects of behavioral valence and degree of behavioral change on nonverbal and verbal reactions. Communication Monographs, 67, 325346. doi:10.1080/03637750009376515 
Hagekull, B., \& Bohlin, G. (2003). Early temperament and attachment as predictors of the five factor model of personality. Attachment \& Human Development, 5, 2-18. doi:10.1080/1461673031000078643

Hamburger, Y. A., \& Ben-Artzi, E. (2000). The relationship between extraversion and neuroticism and the different uses of the internet. Computers in Human Behavior, 16, 441-449. doi:10.1016/S0747-5632(00)00017-0

Hargie, O., \& Dickson, D. (2006). Skilled interpersonal communication: Research, theory and practice (4th ed.). New York, NY, US: Routledge/Taylor \& Francis Group. Retrieved from www.csa.com

Harman, J. P., Hansen, C. E., Cochran, M. E., \& Lindsey, C. R. (2005). Liar, liar: Internet faking but not frequency of use affects social skills, self-esteem, social anxiety, and aggression. CyberPsychology \& Behavior, 8(1), 1-6.

doi:10.1089/cpb.2005.8.1

Hazan, C., \& Shaver, P. (1987). Romantic love conceptualized as an attachment process. Journal of Personality and Social Psychology, 52, 511-524. doi:10.1037/00223514.52 .3 .511

Hendrick, S. S., Hendrick, C., \& Adler, N. L. (1988). Romantic relationships: Love, satisfaction, and staying together. Journal of Personality and Social Psychology, 54, 980-988. doi:10.1037/0022-3514.54.6.980

Hermann, K. S., \& Betz, N. E. (2004). Path models of the relationships of instrumentality and expressiveness to social self-efficacy, shyness, and depressive symptoms. Sex Roles, 51, 55-66. doi:10.1023/B:SERS.0000032309.71973.14 
Hiester, M., Nordstrom, A., \& Swenson, L. M. (2009). Stability and change in parental attachment and adjustment outcomes during the first semester transition to college life. Journal of College Student Development, 50, 521-538. doi:10.1353/csd.0.0089

Holland, A. S., \& Roisman, G. I. (2010). Adult attachment security and young adults' dating relationships over time: Self-reported, observational, and physiological evidence. Developmental Psychology, 46, 552-557. doi:10.1037/a0018542

Holland, J. L. (1973). Making vocational choices: A theory of careers. Englewood Cliffs, NJ: Prentice Hall.

Hoyle, R.H. (1995). Structural equation modeling: Concepts, issues, and applications. Thousand Oaks, CA: Sage Publications. Retrieved from www.csa.com.

Hu, L., \& Bentler, P. M. (1999). Cutoff criteria for fit indexes in covariance structure analysis: Conventional versus new alternatives. Structural Equation Modeling, 6, $1-55$.

Hutchinson, S. R., \& Olmos, A. (1998). Behavior of descriptive fit indexes in confirmatory factor analysis using ordered categorical data. Structural Equation Modeling, 5, $344-364$.

Iacobucci, D. (2010). Structural equations modeling: Fit indices, sample size, and advanced topics. Journal of Consumer Psychology, 20, 90-98. doi:10.1016/j.jcps.2009.09.003

Jackson, D. L. (2003). Revisiting sample size and number of parameter estimates: Some support for the N:Q hypothesis. Structural Equation Modeling, 10, 128-141. doi:10.1207/S15328007SEM1001_6 
Jackson, L. A., von Eye, A., Biocca, F. A., Barbatsis, G., Fitzgerald, H. E., \& Zhao, Y. (2003). Personality, cognitive style, demographic characteristics and internet use findings from the HomeNetToo project. Swiss Journal of Psychology/Schweizerische Zeitschrift Für Psychologie/Revue Suisse De Psychologie. Special Issue: Studying the Internet - A Challenge for Modern Psychology, 62, 79-90. doi:10.1024//1421-0185.62.2.79

Jang, S. A., Smith, S. W., \& Levine, T. R. (2002). To stay or to leave? the role of attachment styles in communication patterns and potential termination of romantic relationships following discovery of deception. Communication Monographs, 69, 236-252. doi:10.1080/03637750216543

Jenkins-Guarnieri, M.A., Wright, S. \& Hudiburgh, L. (2012). The relationships among attachment style, personality traits, interpersonal competency, and Facebook use. Manuscript in preparation.

Jenkins-Guarnieri, M.A., Wright, S., \& Johnson, B. (2012). Development and validation of a social media use integration scale. Manuscript submitted for publication.

Jin, B., \& Peña, J. F. (2010). Mobile communication in romantic relationships: Mobile phone use, relational uncertainty, love, commitment, and attachment styles. Communication Reports, 23, 39-51. doi:10.1080/08934211003598742

John, O. P., Donahue, E. M., \& Kentle, R. L. (1991). The Big Five Inventory--Versions $4 a$ and 54. Berkeley, CA: University of California, Berkeley.

John, O. P., Naumann, L. P., \& Soto, C. J. (2008). Paradigm shift to the integrative big five trait taxonomy: History, measurement, and conceptual issues. In O. P. John, 
R. W. Robins \& L. A. Pervin (Eds.), Handbook of personality psychology: Theory and research (3rd ed.). (pp. 114-158). New York, NY, US: Guilford Press.

Johnson, D. R., \& Creech, J. C. (1983). Ordinal measures in multiple indicator models: A simulation study of categorization error. American Sociological Review, 48, 398407. doi:10.2307/2095231

Johnson, J. A. (2005). Ascertaining the validity of individual protocols from web-based personality inventories. Journal of Research in Personality, 39, 103-129. doi:10.1016/j.jrp.2004.09.009

Johnson, S. M. (2003). Attachment theory: A guide for couple therapy. New York, NY, US: Guilford Press. Retrieved from www.csa.com

Joinson, A. N. (2004). Self-esteem, interpersonal risk, and preference for E-mail to faceto-face communication. CyberPsychology \& Behavior, 7, 472-478. doi:10.1089/cpb.2004.7.472

Jöreskog, K. G., \& Sörbom, D. (1996). LISREL 8: User's reference guide. Chicago: Scientific Software International.

Jöreskog, K.G. (1993) Testing structural equation models. In K.A. Bollen \& J.S. Long (Eds.), Testing structural equation models (pp. 294-316). Newbury Park, CA: Sage. Retrieved from www.csa.com

Kafetsios, K., \& Nezlek, J. B. (2002). Attachment styles in everyday social interaction. European Journal of Social Psychology, 32, 719-735. doi:10.1002/ejsp.130

Kaitz, M., Bar-Haim, Y., Lehrer, M., \& Grossman, E. (2004). Adult attachment style and interpersonal distance. Attachment \& Human Development, 6, 285-304. doi:10.1080/14616730412331281520 
Kanning, U. P. (2006). Development and validation of a german-language version of the interpersonal competence questionnaire (ICQ). European Journal of Psychological Assessment, 22, 43-51. doi:10.1027/1015-5759.22.1.43

Karney, B. R., \& Bradbury, T. N. (1995). The longitudinal course of marital quality and stability: A review of theory, methods, and research. Psychological Bulletin, 118, 3-34. doi:10.1037/0033-2909.118.1.3

Keniston, K. (1971). Youth and dissent: The rise of a new opposition. New York: Harcourt Brace Jovanovich.

Kenny, M. E., \& Rice, K. G. (1995). Attachment to parents and adjustment in late adolescent college students: Current status, applications, and future considerations. The Counseling Psychologist, 23, 433-456. doi:10.1177/0011000095233003

Kenny, M. E., \& Sirin, S. R. (2006). Parental attachment, self-worth, and depressive symptoms among emerging adults. Journal of Counseling \& Development, 84, 61-71. Retrieved from www.csa.com

Kline, R. B. (2011). Principles and practice of structural equation modeling (3rd ed.). New York, NY, US: Guilford Press. Retrieved from www.csa.com Kluemper, D. H., \& Rosen, P. A. (2009). Future employment selection methods: Evaluating social networking web sites. Journal of Managerial Psychology, 24, 567-580. doi:10.1108/02683940910974134

Kraut, R., Kiesler, S., Boneva, B., Cummings, J. N., Helgeson, V., \& Crawford, A. M. (2002). Internet paradox revisited. Journal of Social Issues. Special Issue: 
Consequences of the Internet for Self and Society: Is Social Life being

Transformed?, 58, 49-74. doi:10.1111/1540-4560.00248

Landers, R. N., \& Lounsbury, J. W. (2006). An investigation of big five and narrow personality traits in relation to internet usage. Computers in Human Behavior, 22, 283-293. doi:10.1016/j.chb.2004.06.001

Lapsley, D. K., \& Edgerton, J. (2002). Separation-individuation, adult attachment style, and college adjustment. Journal of Counseling \& Development, 80, 484-492. Retrieved from www.csa.com

Larson, J. J., Whitton, S. W., Hauser, S. T., \& Allen, J. P. (2007). Being close and being social: Peer ratings of distinct aspects of young adult social competence. Journal of Personality Assessment, 89, 136-148. Retrieved from www.csa.com

Ledbetter, A. M. (2010). Family communication patterns and communication competence as predictors of online communication attitude: Evaluating a dual pathway model. Journal of Family Communication, 10, 99-115. doi:10.1080/15267431003595462

Levinson, D. J. (1978). The seasons of a man's life. New York: Ballantine.

Lipsey, M. W., \& Wilson, D. B. (2001). Practical meta-analysis. Thousand Oaks, CA, US: Sage Publications. Retrieved from www.csa.com

Luteijn, F. (1994). Personality and the quality of an intimate relationship. European Journal of Psychological Assessment, 10, 220-223. Retrieved from www.csa.com Mallinckrodt, B. (2000). Attachment, social competencies, social support, and interpersonal process in psychotherapy. Psychotherapy Research, 10, 239-266. doi:10.1093/ptr/10.3.239 
Mallinckrodt, B., \& Wei, M. (2005). Attachment, social competencies, social support, and psychological distress. Journal of Counseling Psychology, 52, 358-367. doi:10.1037/0022-0167.52.3.358

Manago, A. M., Graham, M. B., Greenfield, P. M., \& Salimkhan, G. (2008). Selfpresentation and gender on MySpace. Journal of Applied Developmental Psychology, 29, 446-458. doi:10.1016/j.appdev.2008.07.001

Marcus, B., Machilek, F., \& Schütz, A. (2006). Personality in cyberspace: Personal websites as media for personality expressions and impressions. Journal of Personality and Social Psychology, 90, 1014-1031.

Marsh, H. W., Hau, K., Balla, J. R., \& Grayson, D. (1998). Is more ever too much? the number of indicators per factor in confirmatory factor analysis. Multivariate Behavioral Research, 33, 181-220. doi:10.1207/s15327906mbr3302_1

Masten, A. S., Burt, K. B., Roisman, G. I., Obradović, J., Long, J. D., \& Tellegen, A. (2004). Resources and resilience in the transition to adulthood: Continuity and change. Development and Psychopathology. Special Issue: Transition from Adolescence to Adulthood, 16, 1071-1094. doi:10.1017/S0954579404040143

Mattanah, J. F., Hancock, G. R., \& Brand, B. L. (2004). Parental attachment, separationindividuation, and college student adjustment: A structural equation analysis of mediational effects. Journal of Counseling Psychology, 51, 213-225. doi:10.1037/0022-0167.51.2.213

Mayseless, O., \& Scharf, M. (2007). Adolescents' attachment representations and their capacity for intimacy in close relationships. Journal of Research on Adolescence, 17, 23-50. doi:10.1111/j.1532-7795.2007.00511.x 
Mazer, J. P., Murphy, R. E., \& Simonds, C. J. (2007). I'll see you on "facebook": The effects of computer-mediated teacher self-disclosure on student motivation, affective learning, and classroom climate. Communication Education, 56, 1-17. doi:10.1080/03634520601009710

McCrae, R. R. (1996). Social consequences of experiential openness. Psychological Bulletin, 120, 323-337. doi:10.1037/0033-2909.120.3.323

McCrae, R. R., \& Costa, P. T., Jr. (1997). Personality trait structure as a human universal. American Psychologist, 52, 509-516. doi:10.1037/0003-066X.52.5.509

McCrae, R. R., \& Costa, P. T., Jr. (2003). Personality in adulthood: A five-factor theory perspective (2nd ed.). New York: Guilford Press.

McCrae, R. R., \& John, O. P. (1992). An introduction to the five-factor model and its applications. Journal of Personality. Special Issue: The Five-Factor Model: Issues and Applications, 60, 175-215. doi:10.1111/j.1467-6494.1992.tb00970.x

McKenna, K. Y. A., \& Bargh, J. A. (2000). Plan 9 from cyberspace: The implications of the internet for personality and social psychology. Personality and Social Psychology Review. Special Issue: Personality and Social Psychology at the Interface: New Directions for Interdisciplinary Research, 4, 57-75. doi:10.1207/S15327957PSPR0401_6

McKenna, K. Y. A., Green, A. S., \& Gleason, M. E. J. (2002). Relationship formation on the internet: What's the big attraction? Journal of Social Issues, 58, 9-31. doi:10.1111/1540-4560.00246

Mikulincer, M., \& Shaver, P. R. (2007). Attachment in adulthood: Structure, dynamics, and change. New York, NY, US: Guilford Press. Retrieved from www.csa.com 
Miller, J. B., \& de Winstanley, P. A. (2002). The role of interpersonal competence in memory for conversation. Personality and Social Psychology Bulletin, 28, 78-89. doi:10.1177/0146167202281007

Miller, J. B., \& Hoicowitz, T. (2004). Attachment contexts of adolescent friendship and romance. Journal of Adolescence, 27, 191-206.

doi:10.1016/j.adolescence.2003.11.008

Montgomery, M. J. (2005). Psychosocial intimacy and identity: From early adolescence to emerging adulthood. Journal of Adolescent Research, 20, 346-374. doi: $10.1177 / 0743558404273118$

Mundfrom, D. J., Shaw, D. G., \& Ke, T. L. (2005). Minimum sample size recommendations for conducting factor analyses. International Journal of Testing, 5, 159-159-168. doi:10.1207/s15327574ijt0502_4

Muthen, B., \& Kaplan, D. (1992). A comparison of some methodologies for the factor analysis of non-normal likert variables: A note on the size of the model. British Journal of Mathematical and Statistical Psychology, 45, 19-30. Retrieved from www.csa.com

O'Brien, R. M. (1985). The relationship between ordinal measures and their underlying values: Why all the disagreement?. Quality \& Quantity, 19, 265. Retrieved from EBSCOhost.

Ogan, C. L., Ozakca, M., \& Groshek, J. (2008). Embedding the internet in the lives of college students: Online and offline behavior. Social Science Computer Review, 26, 170-177. doi:10.1177/0894439307306129 
Orchard, L. J., \& Fullwood, C. (2010). Current perspectives on personality and internet use. Social Science Computer Review, 28, 155-169. doi:10.1177/0894439309335115

Orr, E. S., Sisic, M., Ross, C., Simmering, M. G., Arseneault, J. M., \& Orr, R. R. (2009). The influence of shyness on the use of facebook in an undergraduate sample. CyberPsychology \& Behavior, 12, 337-340. doi:10.1089/cpb.2008.0214

Ozer, D. J., \& Benet-Martínez, V. (2006). Personality and the prediction of consequential outcomes. Annual Review of Psychology, 57, 401-421. doi:10.1146/annurev.psych.57.102904.190127

Ozer, D.J., \& Reise, S.P. (1994). Personality Assessment. Annual Review of Psychology, $45,357-388$.

Padilla-Walker, L. M., Nelson, L. J., Carroll, J. S., \& Jensen, A. C. (2010). More than a just a game: Video game and internet use during emerging adulthood. Journal of Youth and Adolescence, 39, 103-113. doi:10.1007/s10964-008-9390-8

Patchin, J. W., \& Hinduja, S. (2010). Cyberbullying and self-esteem. Journal of School Health, 80, 614-621. doi: 10.1111/j.1746-1561.2010.00548.x

Peluchette, J., \& Karl, K. (2010). Examining students' intended image on facebook: "what were they thinking?!" Journal of Education for Business, 85, 30-37. doi: $10.1080 / 08832320903217606$

Pempek, T. A., Yermolayeva, Y. A., \& Calvert, S. L. (2009). College students' social networking experiences on facebook. Journal of Applied Developmental Psychology, 30, 227-238. doi:10.1016/j.appdev.2008.12.010 
Peter, J., Valkenburg, P. M., \& Schouten, A. P. (2005). Developing a model of adolescent friendship formation on the internet. CyberPsychology \& Behavior, 8, 423-430. doi:10.1089/cpb.2005.8.423

Picardi, A., Caroppo, E., Toni, A., Bitetti, D., \& Di Maria, G. (2005). Stability of attachment-related anxiety and avoidance and their relationships with the fivefactor model and the psychobiological model of personality. Psychology and Psychotherapy: Theory, Research and Practice, 78, 327-345. doi:10.1348/147608305X26882

Pietromonaco, P. R., \& Barrett, L. F. (1997). Working models of attachment and daily social interactions. Journal of Personality and Social Psychology, 73, 1409-1423. doi:10.1037/0022-3514.73.6.1409

Pietromonaco, P. R., \& Barrett, L. F. (2000). The internal working models concept: What do we really know about the self in relation to others? Review of General Psychology. Special Issue: Adult Attachment, 4, 155-175. doi:10.1037/10892680.4.2.155

Pietromonaco, P. R., Greenwood, D., \& Barrett, L. F. (2004). Conflict in adult close relationships: An attachment perspective. In W. S. Rholes and J. A. Simpson (Eds.), Adult attachment: Theory, research, and clinical implications (pp. 267299). New York: Guilford Press.

ProQuest LLC. (2011). Proquest. Retrieved February $19^{\text {th }}, 2011$, from http://www.proquest.com/en-US/ 
Raacke, J., \& Bonds-Raacke, J. (2008). MySpace and facebook: Applying the uses and gratifications theory to exploring friend-networking sites. CyberPsychology \& Behavior, 11, 169-174. doi:10.1089/cpb.2007.0056

Reich, S. M. (2010). Adolescents' sense of community on MySpace and facebook: A mixed-methods approach. Journal of Community Psychology, 38, 688-705. doi:10.1002/jcop.20389

Rholes, W. S., Paetzold, R. L., \& Friedman, M. (2008). Ties that bind: Linking personality to interpersonal behavior through the study of adult attachment style and relationship satisfaction. In F. Rhodewalt (Ed.), Personality and social behavior. ( pp. 117-148). New York: Psychology Press. Retrieved from www.csa.com

Roberts, B. W., \& DelVecchio, W. F. (2000). The rank-order consistency of personality traits from childhood to old age: A quantitative review of longitudinal studies. Psychological Bulletin, 126, 3-25. doi:10.1037/0033-2909.126.1.3

Roberts, B. W., Walton, K. E., \& Viechtbauer, W. (2006). Patterns of mean-level change in personality traits across the life course: A meta-analysis of longitudinal studies. Psychological Bulletin, 132, 1-25. doi:10.1037/0033-2909.132.1.1

Robins, R. W., Fraley, R. C., Roberts, B. W., \& Trzesniewski, K. H. (2001). A longitudinal study of personality change in young adulthood. Journal of Personality, 69, 617-640. doi:10.1111/1467-6494.694157

Ross, C., Orr, E. S., Sisic, M., Arseneault, J. M., Simmering, M. G., \& Orr, R. R. (2009). Personality and motivations associated with facebook use. Computers in Human Behavior, 25, 578-586. doi:10.1016/j.chb.2008.12.024 
Ross, J., \& Fuertes, J. (2010). Parental attachment, interparental conflict, and young adults' emotional adjustment. The Counseling Psychologist, 38, 1050-1077. doi:10.1177/0011000010376094

Ryff, C. D., \& Singer, B. (2000). Interpersonal flourishing: A positive health agenda for the new millennium. Personality and Social Psychology Review. Special Issue: Personality and Social Psychology at the Interface: New Directions for Interdisciplinary Research, 4, 30-44. doi:10.1207/S15327957PSPR0401_4

Saferstein, J. A., Neimeyer, G. J., \& Hagans, C. L. (2005). Attachment as a predictor of friendship qualities in college youth. Social Behavior and Personality, 33, 767776. doi:10.2224/sbp.2005.33.8.767

Satorra, A., \& Bentler, P. M. (1988). Scaling corrections for chi-square statistics in covariance structure analysis. American Statistical Association, Proceedings of the Economics and Statistics Section, 308-313.

Schachner, D. A., Shaver, P. R., \& Mikulincer, M. (2005). Patterns of nonverbal behavior and sensitivity in the context of attachment relations. Journal of Nonverbal Behavior, 29, 141-169. doi:10.1007/s10919-005-4847-x

Schmitt, D. P., Youn, G., Bond, B., Brooks, S., Frye, H., Johnson, S., . . . (2009). When will i feel love? the effects of culture, personality, and gender on the psychological tendency to love. Journal of Research in Personality, 43(5), 830846. doi:10.1016/j.jrp.2009.05.008

Schmitt, K. L., Dayanim, S., \& Matthias, S. (2008). Personal homepage construction as an expression of social development. Developmental Psychology, 44, 496-506. doi:10.1037/0012-1649.44.2.496 
Schneider, B. H., Atkinson, L., \& Tardif, C. (2001). Child-parent attachment and children's peer relations: A quantitative review. Developmental Psychology, 37, 86-100. doi:10.1037/0012-1649.37.1.86

Shulman. S., Elicker, J., \& Stroufe, A. (1994). Stages of friendship in preadolescence as related to attachment history. Journal of Social and Personal Relationships, 11, 341-361.

Segrin, C. (2000). Social skills deficits associated with depression. Clinical Psychology Review, 20, 379-403. doi:10.1016/S0272-7358(98)00104-4

Segrin, C., \& Flora, J. (2000). Poor social skills are a vulnerability factor in the development of psychosocial problems. Human Communication Research, 26, 489-514. doi:10.1111/j.1468-2958.2000.tb00766.x

Segrin, C., \& Taylor, M. (2007). Positive interpersonal relationships mediate the association between social skills and psychological well-being. Personality and Individual Differences, 43, 637-646. doi:10.1016/j.paid.2007.01.017

Shaver, P. R., \& Brennan, K. A. (1992). Attachment styles and the "big five" personality traits: Their connections with each other and with romantic relationship outcomes. Personality and Social Psychology Bulletin, 18, 536-545. doi: $10.1177 / 0146167292185003$

Sheldon, P. (2008). The relationship between unwillingness-to-communicate and students' facebook use. Journal of Media Psychology: Theories, Methods, and Applications, 20, 67-75. doi:10.1027/1864-1105.20.2.67 
Sherer, M., Maddux, J. E., Mercadante, B., Prentice-Dunn, S., Jacobs, B., \& Rogers, R. W. (1982). The Self-Efficacy Scale: Construction and validation. Psychological Reports, 51, 663-671.

Shih, T., \& Fan, X. (2008). Comparing response rates from web and mail surveys: A meta-analysis. Field Methods, 20, 249-271. doi:10.1177/1525822X08317085

Shomaker, L. B., \& Furman, W. (2009). Parent-adolescent relationship qualities, internal working models, and attachment styles as predictors of adolescents' interactions with friends. Journal of Social and Personal Relationships, 26, 579-603. doi:10.1177/0265407509354441

Sibley, C. G., \& Liu, J. H. (2004). Short-term temporal stability and factor structure of the revised experiences in close relationships (ECR-R) measure of adult attachment. Personality and Individual Differences, 36, 969-975. doi:10.1016/S0191-8869(03)00165

Sibley, C. G., \& Overall, N. C. (2008). The boundaries between attachment and personality: Localized versus generalized effects in daily social interaction. Journal of Research in Personality, 42, 1394-1407. doi:10.1016/j.jrp.2008.06.004

Sibley, C. G., Fischer, R., \& Liu, J. H. (2005). Reliability and validity of the revised experiences in close relationships (ECR-R) self-report measure of adult romantic attachment. Personality and Social Psychology Bulletin, 31, 1524-1536. doi:10.1177/0146167205276865

Simon, E. P., \& Baxter, L. A. (1993). Attachment-style differences in relationship maintenance strategies. Western Journal of Communication, 57, 416-430. Retrieved from www.csa.com 
Simpson, J. A., Collins, W. A., Tran, S., \& Haydon, K. C. (2007). Attachment and the experience and expression of emotions in romantic relationships: A developmental perspective. Journal of Personality and Social Psychology, 92, 355-367. doi:10.1037/0022-3514.92.2.355

Smith, H. M., \& Betz, N. E. (2000). Development and validation of a scale of perceived social self-efficacy. Journal of Career Assessment, 8, 283-301. doi:10.1177/106907270000800306

Smith, H. M., \& Betz, N. E. (2002). An examination of efficacy and esteem pathways to depression in young adulthood. Journal of Counseling Psychology, 49, 438-448. doi:10.1037/0022-0167.49.4.438

Soto, C. J., John, O. P., Gosling, S. D., \& Potter, J. (2010). Age differences in personality traits from 10 to 65: Big five domains and facets in a large cross-sectional sample. Journal of Personality and Social Psychology, 100(2), 330-348. doi:10.1037/a0021717

SPSS Inc. (2009). PASW Statistics 17.0. SPSS Inc., Chicago

Srivastava, S., John, O. P., Gosling, S. D., \& Potter, J. (2003). Development of personality in early and middle adulthood: Set like plaster or persistent change? Journal of Personality and Social Psychology, 84, 1041-1053. doi:10.1037/00223514.84 .5 .1041

Steiger, J. H. (1990). Structural model evaluation and modification: An interval estimation approach. Multivariate Behavioral Research, 25, 173-180. doi:10.1207/s15327906mbr2502_4 
Steinfield, C., Ellison, N. B., \& Lampe, C. (2008). Social capital, self-esteem, and use of online social network sites: A longitudinal analysis. Journal of Applied Developmental Psychology, 29, 434-445. doi:10.1016/j.appdev.2008.07.002

Stumpf, H. (1993). The factor structure of the personality research form: A cross-national evaluation. Journal of Personality, 61, 27-48. doi:10.1111/j.14676494.1993.tb00277.x

Sturaro, C., Denissen, J. J. A., van Aken, M. A. G., \& Asendorpf, J. B. (2008). Personenvironment transactions during emerging adulthood: The interplay between personality characteristics and social relationships. European Psychologist, 13, 111. doi:10.1027/1016-9040.13.1.1

Subrahmanyam, K., \& Greenfield, P. M. (2008). Virtual worlds in development: Implications of social networking sites. Journal of Applied Developmental Psychology, 29, 417-419. doi:10.1016/j.appdev.2008.07.004

Subrahmanyam, K., Reich, S. M., Waechter, N., \& Espinoza, G. (2008). Online and offline social networks: Use of social networking sites by emerging adults. Journal of Applied Developmental Psychology, 29, 420-433. doi:10.1016/j.appdev.2008.07.003

SurveyMonkey. (2011). SurveyMonkey - About Us. Retrieved from http://www.surveymonkey.com/AboutUs.aspx

Swann, W., \& Seyle, D. C. (2006). The antecedents of self-esteem. In M. H. Kernis (Ed.), Self-esteem issues and answers: A sourcebook of current perspectives. ( pp. 201106). New York, NY, US: Psychology Press. Retrieved from www.csa.com 
Swickert, R. J., Hittner, J. B., Harris, J. L., \& Herring, J. A. (2002). Relationship among internet use, personality, and social support. Computers in Human Behavior, 18, 437-451. doi:10.1016/S0747-5632(01)00054-1

Tabachnick, B. G., \& Fidell, L. S. (2001). Using multivariate statistics (4th ed.). Boston, MA: Allyn \& Bacon/Pearson Education. Retrieved from www.csa.com

Thayer, S., \& Ray, S. (2006). Online communication preferences across age, gender, and duration of Internet use. CyberPsychology \& Behavior, 9, 432-440. doi:10.1089/cpb.2006.9.432.

Tosun, L. P., \& Lajunen, T. (2010). Does internet use reflect your personality? relationship between eysenck's personality dimensions and internet use. Computers in Human Behavior, 26, 162-167. doi:10.1016/j.chb.2009.10.010

Tucker, J. S., \& Anders, S. L. (1998). Adult attachment style and nonverbal closeness in dating couples. Journal of Nonverbal Behavior, 22, 109-124. doi:10.1023/A:1022980231204

Tucker, J. S., \& Anders, S. L. (1999). Attachment style, interpersonal perception accuracy, and relationship satisfaction in dating couples. Personality and Social Psychology Bulletin, 25, 403-412. doi:10.1177/0146167299025004001

Tuten, T. L., \& Bosnjak, M. (2001). Understanding differences in web usage: The role of need for cognition and the five factor model of personality. Social Behavior and Personality, 29, 391-398. doi:10.2224/sbp.2001.29.4.391

Valenzuela, S., Park, N., \& Kee, K. F. (2009). Is there social capital in a social network site?: Facebook use and college students' life satisfaction, trust, and 
participation. Journal of Computer-Mediated Communication, 14, 875-901. doi:10.1111/j.1083-6101.2009.01474.x

Valkenburg, P. M., \& Peter, J. (2008). Adolescents' identity experiments on the internet: Consequences for social competence and self-concept unity. Communication Research, 35, 208-231. doi:10.1177/0093650207313164

Vazire, S., \& Gosling, S. D. (2004). e-perceptions: Personality impressions based on personal websites. Journal of Personality and Social Psychology, 87(1), 123-132. doi:10.1037/0022-3514.87.1.123

Ward, C. C., \& Tracey, T. J. G. (2004). Relation of shyness with aspects of online relationship involvement. Journal of Social and Personal Relationships, 21, 611623. doi: $10.1177 / 0265407504045890$

Watson, D., Hubbard, B., \& Wiese, D. (2000). General traits of personality and affectivity as predictors of satisfaction in intimate relationships: Evidence from self- and partner-ratings. Journal of Personality, 68, 413-449. doi:10.1111/14676494.00102

Wei, M., Russell, D. W., \& Zakalik, R. A. (2005). Adult attachment, social self-efficacy, self-disclosure, loneliness, and subsequent depression for freshman college students: A longitudinal study. Journal of Counseling Psychology, 52, 602-614.

Weisbuch, M., Ivcevic, Z., \& Ambady, N. (2009). On being liked on the web and in the "real world": Consistency in first impressions across personal webpages and spontaneous behavior. Journal of Experimental Social Psychology, 45(3), 573576. doi:10.1016/j.jesp.2008.12.009 
Welch, R. D., \& Houser, M. E. (2010). Extending the four-category model of adult attachment: An interpersonal model of friendship attachment. Journal of Social and Personal Relationships, 27, 351-366. doi:10.1177/0265407509349632

Weston, R., \& Gore, P. A., Jr. (2006). A brief guide to structural equation modeling. The Counseling Psychologist, 34, 719-751. doi:10.1177/0011000006286345

White, J. K., Hendrick, S. S., \& Hendrick, C. (2004). Big five personality variables and relationship constructs. Personality and Individual Differences, 37, 1519-1530.

Wilson, K., Fornasier, S., \& White, K. M. (2010). Psychological predictors of young adults' use of social networking sites. Cyberpsychology, Behavior, and Social Networking, 13, 173-177. Retrieved from www.csa.com

Wilson, S. R., \& Sabee, C. M. (2003). Explicating communicative competence as a theoretical term. In J. O. Greene, \& B. R. Burleson (Eds.), Handbook of communication and social interaction skills. (pp. 3-50). Mahwah, NJ, US: Lawrence Erlbaum Associates Publishers. Retrieved from www.csa.com Wolak, J., Mitchell, K. J., \& Finkelhor, D. (2003). Escaping or connecting? characteristics of youth who form close online relationships. Journal of Adolescence, 26, 105-119. doi:10.1016/S0140-1971(02)00114-8

Wolf, H., Spinath, F. M., Riemann, R., \& Angleitner, A. (2009). Self-monitoring and personality: A behavioural-genetic study. Personality and Individual Differences, 47, 25-29. doi:10.1016/j.paid.2009.01.040

Wood, J. J., Emmerson, N. A., \& Cowan, P. A. (2004). Is early attachment security carried forward into relationships with preschool peers? British Journal of Developmental Psychology, 22, 245-253. doi:10.1348/026151004323044591 
Wood, V. F., \& Bell, P. A. (2008). Predicting interpersonal conflict resolution styles from personality characteristics. Personality and Individual Differences, 45, 126-131. doi:10.1016/j.paid.2008.03.010

Wright, S. L., \& Perrone, K. M. (2010). An examination of the role of attachment and efficacy in life satisfaction. The Counseling Psychologist, 38, 796-823. doi:10.1177/0011000009359204

Wu, P., Foo, M., \& Turban, D. B. (2008). The role of personality in relationship closeness, developer assistance, and career success. Journal of Vocational Behavior, 73, 440-448. doi:10.1016/j.jvb.2008.08.005

Yang, C., Nay, S., \& Hoyle, R. H. (2010). Three approaches to using lengthy ordinal scales in structural equation models: Parceling, latent scoring, and shortening scales. Applied Psychological Measurement, 34, 122-142. doi: $10.1177 / 0146621609338592$

Yang-Wallentin, F., Jöreskog, K. G., \& Luo, H. (2010). Confirmatory factor analysis of ordinal variables with misspecified models. Structural Equation Modeling, 17, 392-423. doi:10.1080/10705511.2010.489003

Zickuhr, K. (2010). Generations online in 2010. Retrieved from Pew Internet \& American Life Project website: http://pewresearch.org/pubs/1831/generationsonline-2010

Zimmerman, P. (2004). Attachment representations and characteristics of friendship relations during adolescence. Journal of Experimental Child Psychology, 88, 83101. 
Zywica, J., \& Danowski, J. (2008). The faces of facebookers: Investigating social enhancement and social compensation hypotheses; predicting facebook ${ }^{\mathrm{TM}}$ and offline popularity from sociability and self-esteem, and mapping the meanings of popularity with semantic networks. Journal of Computer-Mediated Communication, 14, 1-34. 
APPENDIX A

\section{CRITERIA FOR INCLUSION OF RESEARCH}


A methodologically rigorous and comprehensive search of relevant literature was conducted to find published peer-reviewed articles, books, edited books, bound monographs, and online material. Fink (2005) calls for research literature reviews to be "a systematic, explicit, reproducible method for identifying, evaluating, and synthesizing the existing body of completed and recorded work produced by researchers, scholars, and practitioners" (p. 3). In following this approach, I first outlined a reproducible methodology for conducting the search which consisted of the following steps: a) chose appropriate research questions, b) selected article databases, c) chose relevant search terms from database thesauruses, d) chose practical screening criteria (e.g., year range), e) adapted literature search protocol in light of results. This process was documented in detail, as Aveyard (2007) recommends that researchers record the steps and strategies of the search process itself to ensure that it is explicit and reproducible. Documentation of the search process consisted of a detailed list of specific searches conducted, including descriptors and keywords used and the combination thereof, results gleaned from each search, and adaptations made to the search strategy based on these results; literature search strategy documentation available upon request. In addition, review and metaanalysis articles, relevant journals, and online bibliographic databases were searched for relevant sources as recommended by Lipsey and Wilson (2001) in order to achieve comprehensiveness in a literature review. 
APPENDIX B

\section{LITERATURE SEARCH STRATEGY DOCUMENTATION}


Thesaurus DESCRIPTOR terms:

Computer mediated communication

Interpersonal communication

Interpersonal interaction

Online social networks

Personality development

(subsumes social dev.)

Five Factor Personality Model

Personality Traits

Social skills
Social interaction

Interpersonal relationships

Social behavior

Attachment behavior

Psychosocial development

Communication skills

Self esteem

Attachment Theory

PsychINFO (using descriptors):

Online social networks AND Interpersonal communication $\rightarrow 8$ results \& ref branching

Online social networks AND personality development $\rightarrow 0$ results

Online social networks AND social behavior $\rightarrow 21$ results \& ref branching

Online social networks AND psychosocial development $\rightarrow 3$ results

Online social networks AND psychological development $\rightarrow 0$ results

Internet AND personality traits $\rightarrow 103$ results \& ref branching

Online social networks AND [keyword] emerging adult* $\rightarrow 4$ results

Internet AND psychosocial development $\rightarrow 29$ results \& ref branching

Online social networks AND personality traits $\rightarrow 5$ results \& ref branching

Five factor personality model AND interpersonal relationships OR social interaction OR interpersonal communication $\rightarrow 19$ and comprehensive reference branching

Berry \& Hansen (2000) $\rightarrow$ cited by $27 \&$ ref branching

White, Hendrick, \& Hendrick (2004) $\rightarrow$ cited by $30 \&$ ref branching

Ansell \& Pincus (2004) $\rightarrow$ cited by $25 \&$ ref branching

Attachment theory OR attachment behavior AND interpersonal communication OR communication skills $\rightarrow 5$

Attachment theory OR attachment behavior AND Five factor personality model $\rightarrow 10 \&$ branching

Attachment theory OR attachment behavior AND social interaction OR interpersonal communication $\rightarrow 124$

[keywords] "interpersonal communication" OR "relational competence" OR "social skills" AND [descriptor] five factor personality model $\rightarrow 5$ results and ref branching Self esteem AND online social networks $\rightarrow 10$ \& branching

Self esteem AND internet $\rightarrow 46$ results \& branching

Kenny \& Rice (1995) $\rightarrow$ cited by $72 \&$ ref branching

Correa, Hinsley, \& deZuniga (2010) $\rightarrow$ reference branching

Orchard et al. (2010) $\rightarrow$ reference branching

Ross et al. (2009) $\rightarrow$ ref branching

Tosun (2010) $\rightarrow$ ref branching

Anders and Tucker $(2000) \rightarrow$ cited by $44 \&$ ref branching

Buhrmester, Furman, Wittenberg and Reis (1988) $\rightarrow$ cited by 152 and ref branching

Schulman, Elicker \& Sroufe, $1994 \rightarrow$ cited by 62 and ref branching

"social self-efficacy" [keyword] $\rightarrow 116$ results and ref branching

Smith and Betz (2000) $\rightarrow$ cited by 27 and ref branching 
APPENDIX C

PARTICIPANT INVITATION EMAIL 
Hello UNC Student,

Please take a few minutes from your crowded schedule to complete my brief survey about Facebook and about your unique personality characteristics!!!

The first 25 participants will earn an iTunes gift card, and everyone can enter into a raffle drawing for a $\$ 100$ Visa Gift Card!

Please click on the link below to participate...

\section{Survey Link}

Your participation will help me understand more about how people use Facebook and the characteristics of its users.

If you have any questions or would like additional information, please contact me at: Michael.Jenkins@unco.edu, or (970) 351-1632.

Thank you,

Michael Jenkins 
APPENDIX D

IRB-APPROVED INFORMED CONSENT LETTER 


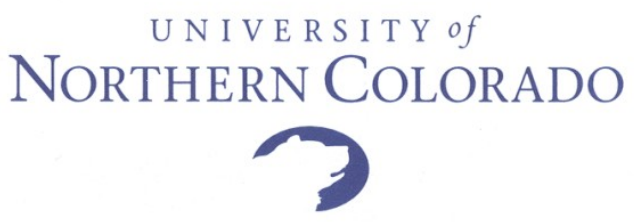

CONSENT FORM FOR HUMAN PARTICIPANTS IN RESEARCH

University of Northern Colorado

Project Title: The Interrelationships Among Attachment Style, Personality Traits, Interpersonal Competency, and Facebook Use

Researchers: Michael Jenkins-Guarnieri, Stephen Wright, Ph.D., \& Brian Johnson, Ph.D., Department of Counseling Psychology.

Phone Number: (970) 351-1632

Email: Michael.Jenkins@unco.edu

Participation in this research project involves answering questions through an online survey about your experience using Facebook.com, your relationships with other adults your age, and how you relate to other people. In addition, you will be asked questions about how you view yourself and how you experience yourself in the world. We are interested in your responses so that we can understand more about how college-aged adults use Facebook, how they experience the relationships they form, and how aspects of personality may be related to these relationships and Facebook use.

Your responses to the online survey will be collected through SurveyMonkey.com, a web-based survey service. In addition, the we will email all participants who complete this study survey in three weeks time with a link to another online survey hosted by the same web site containing a smaller subset of the same survey questions in order to collect your responses again. Data will be treated as confidential and stored on the web site's secure servers. The lead researcher will be the only individual that will have access to the confidential data. Once data has been collected, any identifiable information will be removed and replaced with numerical indicators. It will take approximately 30 minutes to fill out the survey. We foresee no risks to you beyond that which typically occurs in filling out a survey or those normally encountered during regular classroom participation. One benefit of participating in this study is that you may increase your self-awareness in the following areas: relationship interactions, Facebook use, and personality traits. There are also indirect benefits to the discipline as a result of what is learned from the research project.

We will not ask for any identifying information that could connect you to your responses and the results from your participation will be treated as confidential. We will take 
reasonable precautions to ensure the security of your responses to the survey. All survey responses will be kept in a locked cabinet and/or in a password protected electronic file. We will not look at your results individually, but we will look at responses grouped by age, gender, and ethnicity.

As an incentive for your participation, you can choose to enter your email address into a raffle drawing for a $\$ 100$ Visa gift card upon survey completion, and the first 25 participants will receive a $\$ 2$ iTunes gift card. The first 20 participants to complete the second briefer online survey will receive a $\$ 5$ iTunes gift card.

Participation is entirely voluntary. You may decide not to participate in this study and if you begin participation you may still decide to stop and withdraw at any time. Your decision will be respected and will not result in loss of benefits to which you are otherwise entitled. Having read the above and having had an opportunity to ask any questions, please click the continue button below to complete the online survey if you would like to participate in this research. By completing the online survey, you will give permission for your participation. You may print and keep this form for future reference.

If you have any concerns about your selection or treatment as a research participant, please contact the Office of Sponsored Programs, Kepner Hall, University of Northern Colorado Greeley, CO 80639; 970-351-2161. 
APPENDIX E

PARTICIPANT DEBRIEFING PARAGRAPH 
Please read the following information designed to debrief you as a study participant about the nature of this research:

The study you just participated in was conducted to research how college students use Facebook.com and experience the relationships formed through Facebook. Specifically, the study was designed to assess attachment security, interpersonal relationship competence, personality traits, Facebook use, and social self-efficacy. The goal of the study was to determine how aspects of a Facebook user's personality may be associated with Facebook use, relationships formed through Facebook, and how these personality characteristics may be related to each other. 
APPENDIX F

Institutional Review Board (IRB) Approval Letter 
Jenkins, Michael

$\begin{array}{ll}\text { From: } & \text { Stellino, Megan } \\ \text { Sent: } & \text { Tuesday, July 26, 2011 2:40 PM } \\ \text { To: } & \text { Jenkins, Michael } \\ \text { Cc: } & \text { Johnson, Brian; Wright, Stephen } \\ \text { Subject: } & \text { RE: Exempt IRB application for project titled "The Interrlationships Among Attachment Style } \\ & \text { Personality Traits, Interpersonal Competency, and Facebook Use" }\end{array}$

Michael -

Thank you for the prompt response to my email and revised consent form. All of my changes were addressed

satisfactorily. Also, I'm glad that you contacted Kim Black so quickly. Hopefully, there won't be any problem on her end. Again, be sure to file her approval with Sherry May so it is connected with your IRB application.

Given those responses, you now have IRB approval pending approval from Kim Black. Sherry May in the OSP will send

official notification of approval to your advisor. Be sure to also use the revised consent form in your data collection.

Best wishes with your study! If any further questions or concerns related to IRB an your research arise, please don't hesitate to contact me.

Sincerely,

Dr. Stellino

$* * * * * * * * * * * * * * * * * * * * * * * * * * * * * * * * * * * * * * * *$

Dr. Megan Babkes Stellino

Professor

Social Psychology of Sport and Physical Activity

School-of-Sport-and-Exercise-Science

Co-Chair IRB

University of Northern Colorado

Greeley, CO 80639

(970) 351-1809

megan.stellino@unco.edu

*********************************************

From: Jenkins, Michael

Sent: Monday, July 25, 2011 5:03 PM

To: Stellino, Megan

Cc: Jenkins, Michael

Subject: RE: Exempt IRB application for project titled "The Interrlationships Among Attachment Style, Personality Traits, Interpersonal Competency, and Facebook Use"

Good afternoon Dr. Stellino,

Thank you for reviewing my IRB application and for your swift response. I contacted Dr. Black regarding permission to use my Insight access privileges to generate a list of student email addresses and will file her approval email in my IRB application with Sherry May.

Also, I made your suggested changes to my study informed consent letter and the updated version is attached for your review.

Thanks again for your support in this process and please let me know what you think when you have a chance.

Michael 
Jenkins, Michael

$\begin{array}{ll}\text { From: } & \text { Black, Kim } \\ \text { Sent: } & \text { Wednesday, July 27, 2011 1:38 PM } \\ \text { To: } & \text { Jenkins, Michael } \\ \text { Subject: } & \text { RE: Approval to Use Insight }\end{array}$

To Whom It May Concern:

Michael Jenkins is approved to use a list of email addresses of 2011 incoming freshman to support his doctoral dissertation. Michael will request the list of emails from the Office of.Information Management Technology.

Please let me know if you need additional information.

Kim Black, Ph.D.

Director of Assessment

University of Northern Colorado

Greeley, CO 80639

970-351-1102 